\title{
CATALOG OF NEARBY EXOPLANETS ${ }^{1}$
}

\author{
R. P. Butler, ${ }^{2}$ J. T. Wright, ${ }^{3}$ G. W. Marcy,${ }^{3,4}$ D. A. Fischer, ${ }^{3,4}$ S. S. Vogt, ${ }^{5}$ C. G. Tinney, ${ }^{6}$ H. R. A. Jones, ${ }^{7}$ \\ B. D. Carter, ${ }^{8}$ J. A. Johnson, ${ }^{3}$ C. McCarthy, ${ }^{2,4}$ and A. J. Penny ${ }^{9,10}$ \\ Received 2005 November 5; accepted 2006 March 10
}

\begin{abstract}
We present a catalog of nearby exoplanets. It contains the 172 known low-mass companions with orbits established through radial velocity and transit measurements around stars within $200 \mathrm{pc}$. We include five previously unpublished exoplanets orbiting the stars HD 11964, HD 66428, HD 99109, HD 107148, and HD 164922. We update orbits for 83 additional exoplanets, including many whose orbits have not been revised since their announcement, and include radial velocity time series from the Lick, Keck, and Anglo-Australian Observatory planet searches. Both these new and previously published velocities are more precise here due to improvements in our data reduction pipeline, which we applied to archival spectra. We present a brief summary of the global properties of the known exoplanets, including their distributions of orbital semimajor axis, minimum mass, and orbital eccentricity.
\end{abstract}

Subject headings: planetary systems — stars: activity — stars: chromospheres

Online material: machine-readable tables

\section{INTRODUCTION}

It has now been more than $10 \mathrm{yr}$ since the discovery of the first objects that were identified as planets orbiting normal stars. The epochal announcement in 1995 October of 51 Peg b (Mayor \& Queloz 1995) was confirmed within a week (Marcy et al. 1997) and followed within 2 months by two other planets, $47 \mathrm{UMa} b$ and 70 Vir b (Butler \& Marcy 1996; Marcy \& Butler 1996). The unexpected diversity and mass distribution of exoplanets was represented well by those first three planets, as the first one orbits close in, the second orbits beyond $2 \mathrm{AU}$, and the last resides in a very eccentric orbit. The paucity of companions having larger masses, with $M \sin i$ between $10 M_{\mathrm{J}}$ and $80 M_{\mathrm{J}}$, suggested a mass distribution separated from that of stars, rising with decreasing mass and peaking below $1 M_{\mathrm{J}}$ (Marcy \& Butler 2000; Halbwachs et al. 2000; Udry et al. 2003a).

During the past $10 \mathrm{yr}$, over 160 exoplanet candidates have been identified orbiting stars within $200 \mathrm{pc}$, and most have been detected by Doppler search programs based at the Keck, Lick, and Anglo-Australian Observatories (the California \& Carnegie and Anglo-Australian planet searches; e.g., Butler et al. 1996; Tinney et al. 2001) and teams based at l'Observatoire de Haute Provence and La Silla Observatory (the Geneva Extrasolar

\footnotetext{
1 Based on observations obtained at the W. M. Keck Observatory, which is operated jointly by the University of California and the California Institute of Technology. The Keck Observatory was made possible by the generous financial support of the W. M. Keck Foundation.

2 Department of Terrestrial Magnetism, Carnegie Institute of Washington, 5241 Broad Branch Road NW, Washington, DC 20015-1305.

3 Department of Astronomy, University of California, 601 Campbell Hall, Berkeley, CA 94720-3411.

4 Department of Physics and Astronomy, San Francisco State University, 1600 Holloway Avenue, San Francisco, CA 94132.

5 University of California Observatories/Lick Observatory, University of California, 373 Interdisciplinary Sciences, Santa Cruz, CA 95064.

${ }^{6}$ Anglo-Australian Observatory, P.O. Box 296, Epping NSW 1710, Australia.

${ }^{7}$ Centre for Astrophysics Research, University of Hertfordshire, Hatfield, AL 10 9AB, UK.

${ }^{8}$ Faculty of Sciences, University of Southern Queensland, Toowoomba 4350, Australia.

9 Rutherford Appleton Laboratory, Chilton, Didcot, Oxon OX11 0QX, UK.

10 SETI Institute, 515 North Whisman Road, Mountain View, CA 94043.
}

Planet Search; e.g., Mayor \& Santos 2003). Other Doppler programs have contributed important discoveries of nearby planets (Cochran et al. 1997; Endl et al. 2003; Noyes et al. 1999; Kürster et al. 2003; Charbonneau et al. 2000; Sato et al. 2005). One nearby planet, TrES-1, has been discovered by its transit across the star (Alonso et al. 2004).

Here we present a catalog of all known exoplanets that reside within $200 \mathrm{pc}$, containing the vast majority of well-studied exoplanets. This distance threshold serves several purposes. First, nearby planets and their host stars are amenable to confirmation and follow-up by a variety of techniques, including highresolution imaging and stellar spectroscopy with high signal-tonoise ratios, as well as astrometric follow-up (e.g., Benedict et al. 2001; McArthur et al. 2004). In addition, milliarcsecond astrometry for planet host stars within $200 \mathrm{pc}$ can provide precise distance estimates, and most planet search target stars within 100 pc already have parallaxes from Hipparcos (Perryman et al. 1997). Third, nearby planet host stars are bright enough to permit precise photometric and chromospheric monitoring by telescopes of modest size, permitting careful assessment of velocity jitter, starspots, and possible transits (e.g., Henry 1999; Henry et al. 2000; Queloz et al. 2001; Eaton et al. 2003).

This paper updates the last published list of exoplanets (Butler et al. 2002). The growth of the field is reflected by the discovery of over 100 planets in the $3 \mathrm{yr}$ since the publication of that list of 57 exoplanets.

About a dozen exoplanet candidates have been discovered that reside beyond $200 \mathrm{pc}$, including a half-dozen in the Galactic bulge found in the OGLE survey and a few other planets found by microlensing (e.g., Torres et al. 2003; Konacki et al. 2003; Bouchy et al. 2005a). Perhaps most notable are the first planets ever found outside our solar system, orbiting a pulsar (Wolszczan $\&$ Frail 1992). Such distant planets reside beyond the scope of this catalog.

We include known companions with minimum masses $(M \sin i)$ up to $24 M_{\mathrm{J}}$. This is well above the usual $13 M_{\mathrm{J}}$ deuterium-burning limit for planets adopted by the IAU. We do this for two reasons. First, uncertainties in stellar mass and orbital inclination complicate the measurement of sufficiently precise masses to apply a robust $13 M_{\mathrm{J}}$ cutoff. Second, there is little or no evidence indicating that such a cutoff has any relevance to the formation 
mechanisms of these objects. We therefore use a generous minimum mass criterion for inclusion in this catalog and decline to choose a precise definition of an "exoplanet."

Two other planet candidates were detected by direct imaging, 2M 1207b (Chauvin et al. 2004) and GQ Lup b (Neuhäuser et al. 2005). We exclude these from the tabular catalog due to their considerably uncertain orbital periods, eccentricities, and masses. Similarly, we exclude many Doppler-detected planets due to their lack of data spanning one full period, which precludes a secure determination of their orbits and minimum masses.

One might question the value of a catalog of exoplanets in the face of such rapid discovery. Without question, the catalog presented here will become out of date before it is printed. ${ }^{11}$ However, this catalog offers many attributes of unique value. First, it contains updated orbital parameters for 90 exoplanets, computed anew from our large database of Doppler measurements of over 1300 stars from the Lick, Anglo-Australian, and Keck Observatories obtained during the past 18,7 , and $8 \mathrm{yr}$, respectively (Butler et al. 2003; Marcy et al. 2005a). These new orbital parameters significantly supersede the previously quoted orbital parameters in most cases.

Second, we use the latest estimates of stellar mass to improve the precision of the minimum planet mass, $M \sin i$ (Valenti \& Fischer 2005 ). Third, the catalog contains Doppler measurements for the planet host stars in our database, allowing both further analyses of these velocities and novel combinations with other measurements. The publication of this archive foreshows a forthcoming work (J. T. Wright et al. 2006, in preparation) that will identify and catalog prospective exoplanets and substellar companions of indeterminate mass and orbital period. Finally, the catalog will serve as an archive of known nearby exoplanets and their parameters circa 2005 . The catalog may serve ongoing exoplanet research, both observation and theory, and provide useful information for future exoplanet studies of nearby stars.

\section{DATA}

The radial velocity data here come from three sources: observations at Lick Observatory using the Hamilton spectrograph (Vogt 1987), at Keck Observatory using HIRES (Vogt et al. 1994), and at the $3.9 \mathrm{~m}$ Anglo-Australian Telescope (AAT) using UCLES (Diego et al. 1990). These instruments, their characteristics, and typical uncertainties in the radial velocities they produce are discussed in the discovery papers of the exoplanets found with them (in particular, Fischer et al. 1999; Butler et al. 1998; Tinney et al. 2001). We explicitly note here upgrades over the years that have significantly improved their precision at typical exposure times: the Hamilton spectrograph was upgraded in 1994 November, increasing the precision of a typical observation from $10-15$ to $\sim 4 \mathrm{~m} \mathrm{~s}^{-1}$; in 2004 August HIRES was upgraded, increasing the precision of a typical observation from $\sim 3$ to $\sim 1 \mathrm{~m} \mathrm{~s}^{-1}$; and the precision of UCLES data is $2-3 \mathrm{~m} \mathrm{~s}^{-1}$.

We have also revised our entire reduction pipeline, including an overhauled raw reduction package that includes corrections for cosmic rays and an improved flat-fielding algorithm, a more accurate barycentric velocity correction that includes propermotion corrections, and a refined precision velocity reduction package that includes a telluric filter and a more sophisticated

\footnotetext{
${ }^{11}$ Note added in proof.- - Indeed, after submission of this paper, C. Lovis et al. (Nature, 441, 305 [2006]) announced a triple-Neptune system orbiting HD 69830, A. P. Hatzes et al. (A\&A, in press [astro-ph/0606517]) confirmed a $2.3 M_{\text {Jup }}$ planet orbiting Pollux, J. T. Wright et al. (in preparation) announced a planet orbiting HD 154345 and a second planet orbiting HIP 14810, and J. A. Johnson et al. (in preparation) announced a hot Jupiter orbiting HD 185269. Our group will maintain an up-todate version of the Catalog of Nearby Exoplanets at http://www.exoplanets.org.
}

TABLE 1

Radial Velocities for Planet-bearing Stars

\begin{tabular}{ccccc}
\hline \hline $\begin{array}{c}\text { Star Name } \\
(1)\end{array}$ & $\begin{array}{c}\text { Time } \\
(\mathrm{JD}-2,440,000)\end{array}$ & $\begin{array}{c}\text { Velocity } \\
\left(\mathrm{m} \mathrm{s}^{-1}\right) \\
(3)\end{array}$ & $\begin{array}{c}\text { Uncertainty } \\
\left(\mathrm{m} \mathrm{s}^{-1}\right) \\
(4)\end{array}$ & $\begin{array}{c}\text { Observatory } \\
(5)\end{array}$ \\
\hline HD 142 ........ & 10830.958715 & -19.2 & 6.8 & $\mathrm{~A}$ \\
& 11121.019444 & -12.4 & 7.8 & $\mathrm{~A}$ \\
& 11385.310558 & 32 & 12 & $\mathrm{~A}$ \\
& 11411.202523 & 6 & 13 & $\mathrm{~A}$ \\
& 11473.085035 & -11.9 & 7.2 & $\mathrm{~A}$ \\
& 11525.925093 & 6.4 & 8.5 & $\mathrm{~A}$ \\
& 11526.953241 & -5.7 & 6.2 & $\mathrm{~A}$ \\
& 11683.331377 & 36.4 & 8.0 & $\mathrm{~A}$ \\
& 11743.276539 & 34.5 & 7.3 & $\mathrm{~A}$ \\
& 11745.264167 & 37 & 11 & $\mathrm{~A}$ \\
& 11767.269896 & 4.2 & 8.0 & $\mathrm{~A}$
\end{tabular}

Notes.-Table 1 is published in its entirety in the electronic edition of the Astrophysical Journal. A portion is shown here for guidance regarding its form and content.

deconvolution algorithm. We also now correct for the very slight nonlinearity in the new HIRES CCD. We have improved the characterization of the charge transfer inefficiency in the old CCD that limited its precision to $\sim 3 \mathrm{~m} \mathrm{~s}^{-1}$, a problem not present in the new chip.

In previous works we have subtracted a constant velocity such that the median velocity of the set was zero (since these are differential measurements, one may always add an arbitrary constant to the entire set). Here we have applied an offset to the data so that the published orbital solution has $\gamma=0$, where $\gamma$ is the radial velocity of the center of mass of the system.

For the above reasons the measurements listed here are more precise and accurate than the values given in our previous publications and will not exactly match the values given in those works. There may also be slight differences in the binning of measurements made within about $2 \mathrm{hr}$.

\section{RADIAL VELOCITIES}

In the table of radial velocities for our stars (available in full in the electronic edition of the Journal ), we report the time of observation, measured radial velocity, and formal uncertainty in each measurement. The uncertainties reported are measured from the distribution of velocities measured from each of 400 parts of each spectroscopic observation, as discussed in previous works (e.g., Marcy et al. 2005b), and do not include jitter. We present a sample of this data set in Table 1.

The table contains five columns. Column (1) contains the name of the star. Column (2) contains the time of observation as a Julian Date. Column (3) contains the measured precision radial velocity at that time, and column (4) contains the uncertainty in this measurement. Column (5) contains a key indicating which observatory made the observation: " $\mathrm{K}$ " for Keck Observatory, "A" for the AAT, and "L" for Lick Observatory.

In addition to the uncertainties published here, there are known sources of error associated with astrophysical jitter, the instrument, and the analysis. These sources combine to give an additional source of noise, collectively termed "jitter." The magnitude of the jitter is a function of the spectral type of the star observed and the instrument used. Wright (2005) gives a model (for stars observed before 2004 August at Keck) that estimates, to within a factor of roughly 2 , the jitter for a star based on a star's activity, color, $T_{\text {eff }}$, and height above the main sequence. More recent measurements on HIRES will have less jitter due to the improved 
TABLE 2

Properties of Exoplanet Host Stars

\begin{tabular}{|c|c|c|c|c|c|c|c|c|c|c|c|c|c|c|c|c|}
\hline $\begin{array}{l}\mathrm{HD} \\
(1)\end{array}$ & $\begin{array}{l}\text { HIP } \\
(2)\end{array}$ & $\begin{array}{l}\text { Alternative } \\
\text { Name } \\
\text { (3) }\end{array}$ & $\begin{array}{c}\text { R.A. } \\
\text { (J2000.0) } \\
\text { (4) }\end{array}$ & $\begin{array}{c}\text { Decl. } \\
(\mathrm{J} 2000.0) \\
(5)\end{array}$ & $\begin{array}{c}B-V \\
(6)\end{array}$ & $\begin{array}{c}V \\
(7)\end{array}$ & $\begin{array}{c}\text { Distance } \\
\text { (pc) } \\
(8)\end{array}$ & $\begin{array}{l}T_{\text {eff }} \\
(\mathrm{K}) \\
(9)\end{array}$ & $\begin{array}{c}\log g \\
\left(\mathrm{~cm} \mathrm{~s}^{-2}\right) \\
(10)\end{array}$ & $\begin{array}{c}{[\mathrm{Fe} / \mathrm{H}]} \\
(11)\end{array}$ & $\begin{array}{c}v \sin i \\
\left(\mathrm{~m} \mathrm{~s}^{-1}\right) \\
(12)\end{array}$ & $\begin{array}{l}\text { Mass } \\
\left(M_{\odot}\right) \\
(13)\end{array}$ & $\begin{array}{c}\text { References } \\
\text { (14) }\end{array}$ & $\begin{array}{c}S \\
(15)\end{array}$ & $\begin{array}{c}\Delta M_{V} \\
(16)\end{array}$ & $\begin{array}{c}\text { Jitter } \\
\left(\mathrm{m} \mathrm{s}^{-1}\right) \\
(17)\end{array}$ \\
\hline $142 \ldots$ & 522 & & 000619.176 & -490430.69 & 0.52 & 5.70 & $25.64(42)$ & 6249 & 4.185 & 0.100 & 10.35 & 1.24 & VF5 & 0.16 & 0.28 & 4.3 \\
\hline $1237 \ldots \ldots \ldots \ldots . . .$. & 1292 & GJ 3021 & 001612.677 & -795104.25 & 0.75 & 6.59 & $17.62(16)$ & 5536 & 4.56 & 0.120 & & 0.90 & Sn4 & & 0.03 & ( \\
\hline $2039 \ldots \ldots \ldots \ldots . . . .$. & 1931 & & 002420.278 & -563900.17 & 0.66 & 9.00 & $89.8(9.1)$ & 5941 & 4.384 & 0.315 & 3.25 & 1.17 & VF5 & 0.18 & 0.60 & 3.7 \\
\hline $2638 \ldots \ldots \ldots \ldots . . . .$. & 2350 & & 002959.872 & -054550.41 & 0.89 & 9.44 & $53.7(3.9)$ & 5192 & 4.29 & 0.160 & & 0.93 & Sn5 & & 0.31 & \\
\hline 3651................ & 3093 & 54 Psc & 003921.806 & +211501.70 & 0.85 & 5.88 & $11.107(89)$ & 5221 & 4.453 & 0.164 & 1.15 & 0.89 & VF5 & 0.17 & 0.28 & 3.5 \\
\hline $4208 \ldots \ldots \ldots \ldots . . . .$. & 3479 & & 004426.650 & -263056.45 & 0.66 & 7.78 & $32.7(1.2)$ & 5600 & 4.517 & -0.284 & $\ldots$ & 0.87 & VF5 & 0.17 & -0.33 & 3.7 \\
\hline 4308.................. & 3497 & & 004439.268 & -653858.28 & 0.65 & 6.55 & $21.85(27)$ & 5695 & 4.580 & -0.310 & $\ldots$ & 0.90 & VF5 & & -0.03 & $\ldots$ \\
\hline $4203 \ldots \ldots \ldots \ldots . . . .$. & 3502 & & 004441.202 & +20 2656.14 & 0.77 & 8.70 & $77.8(7.7)$ & 5702 & 4.361 & 0.453 & 1.23 & 1.13 & VF5 & 0.14 & 1.27 & 4.0 \\
\hline 6434................. & 5054 & & 010440.151 & -392917.58 & 0.61 & 7.72 & $40.3(1.4)$ & 5835 & 4.60 & -0.520 & $\ldots$ & 0.79 & Sn4 & $\ldots$ & -0.14 & $\ldots$ \\
\hline $8574 \ldots \ldots \ldots \ldots . . . .$. & 6643 & & 012512.517 & +283400.10 & 0.58 & 7.12 & $44.2(1.6)$ & 6050 & 4.205 & -0.009 & 4.52 & 1.15 & VF5 & 0.14 & 0.43 & 4.1 \\
\hline 9826.................. & 7513 & $v$ And & 013647.843 & +412419.65 & 0.54 & 4.10 & 13.47(13) & 6213 & 4.253 & 0.153 & 9.62 & 1.32 & VF5 & 0.15 & 0.59 & 4.2 \\
\hline $10647 \ldots \ldots \ldots \ldots . . . .$. & 7978 & & 014229.316 & -534427.00 & 0.55 & 5.52 & $17.35(19)$ & 6105 & 4.345 & -0.078 & 5.61 & 1.10 & VF5 & 0.20 & -0.18 & 4.2 \\
\hline $10697 \ldots \ldots \ldots \ldots . . . .$. & 8159 & $109 \mathrm{Psc}$ & 014455.825 & +200459.34 & 0.72 & 6.27 & $32.56(86)$ & 5680 & 4.123 & 0.194 & 2.48 & 1.16 & VF5 & 0.15 & 1.51 & 4.0 \\
\hline 11977............... & 8928 & & 015456.131 & -673850.29 & 0.93 & 4.70 & $66.5(2.1)$ & 4970(70) & $2.90(20)$ & $-0.21(10)$ & $2.40(1.0)$ & 1.91 & Sw5 & & 5.73 & $\ldots$ \\
\hline $11964 \ldots \ldots \ldots \ldots$ & 9094 & & 015709.606 & $-10 \quad 1432.74$ & 0.82 & 6.42 & $34.0(1.1)$ & 5349 & 4.026 & 0.122 & 2.74 & 1.12 & VF5 & 0.14 & 2.00 & 5.7 \\
\hline $12661 \ldots \ldots \ldots \ldots$ & 9683 & & 020434.288 & +252451.50 & 0.71 & 7.43 & $37.2(1.1)$ & 5743 & 4.423 & 0.362 & 1.30 & 1.11 & VF5 & ${ }^{\mathrm{a}}$ & 0.58 & 3.5 \\
\hline $13445 \ldots \ldots \ldots \ldots$ & 10138 & GJ 86 & $\begin{array}{lll}02 & 1025.934\end{array}$ & -504925.41 & 0.81 & 6.12 & $10.913(73)$ & 5151 & 4.594 & -0.268 & 2.37 & 0.77 & VF5 & 0.25 & -0.20 & 3.5 \\
\hline $16141 \ldots \ldots \ldots \ldots . . . .$. & 12048 & 79 Cet & 023519.928 & -033338.17 & 0.67 & 6.83 & $35.9(1.8)$ & 5794 & 4.217 & 0.170 & 1.93 & 1.12 & VF5 & 0.14 & 0.86 & 3.6 \\
\hline \multirow[t]{2}{*}{$17051 \ldots \ldots \ldots \ldots . . .}$. & 12653 & $\iota$ Hor & 024233.466 & -504801.06 & 0.56 & 5.40 & $17.24(16)$ & 6097 & 4.342 & 0.111 & 6.47 & 1.17 & VF5 & 0.22 & 0.00 & 13 \\
\hline & 14810 & & $03 \quad 1114.230$ & +210550.49 & 0.78 & 8.52 & $52.9(4.1)$ & $5485(44)$ & $4.300(70)$ & $0.231(30)$ & $0.50(50)$ & 0.99 & Wr6 & & 0.64 & $\ldots$ \\
\hline 19994................ & 14954 & 94 Cet & $03 \quad 1246.437$ & -011145.96 & 0.57 & 5.07 & $22.38(38)$ & 6188 & 4.242 & 0.186 & 8.57 & 1.35 & VF5 & $\ldots$ & 0.99 & $\ldots$ \\
\hline $20367 \ldots \ldots \ldots \ldots . . . .$. & 15323 & & 031740.046 & +310737.37 & 0.57 & 6.40 & $27.13(79)$ & 6138 & 4.53 & 0.170 & & 1.17 & Sn4 & $\ldots$ & 0.07 & $\ldots$ \\
\hline $20782 \ldots \ldots \ldots \ldots . . .$. & 15527 & & 032003.577 & -285114.66 & 0.63 & 7.36 & $36.0(1.1)$ & 5758 & 4.349 & -0.051 & 2.36 & 0.98 & VF5 & $\ldots$ & 0.09 & $\ldots$ \\
\hline $22049 \ldots \ldots \ldots \ldots$ & 16537 & $\epsilon$ Eri & 033255.844 & -092729.74 & 0.88 & 3.72 & $3.2180(88)$ & 5146 & 4.574 & -0.031 & 2.45 & 0.82 & VF5 & 0.45 & -0.10 & 9.5 \\
\hline $23079 \ldots \ldots \ldots \ldots . . .$. & 17096 & & 033943.095 & -525457.02 & 0.58 & 7.12 & $34.60(67)$ & 5927 & 4.337 & -0.150 & 2.99 & 1.01 & VF5 & 0.16 & -0.06 & 4.0 \\
\hline $23596 \ldots \ldots \ldots \ldots$ & 17747 & & 034800.374 & +403150.29 & 0.63 & 7.25 & $52.0(2.3)$ & 5904 & 3.970 & 0.218 & 4.22 & 1.23 & VF5 & $\ldots$ & 1.02 & $\ldots$ \\
\hline $27442 \ldots \ldots \ldots \ldots . . .$. & 19921 & $\epsilon$ Ret & 041629.029 & -591807.76 & 1.08 & 4.44 & $18.23(17)$ & 4846 & 3.783 & 0.420 & 2.80 & 1.49 & VF5 & 0.15 & 3.76 & 5.7 \\
\hline $27894 \ldots \ldots \ldots \ldots . . .$. & 20277 & & 042047.047 & -592439.01 & 1.00 & 9.36 & $42.4(1.6)$ & 4875 & 4.22 & 0.300 & $\ldots$ & 0.75 & $\operatorname{Sn} 5$ & $\ldots$ & 0.38 & $\ldots$ \\
\hline $28185 \ldots \ldots \ldots \ldots . . .$. & 20723 & & 042626.320 & -103302.95 & 0.75 & 7.80 & $39.6(1.7)$ & 5656 & 4.45 & 0.220 & $\cdots$ & 0.99 & Sn4 & & 0.58 & $\ldots$ \\
\hline 30177................. & 21850 & & 044154.373 & -580114.73 & 0.77 & 8.41 & $54.7(2.3)$ & 5607 & 4.311 & 0.394 & 2.96 & 1.07 & VF5 & 0.15 & 0.80 & 3.5 \\
\hline $33283 \ldots \ldots \ldots \ldots$ & 23889 & & 050801.012 & -264750.90 & 0.64 & 8.05 & $86.9(6.8)$ & $5995(44)$ & $4.210(70)$ & $0.366(30)$ & $3.20(50)$ & 1.24 & Jh6 & & 1.38 & $\ldots$ \\
\hline $33636 \ldots \ldots \ldots \ldots . . .$. & 24205 & & 051146.449 & +042412.74 & 0.59 & 7.00 & $28.7(1.1)$ & 5904 & 4.429 & -0.126 & 3.08 & 1.02 & VF5 & 0.18 & -0.32 & 5.2 \\
\hline $33564 \ldots \ldots \ldots \ldots . . .$. & 25110 & & 052233.532 & +79 1352.13 & 0.51 & 5.08 & $20.98(23)$ & 6250 & $\ldots$ & -0.12 & $\ldots$ & 1.25 & $\mathrm{Nd} 4$ & $\ldots$ & 0.38 & $\ldots$ \\
\hline $37124 \ldots \ldots \ldots \ldots . . .$. & 26381 & & 053702.486 & +204350.84 & 0.67 & 7.68 & $33.2(1.3)$ & 5500 & 4.599 & -0.442 & 1.22 & 0.83 & VF5 & & -0.17 & \\
\hline 39091_............... & 26394 & $\pi$ Men & 053709.892 & -802808.84 & 0.60 & 5.65 & 18.21(15) & 5950 & 4.363 & 0.048 & 3.14 & 1.10 & VF5 & 0.16 & 0.12 & 3.9 \\
\hline $37605 \ldots \ldots \ldots \ldots . . .$. & 26664 & & 054001.730 & +060338.08 & 0.83 & 8.67 & $42.9(2.4)$ & 5391 & 4.37 & 0.310 & & 0.80 & Sn5 & & 0.30 & \\
\hline 38529............... & 27253 & & 054634.912 & $+01 \quad 1005.50$ & 0.77 & 5.95 & $42.4(1.7)$ & 5697 & 4.049 & 0.445 & 3.90 & 1.47 & VF5 & 0.17 & 2.71 & 5.7 \\
\hline 41004 А ........ & 28393 & & 055949.649 & $\begin{array}{llll}-48 & 14 & 22.89\end{array}$ & 0.89 & 8.65 & $43.0(1.9)$ & 5242 & 4.35 & 0.160 & $\ldots$ & 0.70 & Sn5 & $\ldots$ & 0.63 & $\ldots$ \\
\hline 41004 B ........ & 28393 & & 055949.649 & -481422.89 & 1.52 & 12.33 & $43.0(1.9)$ & $3952^{\mathrm{b}}$ & & & & 0.40 & $\mathrm{Z3}$ & & 1.22 & \\
\hline $40979 \ldots \ldots \ldots \ldots . . . .$. & 28767 & & $\begin{array}{lll}06 & 04 & 29.943\end{array}$ & +441537.60 & 0.57 & 6.74 & 33.33(91) & 6089 & 4.302 & 0.168 & 7.43 & 1.19 & VF5 & 0.23 & 0.17 & 15 \\
\hline $45350 \ldots \ldots \ldots \ldots . .$. & 30860 & & 062845.710 & +385746.67 & 0.74 & 7.89 & $48.9(2.3)$ & 5616 & 4.325 & 0.291 & 1.37 & 1.06 & VF5 & 0.15 & 0.90 & 3.5 \\
\hline $46375 \ldots \ldots \ldots \ldots$ & 31246 & & 063312.624 & +052746.53 & 0.86 & 7.91 & $33.4(1.2)$ & 5285 & 4.533 & 0.240 & 0.86 & 0.92 & VF5 & 0.19 & 0.69 & 3.5 \\
\hline $47536 \ldots \ldots \ldots \ldots$ & 31688 & & 063747.619 & -322023.05 & 1.18 & 5.25 & $121.4(8.2)$ & $4380(50)$ & & $\cdots$ & $1.93(50)$ & $1.1,3.0^{\mathrm{c}}$ & Sw3 & & 7.46 & $\ldots$ \\
\hline $49674 \ldots \ldots \ldots \ldots . . .$. & 32916 & & 065130.516 & +40 5203.92 & 0.73 & 8.10 & $40.7(1.9)$ & 5662 & 4.560 & 0.310 & 0.42 & 1.06 & VF5 & 0.21 & 0.22 & 6.6 \\
\hline $50499 \ldots \ldots \ldots \ldots$ & 32970 & & 065202.024 & -335456.02 & 0.61 & 7.21 & $47.3(1.5)$ & 6070 & 4.373 & 0.335 & 4.21 & 1.25 & VF5 & & 0.72 & $\ldots$ \\
\hline $50554 \ldots \ldots \ldots \ldots$ & 33212 & & 065442.825 & +241444.01 & 0.58 & 6.84 & $31.03(97)$ & 5929 & 4.285 & -0.066 & 3.88 & 1.05 & VF5 & 0.16 & -0.03 & 4.0 \\
\hline
\end{tabular}


TABLE 2-Continued

\begin{tabular}{|c|c|c|c|c|c|c|c|c|c|c|c|c|c|c|c|c|}
\hline $\begin{array}{l}\mathrm{HD} \\
(1)\end{array}$ & $\begin{array}{l}\text { HIP } \\
(2)\end{array}$ & $\begin{array}{l}\text { Alternative } \\
\text { Name } \\
\text { (3) }\end{array}$ & $\begin{array}{c}\text { R.A. } \\
\text { (J2000.0) } \\
\text { (4) }\end{array}$ & $\begin{array}{c}\text { Decl. } \\
(\mathrm{J} 2000.0) \\
(5)\end{array}$ & $\begin{array}{c}B-V \\
(6)\end{array}$ & $\begin{array}{c}V \\
(7)\end{array}$ & $\begin{array}{l}\text { Distance } \\
\text { (pc) } \\
\text { (8) }\end{array}$ & $\begin{array}{l}T_{\text {eff }} \\
(\mathrm{K}) \\
(9)\end{array}$ & $\begin{array}{c}\log g \\
\left(\mathrm{~cm} \mathrm{~s}^{-2}\right) \\
(10)\end{array}$ & $\begin{array}{c}{[\mathrm{Fe} / \mathrm{H}]} \\
(11)\end{array}$ & $\begin{array}{c}v \sin i \\
\left(\mathrm{~m} \mathrm{~s}^{-1}\right) \\
(12)\end{array}$ & $\begin{array}{l}\text { Mass } \\
\left(M_{\odot}\right) \\
(13)\end{array}$ & $\begin{array}{c}\text { References } \\
\text { (14) }\end{array}$ & $\begin{array}{c}S \\
(15)\end{array}$ & $\begin{array}{l}\Delta M_{V} \\
(16)\end{array}$ & $\begin{array}{c}\text { Jitter } \\
\left(\mathrm{m} \mathrm{s}^{-1}\right) \\
(17)\end{array}$ \\
\hline $52265 \ldots \ldots \ldots \ldots$ & 33719 & & 070018.036 & -052201.78 & 0.57 & 6.29 & $28.07(66)$ & 6076 & 4.263 & 0.193 & 4.67 & 1.20 & VF5 & 0.15 & 0.24 & 4.1 \\
\hline $63454 \ldots \ldots \ldots \ldots$ & 37284 & & 073921.851 & $-78 \quad 1644.30$ & 1.01 & 9.37 & $35.8(1.1)$ & 4841 & 4.23 & 0.110 & $\ldots$ & 0.80 & Sn5 & $\ldots$ & 0.02 & $\ldots$ \\
\hline 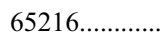 & 38558 & & 075341.322 & -633850.36 & 0.67 & 7.97 & $35.59(87)$ & 5666 & 4.53 & -0.120 & $\ldots$ & 0.92 & $\mathrm{Sn} 4$ & $\ldots$ & -0.28 & $\ldots$ \\
\hline $66428 \ldots \ldots \ldots \ldots . . .$. & 39417 & & 080328.665 & -010945.75 & 0.71 & 8.25 & $55.0(3.8)$ & 5752 & 4.490 & 0.310 & $\ldots$ & 1.10 & VF5 & 0.15 & 0.64 & 5.7 \\
\hline $68988 \ldots \ldots \ldots \ldots$ & 40687 & & $\begin{array}{lll}08 & 1822.173\end{array}$ & +612738.60 & 0.65 & 8.20 & $58.8(3.3)$ & 5960 & 4.413 & 0.324 & 2.84 & 1.18 & VF5 & 0.15 & 0.45 & 3.7 \\
\hline $70642 \ldots \ldots \ldots \ldots . . .$. & 40952 & & 082128.136 & -394219.47 & 0.69 & 7.17 & $28.76(50)$ & 5706 & 4.432 & 0.164 & 0.30 & 1.05 & VF5 & a & 0.18 & 3.5 \\
\hline $72659 \ldots \ldots \ldots \ldots$ & 42030 & & 083403.190 & -013405.58 & 0.61 & 7.46 & $51.4(2.7)$ & 5920 & 4.236 & -0.004 & 2.21 & 1.10 & VF5 & 0.15 & 0.64 & 3.9 \\
\hline $73256 \ldots \ldots \ldots \ldots$ & 42214 & & 083623.015 & $-3002 \quad 15.46$ & 0.78 & 8.08 & $36.5(1.0)$ & 5636 & 4.30 & 0.260 & & 1.05 & Sn4 & $\ldots$ & 0.31 & $\ldots$ \\
\hline $73526 \ldots \ldots \ldots \ldots . .$. & 42282 & & 083716.484 & $-41 \quad 1908.77$ & 0.74 & 8.99 & $94.6(9.0)$ & 5584 & 4.159 & 0.250 & 2.62 & 1.05 & VF5 & $\ldots$ & 1.21 & $\ldots$ \\
\hline $74156 \ldots \ldots \ldots \ldots . .$. & 42723 & & 084225.122 & +043441.15 & 0.58 & 7.61 & $64.6(4.6)$ & 6068 & 4.259 & 0.131 & 4.32 & 1.21 & VF5 & $\ldots$ & 0.81 & $\ldots$ \\
\hline $75289 \ldots \ldots \ldots \ldots . . . .$. & 43177 & & 084740.389 & -414412.45 & 0.58 & 6.35 & 28.94(47) & 6095 & 4.335 & 0.217 & 4.14 & 1.21 & VF5 & 0.15 & 0.28 & 4.0 \\
\hline $75732 \ldots \ldots \ldots \ldots$ & 43587 & $55 \mathrm{Cnc}, \rho^{1} \mathrm{Cnc}$ & 085235.811 & +281950.95 & 0.87 & 5.96 & $12.53(13)$ & 5235 & 4.448 & 0.315 & 2.46 & 0.91 & VF5 & $\ldots$ & 0.55 & $\ldots$ \\
\hline $76700 \ldots \ldots \ldots \ldots . . .$. & 43686 & & 085355.515 & -664803.57 & 0.75 & 8.16 & $59.7(2.4)$ & 5668 & 4.299 & 0.345 & 1.35 & 1.13 & VF5 & $\mathrm{a}$ & 1.09 & 3.5 \\
\hline $80606 \ldots \ldots \ldots \ldots$ & 45982 & & 092237.568 & +503613.40 & 0.76 & 9.06 & $58(20)$ & 5573 & 4.439 & 0.343 & 1.80 & 1.10 & VF5 & 0.15 & 0.25 & 3.5 \\
\hline 81040_................. & 46076 & & 092347.087 & +202152.03 & 0.68 & 7.72 & $32.6(1.3)$ & $5700(50)$ & $4.50(10)$ & $-0.160(60)$ & $2.0(1.0)$ & 0.96 & Sz6 & $\ldots$ & -0.18 & $\ldots$ \\
\hline $82943 \ldots \ldots \ldots \ldots$ & 47007 & & 093450.736 & -120746.37 & 0.62 & 6.54 & $27.46(63)$ & 5997 & 4.421 & 0.265 & 1.35 & 1.18 & VF5 & $\ldots$ & 0.27 & $\ldots$ \\
\hline $83443 \ldots \ldots \ldots . .$. & 47202 & & 093711.828 & -431619.94 & 0.81 & 8.23 & $43.5(1.7)$ & 5453 & 4.491 & 0.357 & 1.28 & 1.00 & VF5 & 0.22 & 0.69 & 5.2 \\
\hline $86081 \ldots \ldots \ldots \ldots . . .$. & 48711 & & 095605.918 & -034830.32 & 0.66 & 8.73 & $91(10)$ & $6028(44)$ & $4.360(70)$ & $0.257(30)$ & $4.20(50)$ & 1.21 & Jh6 & $\ldots$ & 0.95 & $\ldots$ \\
\hline $88133 \ldots \ldots \ldots \ldots . . .$. & 49813 & & 101007.675 & $+1811 \quad 12.74$ & 0.81 & 8.01 & $74.5(6.4)$ & 5494 & 4.230 & 0.340 & 2.20 & 1.20 & Fi5 & 0.13 & 2.07 & 5.7 \\
\hline 89307 ................. & 50473 & & 101821.288 & +12 3715.99 & 0.59 & 7.02 & $30.88(94)$ & 5898 & 4.341 & -0.159 & 2.88 & 1.00 & VF5 & 0.16 & -0.14 & 4.0 \\
\hline $89744 \ldots \ldots \ldots \ldots . . . .$. & 50786 & & 102210.562 & +411346.31 & 0.53 & 5.73 & $39.0(1.1)$ & 6291 & 4.072 & 0.265 & 9.51 & 1.64 & VF5 & 0.16 & 1.24 & 4.0 \\
\hline $92788 \ldots \ldots \ldots \ldots . . .$. & 52409 & & 104248.529 & $-02 \quad 1101.52$ & 0.69 & 7.31 & $32.3(1.0)$ & 5836 & 4.658 & 0.318 & 0.26 & 1.13 & VF5 & 0.15 & 0.30 & 3.5 \\
\hline \multirow[t]{2}{*}{ 93083............... } & 52521 & & 104420.915 & -333437.28 & 0.94 & 8.30 & $28.90(84)$ & 4995 & 4.26 & 0.150 & $\ldots$ & 0.70 & Sn5 & $\ldots$ & 0.37 & $\ldots$ \\
\hline & & BD -10 3166 & 105828.780 & -104613.39 & 0.90 & 10.08 & $80(10)^{\mathrm{d}}$ & 5393 & 4.685 & 0.382 & 0.92 & 1.01 & VF5 & 0.22 & e & 5.7 \\
\hline $95128 \ldots \ldots \ldots \ldots . . . .$. & 53721 & $47 \mathrm{UMa}$ & 105927.974 & +402548.92 & 0.62 & 5.03 & $14.08(13)$ & 5882 & 4.377 & 0.043 & 2.80 & 1.08 & VF5 & $\ldots$ & 0.34 & $\ldots$ \\
\hline $99109 \ldots \ldots \ldots . . . .$. & 55664 & & 112417.358 & -013144.67 & 0.87 & 9.10 & $60.5(4.8)$ & 5272 & 4.438 & 0.315 & 1.86 & 0.93 & VF5 & 0.16 & 0.85 & 5.7 \\
\hline \multirow[t]{2}{*}{ 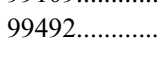 } & 55848 & 83 Leo B & 112646.277 & +030022.78 & 1.00 & 7.58 & $18.0(1.1)$ & 4955 & 4.770 & 0.362 & 1.36 & 0.86 & VF5 & 0.25 & 0.30 & 3.5 \\
\hline & 57087 & GJ 436 & 114211.094 & +264223.65 & 1.49 & 10.67 & $10.23(24)$ & $4002^{\mathrm{b}}$ & $\ldots$ & $\ldots$ & $\ldots$ & 0.41 & $\mathrm{Bu} 4$ & 0.73 & -0.66 & 3.9 \\
\hline $101930 \ldots \ldots \ldots . .$. & 57172 & & 114330.111 & -580024.79 & 0.91 & 8.21 & $30.50(89)$ & 5079 & 4.24 & 0.170 & $\ldots$ & 0.74 & Sn5 & $\ldots$ & 0.42 & $\ldots$ \\
\hline $102117 \ldots \ldots \ldots \ldots$ & 57291 & & 114450.462 & $-5842 \quad 13.35$ & 0.72 & 7.47 & $42.0(1.5)$ & 5695 & 4.366 & 0.295 & 0.88 & 1.11 & VF5 & $\mathrm{a}$ & 0.87 & 3.5 \\
\hline $102195 \ldots \ldots \ldots$ & 57370 & & 114542.292 & +024914.34 & 0.83 & 8.07 & $28.98(97)$ & $5200^{\mathrm{b}}$ & $\ldots$ & $-0.090(14)$ & $\ldots$ & 0.93 & Ge6 & $\ldots$ & 0.09 & $\ldots$ \\
\hline $104985 \ldots \ldots \ldots . . . .$. & 58952 & & 120515.118 & +76 5420.64 & 1.03 & 5.78 & $102.0(5.4)$ & $4794^{b}$ & $\ldots$ & $\ldots$ & $\ldots$ & 1.60 & St3 & $\ldots$ & 5.97 & $\ldots$ \\
\hline $106252 \ldots \ldots \ldots$ & 59610 & & 121329.509 & +100229.90 & 0.63 & 7.41 & $37.4(1.3)$ & 5870 & 4.364 & -0.076 & 1.93 & 1.02 & VF5 & 0.16 & 0.15 & 3.8 \\
\hline $107148 \ldots \ldots \ldots . . .$. & 60081 & & 121913.491 & $-03 \quad 1911.24$ & 0.71 & 8.01 & $51.3(2.6)$ & 5797 & 4.446 & 0.314 & 0.73 & 1.12 & VF5 & 0.16 & 0.68 & 3.5 \\
\hline $108147 \ldots \ldots \ldots . .$. & 60644 & & 122546.269 & -640119.52 & 0.54 & 6.99 & $38.6(1.0)$ & 6156 & 4.292 & 0.087 & 6.10 & 1.19 & VF5 & 0.19 & 0.00 & 8.1 \\
\hline $108874 \ldots \ldots \ldots$ & 61028 & & 123026.883 & +225247.38 & 0.74 & 8.76 & $68.5(5.8)$ & 5551 & 4.349 & 0.182 & 2.22 & 1.00 & VF5 & $\ldots$ & 0.75 & \\
\hline $109749 \ldots \ldots \ldots . . .$. & 61595 & & 123716.378 & -404843.62 & 0.68 & 8.08 & $59.0(6.7)$ & $5903(50)$ & $4.403(70)$ & $0.25(50)$ & $2.50(50)$ & 1.21 & Fi6 & $\ldots$ & 0.75 & $\ldots$ \\
\hline $111232 \ldots \ldots \ldots .$. & 62534 & & 124851.754 & -682530.54 & 0.70 & 7.59 & $28.88(67)$ & 5494 & 4.50 & -0.360 & & 0.78 & Sn4 & $\ldots$ & -0.18 & \\
\hline $114386 \ldots \ldots \ldots . .$. & 64295 & & $13 \quad 1039.823$ & $\begin{array}{lll}-35 & 03 & 17.22\end{array}$ & 0.98 & 8.73 & $28.0(1.0)$ & 4820 & 4.707 & 0.004 & 0.59 & 0.76 & VF5 & $\ldots$ & 0.03 & $\ldots$ \\
\hline $114762 \ldots \ldots \ldots$ & 64426 & & $13 \quad 1219.743$ & +173101.64 & 0.52 & 7.30 & $40.6(2.4)$ & 5953 & 4.545 & -0.653 & 1.77 & 0.89 & VF5 & $\mathrm{a}$ & -0.28 & 4.3 \\
\hline $114783 \ldots \ldots \ldots . .$. & 64457 & & 131243.786 & $-02 \quad 1554.14$ & 0.93 & 7.56 & $20.43(44)$ & 5135 & 4.527 & 0.116 & 0.87 & 0.86 & VF5 & 0.21 & 0.29 & 3.5 \\
\hline $114729 \ldots \ldots \ldots . .$. & 64459 & & $13 \quad 1244.257$ & $-3152 \quad 24.06$ & 0.59 & 6.68 & $35.0(1.2)$ & 5821 & 4.143 & -0.262 & 2.29 & 1.00 & VF5 & 0.15 & 0.45 & 4.0 \\
\hline $117176 \ldots \ldots \ldots$ & 65721 & 70 Vir & 132825.809 & +134643.63 & 0.71 & 4.97 & $18.11(24)$ & 5545 & 4.068 & -0.012 & 2.68 & 1.11 & VF5 & 0.17 & 1.50 & 4.0 \\
\hline $117207 \ldots \ldots \ldots . . .$. & 65808 & & 132921.114 & -353415.59 & 0.72 & 7.26 & $33.0(1.0)$ & 5724 & 4.507 & 0.266 & 1.05 & 1.08 & VF5 & 0.15 & 0.58 & 3.5 \\
\hline $117618 \ldots \ldots \ldots$ & 66047 & & 133225.556 & $-47 \quad 1616.91$ & 0.60 & 7.17 & $38.0(1.3)$ & 5964 & 4.350 & 0.003 & 3.19 & 1.09 & VF5 & 0.17 & 0.22 & 5.3 \\
\hline $118203 \ldots \ldots \ldots$ & 66192 & & 133402.537 & +534342.70 & 0.70 & 8.05 & $88.6(6.4)$ & $5600(150)$ & 3.87 & $0.100(50)$ & 4.70 & 1.23 & $\mathrm{Da} 6$ & $\ldots$ & 1.78 & $\ldots$ \\
\hline $120136 \ldots \ldots \ldots . .$. & 67275 & $\tau$ Boo & 134715.743 & +172724.86 & 0.51 & 4.50 & $15.60(17)$ & 6387 & 4.256 & 0.234 & 14.98 & 1.35 & VF5 & 0.20 & 0.33 & 15 \\
\hline
\end{tabular}


TABLE 2-Continued

\begin{tabular}{|c|c|c|c|c|c|c|c|c|c|c|c|c|c|c|c|c|}
\hline $\begin{array}{l}\text { HD } \\
(1)\end{array}$ & $\begin{array}{l}\text { HIP } \\
(2)\end{array}$ & $\begin{array}{l}\text { Alternative } \\
\text { Name } \\
\text { (3) }\end{array}$ & $\begin{array}{l}\text { R.A. } \\
\text { (J2000.0) } \\
\text { (4) }\end{array}$ & $\begin{array}{c}\text { Decl. } \\
(\mathrm{J} 2000.0) \\
(5)\end{array}$ & $\begin{array}{c}B-V \\
(6)\end{array}$ & $\begin{array}{c}V \\
(7)\end{array}$ & $\begin{array}{l}\text { Distance } \\
\text { (pc) } \\
(8)\end{array}$ & $\begin{array}{l}T_{\text {eff }} \\
(\mathrm{K}) \\
(9)\end{array}$ & $\begin{array}{c}\log g \\
\left(\mathrm{~cm} \mathrm{~s}^{-2}\right) \\
(10)\end{array}$ & $\begin{array}{c}{[\mathrm{Fe} / \mathrm{H}]} \\
(11)\end{array}$ & $\begin{array}{c}v \sin i \\
\left(\mathrm{~m} \mathrm{~s}^{-1}\right) \\
(12)\end{array}$ & $\begin{array}{l}\text { Mass } \\
\left(M_{\odot}\right) \\
(13)\end{array}$ & $\begin{array}{c}\text { References } \\
\text { (14) }\end{array}$ & $\begin{array}{c}S \\
(15)\end{array}$ & $\begin{array}{c}\Delta M_{V} \\
(16)\end{array}$ & $\begin{array}{c}\text { Jitter } \\
\left(\mathrm{m} \mathrm{s}^{-1}\right) \\
(17)\end{array}$ \\
\hline $121504 \ldots \ldots \ldots \ldots$ & 68162 & & 135717.237 & -560224.15 & 0.59 & 7.54 & $44.4(1.8)$ & 6075 & 4.64 & 0.160 & $\ldots$ & 1.18 & Sn4 & $\ldots$ & 0.12 & $\ldots$ \\
\hline $128311 \ldots \ldots \ldots \ldots$ & 71395 & & 143600.561 & +094447.47 & 0.97 & 7.48 & $16.57(27)$ & 4965 & 4.831 & 0.205 & 3.65 & 0.84 & VF5 & $\ldots$ & 0.10 & $\ldots$ \\
\hline $130322 \ldots \ldots \ldots \ldots$ & 72339 & & 144732.727 & -001653.31 & 0.78 & 8.04 & $29.8(1.3)$ & 5308 & 4.408 & 0.006 & 1.61 & 0.88 & VF5 & 0.23 & -0.10 & 3.5 \\
\hline $134987 \ldots \ldots \ldots \ldots$ & 74500 & $23 \mathrm{Lib}$ & $15 \quad 1328.668$ & -251833.65 & 0.69 & 6.47 & $25.65(64)$ & 5750 & 4.348 & 0.279 & 2.17 & 1.10 & VF5 & 0.15 & 0.62 & 3.5 \\
\hline \multirow[t]{2}{*}{$136118 \ldots \ldots \ldots . . . .}$. & 74948 & & 151855.472 & -013532.59 & 0.55 & 6.93 & $52.3(2.3)$ & 6097 & 4.053 & -0.050 & 7.33 & 1.23 & VF5 & 0.16 & 0.82 & 4.2 \\
\hline & 74995 & GJ 581 & 151926.825 & -074320.21 & 1.60 & 10.57 & $6.269(89)$ & $3780^{\mathrm{b}}$ & & -0.25 & $\ldots$ & 0.31 & $\mathrm{Nd} 4$ & & 0.24 & \\
\hline $137759 \ldots \ldots \ldots$ & 75458 & $\iota$ Dra & 152455.775 & +585757.84 & 1.17 & 3.29 & $31.33(50)$ & $4548^{\mathrm{b}}$ & & $\ldots$ & & 1.05 & Ad9 & $\mathrm{a}$ & 6.43 & 5.7 \\
\hline $137510 \ldots \ldots \ldots \ldots$ & 75535 & & $15 \quad 2553.270$ & +192850.54 & 0.62 & 6.26 & $41.8(1.6)$ & 5966 & 3.995 & 0.373 & 7.98 & 1.42 & VF5 & 0.16 & 1.43 & 4.0 \\
\hline $330075 \ldots \ldots \ldots . . .$. & 77517 & & 154937.691 & -495748.69 & 0.94 & 9.36 & $50.2(3.8)$ & 5017 & 4.22 & 0.080 & $\ldots$ & 0.70 & Sn5 & $\ldots$ & 0.47 & $\ldots$ \\
\hline $141937 \ldots \ldots \ldots \ldots$ & 77740 & & $\begin{array}{lll}15 & 52 & 17.547\end{array}$ & -182609.83 & 0.63 & 7.25 & $33.5(1.2)$ & 5847 & 4.420 & 0.129 & 1.88 & 1.08 & VF5 & $\ldots$ & 0.02 & $\ldots$ \\
\hline $142415 \ldots \ldots \ldots \ldots$ & 78169 & & 155740.791 & $\begin{array}{llll}-60 & 12 & 00.93\end{array}$ & 0.62 & 7.33 & $34.6(1.0)$ & 5902 & 4.382 & 0.088 & 3.43 & 1.09 & VF5 & 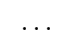 & -0.03 & $\ldots$ \\
\hline $143761 \ldots \ldots \ldots$ & 78459 & $\rho \mathrm{CrB}$ & 160102.662 & +331812.63 & 0.61 & 5.39 & $17.43(22)$ & 5823 & 4.365 & -0.199 & 1.56 & 1.00 & VF5 & 0.15 & 0.37 & 3.9 \\
\hline $142022 \ldots \ldots \ldots \ldots$ & 79242 & & 161015.024 & -841353.80 & 0.79 & 7.70 & $35.87(87)$ & 5499 & 4.36 & 0.190 & $\ldots$ & 0.90 & Sn5 & & 0.69 & $\ldots$ \\
\hline $145675 \ldots \ldots \ldots \ldots$ & 79248 & $14 \mathrm{Her}$ & 161024.314 & +434903.52 & 0.88 & 6.61 & $18.15(19)$ & 5388 & 4.517 & 0.460 & 1.56 & 1.00 & VF5 & 0.16 & 0.74 & 3.5 \\
\hline $147513 \ldots \ldots \ldots . . .$. & 80337 & & 162401.290 & -391134.73 & 0.62 & 5.37 & $12.87(14)$ & 5930 & 4.612 & 0.089 & 1.55 & 1.07 & VF5 & $\ldots$ & -0.19 & $\ldots$ \\
\hline $149026 \ldots \ldots \ldots . . . .$. & 80838 & & 163029.619 & +382050.31 & 0.61 & 8.15 & $78.9(4.9)$ & $6147(50)$ & & $0.360(50)$ & $6.00(50)$ & 1.30 & St5 & $\ldots$ & 0.88 & $\ldots$ \\
\hline $150706 \ldots \ldots \ldots . . .$. & 80902 & & 163117.586 & +794723.19 & 0.61 & 7.01 & $27.23(42)$ & 5961 & 4.50 & -0.010 & $\ldots$ & 0.98 & Sn4 & $\ldots$ & -0.32 & $\ldots$ \\
\hline 149143............. & 81022 & & 163251.050 & +020505.39 & 0.71 & 7.89 & $63.5(4.3)$ & $5884(50)$ & $4.071(70)$ & $0.26(50)$ & $4.00(50)$ & 1.20 & Fi6 & $\ldots$ & 1.31 & $\ldots$ \\
\hline $154857 \ldots \ldots \ldots \ldots$ & 84069 & & 171115.722 & -564050.87 & 0.70 & 7.24 & $68.5(4.3)$ & 5606 & 3.992 & -0.220 & 1.44 & 1.22 & VF5 & $\ldots$ & 2.03 & $\ldots$ \\
\hline $160691 \ldots \ldots \ldots \ldots$ & 86796 & $\mu$ Ara & 174408.703 & -515002.59 & 0.69 & 5.12 & $15.28(19)$ & 5784 & 4.298 & 0.293 & 3.12 & 1.15 & VF5 & $\ldots$ & 0.86 & $\ldots$ \\
\hline $162020 \ldots \ldots \ldots \ldots$ & 87330 & & 175038.357 & -401906.06 & 0.96 & 9.10 & $31.3(1.4)$ & 4845 & 4.901 & 0.112 & 2.32 & 0.78 & VF5 & $\ldots$ & -0.18 & $\ldots$ \\
\hline $164922 \ldots \ldots \ldots \ldots$ & 88348 & & 180230.862 & +261846.81 & 0.80 & 7.01 & 21.93(34) & 5385 & 4.506 & 0.170 & 1.84 & 0.94 & VF5 & 0.16 & 0.36 & 5.7 \\
\hline $168443 \ldots \ldots \ldots . . .$. & 89844 & & 182003.932 & -093544.60 & 0.72 & 6.92 & $37.9(1.2)$ & 5580 & 4.248 & 0.077 & 2.20 & 1.05 & VF5 & a & 1.22 & 4.0 \\
\hline $168746 \ldots \ldots \ldots . . . .$. & 90004 & & 182149.783 & -115521.66 & 0.71 & 7.95 & $43.1(1.8)$ & 5564 & 4.518 & -0.078 & 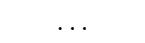 & 0.93 & VF5 & 0.15 & 0.40 & 3.5 \\
\hline \multirow{2}{*}{$169830 \ldots \ldots \ldots . . .}$. & 90485 & & 182749.484 & -294900.71 & 0.52 & 5.90 & $36.3(1.2)$ & 6221 & 4.057 & 0.153 & 3.83 & 1.43 & VF5 & $\ldots$ & 0.82 & $\cdots$ \\
\hline & & TrES-1 & 190409.8 & +36 5757 & 0.78 & 11.79 & $150.0(6.0)$ & $5250(75)$ & $4.60(20)$ & $0.000(90)$ & $10.353(66)$ & 0.89 & Sz4 & $\ldots$ & -0.35 & $\ldots$ \\
\hline $177830 \ldots \ldots \ldots . . .$. & 93746 & & 190520.774 & +255514.38 & 1.09 & 7.18 & $59.0(2.6)$ & 4949 & 4.032 & 0.545 & 2.54 & 1.46 & VF5 & 0.12 & 3.63 & 5.7 \\
\hline 178911 В....... & 94075 & & 190903.104 & +343559.45 & 0.75 & 7.97 & $47(11)$ & 5668 & 4.554 & 0.285 & 1.94 & 1.06 & VF5 & 0.17 & 0.77 & 3.8 \\
\hline $179949 \ldots \ldots \ldots \ldots$ & 94645 & & 191533.228 & -241045.67 & 0.55 & 6.25 & $27.05(59)$ & 6168 & 4.341 & 0.137 & 7.02 & 1.21 & VF5 & 0.19 & 0.04 & 8.6 \\
\hline $183263 \ldots \ldots \ldots \ldots$ & 95740 & & 192824.573 & +082129.00 & 0.68 & 7.86 & $52.8(3.0)$ & 5936 & 4.403 & 0.302 & 1.56 & 1.17 & VF5 & 0.14 & 0.72 & 3.6 \\
\hline $186427 \ldots \ldots \ldots . .$. & 96901 & 16 Cyg B & 194151.972 & +503103.08 & 0.66 & 6.25 & $21.41(24)$ & 5674 & 4.355 & 0.038 & 2.18 & 0.99 & VF5 & 0.15 & 0.26 & 3.7 \\
\hline $187123 \ldots \ldots \ldots \ldots$ & 97336 & & 194658.113 & +342510.29 & 0.66 & 7.83 & $47.9(1.6)$ & 5815 & 4.359 & 0.121 & 2.15 & 1.08 & VF5 & 0.15 & 0.43 & 3.7 \\
\hline
\end{tabular}


TABLE 2-Continued

\begin{tabular}{|c|c|c|c|c|c|c|c|c|c|c|c|c|c|c|c|c|}
\hline $\begin{array}{l}\mathrm{HD} \\
(1)\end{array}$ & $\begin{array}{c}\mathrm{HIP} \\
(2)\end{array}$ & $\begin{array}{l}\text { Alternative } \\
\text { Name } \\
\text { (3) }\end{array}$ & $\begin{array}{c}\text { R.A. } \\
\text { (J2000.0) } \\
\text { (4) }\end{array}$ & $\begin{array}{c}\text { Decl. } \\
\text { (J2000.0) } \\
\text { (5) }\end{array}$ & $\begin{array}{c}B-V \\
\quad(6)\end{array}$ & $\begin{array}{l}V \\
\text { (7) }\end{array}$ & $\begin{array}{c}\text { Distance } \\
\text { (pc) } \\
(8)\end{array}$ & $\begin{array}{l}T_{\text {eff }} \\
(\mathrm{K}) \\
(9)\end{array}$ & $\begin{array}{c}\log g \\
\left(\mathrm{~cm} \mathrm{~s}^{-2}\right) \\
(10)\end{array}$ & $\begin{array}{c}{[\mathrm{Fe} / \mathrm{H}]} \\
(11)\end{array}$ & $\begin{array}{c}v \sin i \\
\left(\mathrm{~m} \mathrm{~s}^{-1}\right) \\
(12)\end{array}$ & $\begin{array}{l}\text { Mass } \\
\left(M_{\odot}\right) \\
(13)\end{array}$ & $\begin{array}{l}\text { References } \\
\text { (14) }\end{array}$ & $\begin{array}{c}S \\
(15)\end{array}$ & $\begin{array}{c}\Delta M_{V} \\
(16)\end{array}$ & $\begin{array}{c}\text { Jitter } \\
\left(\mathrm{m} \mathrm{s}^{-1}\right) \\
(17)\end{array}$ \\
\hline $187085 \ldots \ldots \ldots \ldots \ldots$ & 97546 & & 194933.367 & -374649.98 & 0.57 & 7.22 & $45.0(2.3)$ & 6075 & 4.276 & 0.088 & 5.09 & 1.16 & VF5 & & 0.35 & $\ldots$ \\
\hline $188015 \ldots \ldots \ldots \ldots \ldots$ & 97769 & & 195204.543 & +280601.36 & 0.73 & 8.24 & $52.6(2.6)$ & 5746 & 4.445 & 0.289 & & 1.09 & VF5 & 0.15 & 0.63 & 3.5 \\
\hline $189733 \ldots \ldots \ldots \ldots \ldots$ & 98505 & & 200043.713 & +224239.07 & 1.20 & 7.50 & $19.25(32)$ & $5050(50)$ & $4.53(14)$ & $-0.030(40)$ & $3.5(1.0)$ & 0.82 & Bc5 & $\ldots$ & 1.32 & $\ldots$ \\
\hline $190228 \ldots \ldots \ldots$ & 98714 & & 200300.773 & +281824.68 & 0.79 & 7.30 & $62.1(3.1)$ & 5348 & 3.976 & -0.180 & 1.85 & 1.16 & VF5 & $\ldots$ & 2.30 & $\ldots$ \\
\hline $190360 \ldots \ldots \ldots \ldots \ldots$ & 98767 & GJ $777 \mathrm{~A}$ & 200337.405 & +295348.50 & 0.75 & 5.73 & $15.89(16)$ & 5552 & 4.385 & 0.213 & 2.20 & 1.01 & VF5 & $\ldots$ & 0.66 & $\ldots$ \\
\hline $192263 \ldots \ldots \ldots \ldots \ldots$ & 99711 & & 201359.845 & -005200.76 & 0.94 & 7.79 & $19.89(45)$ & 4975 & 4.604 & 0.054 & 2.63 & 0.81 & VF5 & 0.49 & 0.04 & 7.7 \\
\hline $195019 \ldots \ldots \ldots \ldots \ldots$ & 100970 & & 202818.636 & +184610.19 & 0.66 & 6.87 & $37.4(1.2)$ & 5788 & 4.225 & 0.068 & 2.47 & 1.07 & VF5 & 0.15 & 0.86 & 3.7 \\
\hline $196050 \ldots \ldots \ldots \ldots$ & 101806 & & 203751.710 & -603804.14 & 0.67 & 7.50 & $46.9(2.0)$ & 5892 & 4.267 & 0.229 & 3.27 & 1.15 & VF5 & 0.15 & 0.76 & 3.6 \\
\hline $202206 \ldots \ldots \ldots \ldots \ldots$ & 104903 & & 211457.769 & -204721.15 & 0.71 & 8.08 & $46.3(2.4)$ & 5788 & 4.493 & 0.354 & 2.30 & 1.12 & VF5 & & 0.43 & $\ldots$ \\
\hline $208487 \ldots \ldots \ldots \ldots \ldots$ & 108375 & & 215719.848 & -374549.04 & 0.57 & 7.47 & $44.0(2.0)$ & 6067 & 4.335 & 0.022 & 4.61 & 1.13 & VF5 & 0.17 & 0.01 & 5.4 \\
\hline $209458 \ldots \ldots \ldots \ldots \ldots$ & 108859 & & $2203 \quad 10.800$ & +185304.00 & 0.59 & 7.65 & $47.1(2.2)$ & 6099 & 4.382 & 0.014 & 4.49 & 1.14 & VF5 & & 0.15 & $\ldots$ \\
\hline $210277 \ldots \ldots \ldots \ldots \ldots$ & 109378 & & 220929.866 & -073255.15 & 0.77 & 6.54 & $21.29(36)$ & 5555 & 4.495 & 0.214 & 1.80 & 1.01 & VF5 & 0.16 & 0.62 & 3.5 \\
\hline $212301 \ldots \ldots \ldots \ldots \ldots$ & 110852 & & 222730.920 & -774304.52 & 0.56 & 7.76 & $52.7(2.0)$ & 6000 & & -0.18 & $\ldots$ & 1.05 & $\mathrm{Nd} 4$ & $\ldots$ & 0.06 & $\ldots$ \\
\hline \multirow[t]{2}{*}{$213240 \ldots \ldots \ldots \ldots \ldots \ldots \ldots$} & 111143 & & 223100.367 & -492559.77 & 0.60 & 6.81 & $40.7(1.3)$ & 5968 & 4.222 & 0.139 & 3.97 & 1.22 & VF5 & 0.16 & 0.73 & 3.9 \\
\hline & 113020 & GJ 876 & 225316.734 & -141549.32 & 1.60 & 10.16 & $4.702(46)$ & $3787^{\mathrm{b}}$ & & $\ldots$ & & 0.32 & Mc8 & $\ldots$ & -0.03 & $\ldots$ \\
\hline $216435 \ldots \ldots \ldots \ldots \ldots$ & 113044 & $\tau^{1} \mathrm{Gru}$ & 225337.931 & -483553.83 & 0.62 & 6.03 & $33.29(81)$ & 5999 & 4.154 & 0.244 & 5.78 & 1.30 & VF5 & 0.16 & 1.19 & 4.0 \\
\hline $216437 \ldots \ldots \ldots \ldots \ldots$ & 113137 & $\rho$ Ind & 225439.483 & -700425.35 & 0.66 & 6.04 & $26.52(41)$ & 5849 & 4.231 & 0.225 & 3.13 & 1.19 & VF5 & 0.15 & 0.93 & 3.7 \\
\hline $216770 \ldots \ldots \ldots \ldots$ & 113238 & & 225553.710 & -263931.55 & 0.82 & 8.11 & $37.9(1.5)$ & 5423 & 4.40 & 0.260 & $\ldots$ & 0.90 & $\mathrm{Sn} 4$ & & 0.56 & $\ldots$ \\
\hline $217014 \ldots \ldots \ldots \ldots$ & 113357 & $51 \mathrm{Peg}$ & 225727.980 & +204607.80 & 0.67 & 5.45 & $15.36(18)$ & 5787 & 4.449 & 0.200 & 2.57 & 1.09 & VF5 & 0.15 & 0.37 & 3.7 \\
\hline $217107 \ldots \ldots \ldots \ldots \ldots$ & 113421 & & $2258 \quad 15.541$ & -022343.39 & 0.74 & 6.17 & $19.72(29)$ & 5704 & 4.541 & 0.389 & $\ldots$ & 1.10 & VF5 & $\ldots$ & 0.66 & $\ldots$ \\
\hline $222404 \ldots \ldots \ldots \ldots \ldots$ & 116727 & $\gamma$ Cep & 233920.849 & +773756.19 & 1.03 & 3.21 & $13.793(99)$ & $4791^{\mathrm{b}}$ & $3.33(10)$ & $0.180(80)$ & $1.5(1.0)$ & 1.59 & Fu4 & $\ldots$ & 4.21 & $\ldots$ \\
\hline $222582 \ldots \ldots \ldots \ldots$ & 116906 & & 234151.530 & -055908.73 & 0.65 & 7.68 & $41.9(2.0)$ & 5727 & 4.342 & -0.029 & 2.29 & 0.99 & VF5 & 0.16 & 0.21 & 3.7 \\
\hline $224693 \ldots \ldots \ldots \ldots$ & 118319 & & 235953.833 & -222541.21 & 0.64 & 8.23 & $94(10)$ & $6037(44)$ & $4.380(70)$ & $0.343(30)$ & $3.50(50)$ & 1.33 & Jh6 & $\ldots$ & 1.36 & $\ldots$ \\
\hline
\end{tabular}

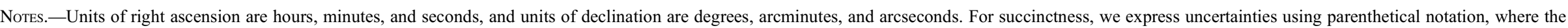

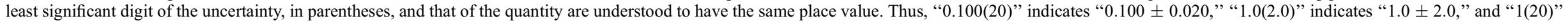
indicates " $1 \pm 20 . "$ Table 2 is also available in machine-readable form in the electronic edition of the Astrophysical Journal.

${ }^{a}$ No $S$-value available: star is assumed to be very inactive.

b No effective temperature available: $T_{\text {eff }}$ is estimated from $B-V$ using Flower (1996).

No effective temperature available: $T_{\text {eff }}$ is estimated from $B-V$ using Flowe
This giant star has a poorly determined mass; both estimates are plausible.

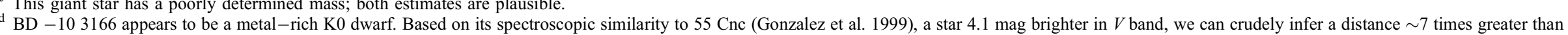
that star, or $\sim 80 \mathrm{pc}$.

No parallax available: star is assumed to be on the main sequence.

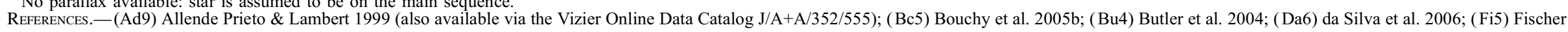

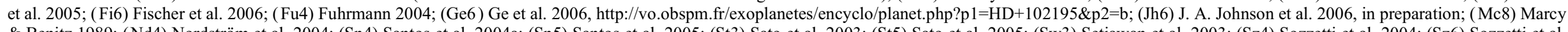

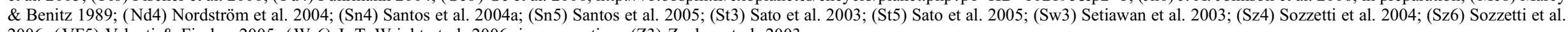
2006; (VF5) Valenti \& Fischer 2005; (Wr6) J. T. Wright et al. 2006, in preparation; (Z3) Zucker et al. 2003. 
characteristics of the new CCD. Nonetheless, we adopt this model as an additional source of noise for all observations at all telescopes. We report these adopted jitter values in Table 2.

\section{ERRORS}

We calculated uncertainties in orbital parameters through the following method, described in Marcy et al. (2005b): We subtracted the best-fit orbital solution from the data and interpreted the residuals as a population of random deviates with a distribution characteristic of the noise in the data. We randomly selected deviates from this set, with replacement, and added this "noise" to the velocities calculated from the best-fit solution at the actual times of observation. We then found the best-fit orbital solutions to this mock data set. Repeating this procedure 100 times, we produced 100 sets of orbital parameters. We report the standard deviation of each individual parameter over the 100 trials as the $1 \sigma$ errors listed in Table 3. For the derived quantities $a$ and $M \sin i$, we calculated these quantities from each mock data set and report the standard deviation in those quantities propagated with an assumed error of $10 \%$ in the stellar mass (which dominates the error budget for many planets).

Uncertainties in $e$ and $\omega$ become non-Gaussian when $\sigma_{e} \gtrsim e / 2$; in particular, $\omega$ and $\sigma_{\omega}$ become ill defined when $e=0$. In order to report uncertainties in an intuitive manner, we calculate $\sigma_{e}$ in such cases as the geometric mean of $\sigma_{e} \cos \omega$ and $\sigma_{e} \sin \omega$. In other words, for cases when $\sigma_{e} \gtrsim e / 2$, we effectively model the uncertainties as a two-dimensional Gaussian in $(e \cos \omega, e \sin \omega)$-space where the values of $e$ and $\omega$ reported in Table 3 are the coordinates of the center of the Gaussian and the error in $e$ is its width.

For succinctness, we express uncertainties using parenthetical notation, where the least significant digit of the uncertainty, in parentheses, and that of the quantity are understood to have the same place value. Thus, " $0.100(20)$ " indicates " $0.100 \pm 0.020$," "1.0(2.0)" indicates " $1.0 \pm 2.0$," and " $1(20)$ " indicates " $1 \pm 20$."

Spectroscopic parameters from SPOCS (Valenti \& Fischer 2005) have typical errors of $44 \mathrm{~K}$ in $T_{\text {eff }}, 0.06$ dex in $\log g, 0.03$ dex in $[\mathrm{Fe} / \mathrm{H}]$, and $0.5 \mathrm{~km} \mathrm{~s}^{-1}$ in $v \sin i$. Errors in the corresponding parameters from Santos et al. (2004a, 2005) are $50 \mathrm{~K}, 0.12 \mathrm{dex}$, and $0.05 \mathrm{dex}$, respectively ( $v \sin i$ is not quoted in these sources). We quote errors in parameters from other sources explicitly.

\section{STELLAR PROPERTIES}

Table 2 represents a compilation of data on the properties of the host stars for the nearby exoplanets. Columns (1) and (2) list the HD and Hipparcos numbers of the stars, and column (3) acts as a gloss for the Flamsteed, Bayer, or commonly used Gliese designations (e.g., 51 Peg, $v$ And, GJ 86), many of which appear in Table 3.

Hipparcos ${ }^{12}$ provides accurate distances and positions to all stars in this catalog save two, BD -10 3166 and the host star of TrES-1. We quote coordinates, $B-V, V$ magnitude, and distance to stars from the Hipparcos catalog in columns (4)-(8).

Columns (9)-(13) contain $T_{\text {eff }}, \log g$, abundance, $v \sin i$, and mass for these stars, collected from the references listed in column (14). Most of these reported values come from the SPOCS catalog (Valenti \& Fischer 2005), whose measurements are based on detailed spectroscopic analysis and evolutionary models, and the catalogs of Nordström et al. (2004) and Santos et al. (2004a, 2005).

Column (15) lists Mount Wilson $S$-values for many of the stars, most of which are drawn from Wright et al. (2004), Tinney et al.

\footnotetext{
12 Vizier Online Data Catalog, I/239 (ESA 1997).
}

(2002), and Jenkins et al. (2005), but some of which are new to this work, measured in the manner described in Wright et al. (2004). Column (16) lists the height of the star above the main sequence, $\Delta M_{V}$ (a function of $M_{V}$ and $B-V$ defined in Wright 2004). Column (17) lists the jitter predicted by the model of Wright (2005) for those stars for which we have updated orbital parameters. We have added these jitter values in quadrature to the formal uncertainties when fitting for the orbital parameters listed in Table 3. This procedure is also discussed in Marcy et al. (2005b).

\section{CATALOG OF NEARBY EXOPLANETS}

Table 3 presents the Catalog of Nearby Exoplanets. For planets with recently published velocities and orbits (e.g., the HD 190360 system in Vogt et al. 2005) or those for which we have insufficient data for an orbital fit or no data at all (e.g., HD 1237b), we quote the most recently published solution. For all others, the orbital parameters in Table 3 represent the best-fit orbital solutions to the velocities in Table 1 .

The name of each host star appears in column (2). Where available, we use Bayer designations or Flamsteed numbers to identify a star (e.g., 51 Peg, not HD 217014) since these names are more mnemonic than HD and Hipparcos catalog numbers, which are cross-referenced in Table 2. For stars with no HD number (e.g., GJ 86), we use the most common designation in the literature. Column (3) gives the component name (b , c, etc.) of each planet. Component names are ostensibly assigned in order of discovery.

Columns (4)-(10) report the parameters of the best-fit solution to the observed radial velocities: $P$, the sidereal orbital period of the planet in days; $K$, the semiamplitude of the reflex motion of the star in $\mathrm{m} \mathrm{s}^{-1} ; e$, the eccentricity of the planet's orbit; $\omega$, the longitude of periastron of the planet's orbit in degrees; $T_{p}$, the time of periastron passage as a Julian Date; $T_{t}$, the predicted midtime of transit assuming $i=90^{\circ}$; and the magnitude of a linear trend (in $\mathrm{m} \mathrm{s}^{-1}$ ) subtracted from the velocities required to achieve the fit. We have not calculated $T_{p}$ or $T_{t}$ values for orbital parameters collected from the literature, but we report them where present. Parameters for dynamical fits in Table 3 from the literature may use slightly different definitions of these parameters, using Jacobi coordinates and synodic periods (e.g., Rivera et al. 2005).

Columns (11) and (12) contain the minimum mass $(M \sin i)$ and orbital semimajor axis $(a)$ of the planet, calculated from the orbital parameters and the mass of the host star $\left(M_{\star}\right.$ given in Table 2) using the following definitions:

$$
\begin{gathered}
M \sin i=K \sqrt{1-e^{2}}\left[\frac{P\left(M_{\star}+M \sin i\right)^{2}}{2 \pi G}\right]^{1 / 3}, \\
\left(\frac{a}{\mathrm{AU}}\right)^{3}=\left(\frac{M_{\star}+M \sin i}{M_{\odot}}\right)\left(\frac{P}{\mathrm{yr}}\right)^{2},
\end{gathered}
$$

where $G$ is the gravitational constant.

Columns (13) and (14) report the quality of the fit as the rms of the residuals and $\chi_{\nu}^{2}$ for the appropriate number of degrees of freedom, and column (15) reports the number of observations used in the fit. Column (16) contains the reference for the quantities in columns (4)-(10), (13), (14), and (15). For many planets (e.g., 51 Peg b), other groups have published an orbital solution independent of ours. In these cases, we cite the most recent such solution parenthetically in column (16). When this independent 
TABLE 3

Catalog of Nearby Extrasolar Planets

\begin{tabular}{|c|c|c|c|c|c|c|c|c|c|c|c|c|c|c|c|}
\hline \multicolumn{3}{|c|}{ Planet } & \multirow[b]{2}{*}{$\begin{array}{l}\text { PERIOD } \\
\text { (days) } \\
\text { (4) }\end{array}$} & \multirow{2}{*}{$\begin{array}{c}K \\
\left(\mathrm{~m} \mathrm{~s}^{-1}\right) \\
(5)\end{array}$} & \multirow[b]{2}{*}{$\begin{array}{c}e \\
(6)\end{array}$} & \multirow[b]{2}{*}{$\begin{array}{c}\omega \\
(\mathrm{deg}) \\
(7)\end{array}$} & \multirow[b]{2}{*}{$\begin{array}{c}T_{p} \\
(\mathrm{JD}-2,440,000) \\
(8)\end{array}$} & \multirow[b]{2}{*}{$\begin{array}{c}T_{t} \\
(\mathrm{JD}-2,440,000) \\
(9)\end{array}$} & \multirow[b]{2}{*}{$\begin{array}{c}\text { TREND } \\
\left(\mathrm{m} \mathrm{s}^{-1} \mathrm{yr}^{-1}\right) \\
(10)\end{array}$} & \multirow[b]{2}{*}{$\begin{array}{c}M \sin i \\
\left(M_{\mathrm{J}}\right) \\
(11)\end{array}$} & \multirow[b]{2}{*}{$\begin{array}{c}a \\
(\mathrm{AU}) \\
(12)\end{array}$} & \multirow[b]{2}{*}{$\begin{array}{c}\mathrm{rms} \\
\left(\mathrm{m} \mathrm{s}^{-1}\right) \\
(13)\end{array}$} & \multirow[b]{2}{*}{$\begin{array}{l}\sqrt{\chi_{\nu}^{2}} \\
(14)\end{array}$} & \multirow[b]{2}{*}{$\begin{array}{l}N_{\text {obs }} \\
(15)\end{array}$} & \multirow[b]{2}{*}{$\begin{array}{c}\text { ReFerences } \\
\text { (AlteRnATIVE) } \\
(16)\end{array}$} \\
\hline $\begin{array}{l}\text { Number } \\
\text { (1) }\end{array}$ & $\begin{array}{l}\text { Name } \\
\text { (2) }\end{array}$ & $\begin{array}{c}\text { Component } \\
\text { (3) }\end{array}$ & & & & & & & & & & & & & \\
\hline $1 \ldots \ldots \ldots \ldots . .$. & HD 142 & $\mathrm{~b}$ & $350.3(3.6)$ & $33.9(4.7)$ & $0.26(18)^{\mathrm{a}}$ & $303^{\mathrm{a}}$ & $11963(43)$ & $11737(25)$ & $-10.4(1.1)$ & $1.31(18)$ & $1.045(61)$ & 12 & 1.5 & 53 & Bu6 \\
\hline $2 \ldots \ldots \ldots \ldots$ & HD 1237 & $\mathrm{~b}$ & $133.71(20)$ & $167.0(4.0)$ & $0.511(17)$ & $290.7(3.0)$ & $11545.86(64)$ & & & $3.37(49)$ & $0.495(29)$ & 19 & 2.8 & 61 & Nf1 \\
\hline 3........... & HD 2039 & $\mathrm{~b}$ & $1120(23)$ & $153(22)$ & $0.715(46)$ & $344.1(3.6)$ & 12041(13) & 10992(26) & $3.5(1.5)$ & $6.11(82)$ & $2.23(13)$ & 11 & 0.84 & 41 & Bu6 \\
\hline 4..................... & HD 2638 & $\mathrm{~b}$ & $3.44420(20)$ & $67.40(40)$ & $0^{\mathrm{b}}$ & $0^{\mathrm{b}}$ & $13323.2060(20)$ & & $\ldots$ & $0.477(68)$ & $0.0436(25)$ & 3.3 & & 28 & Mo5 \\
\hline $5 \ldots \ldots \ldots \ldots$. & 54 Psc & $\mathrm{b}$ & $62.206(21)$ & $16.0(1.2)$ & $0.618(51)$ & 233.3(7.4) & $12189.83(68)$ & $12176.3(1.9)$ & $\ldots$ & $0.227(23)$ & $0.296(17)$ & 6.6 & 1.3 & 163 & Bu6 \\
\hline 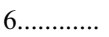 & HD 4208 & $\mathrm{~b}$ & $828.0(8.1)$ & $19.06(73)$ & $0.052(40)^{\mathrm{a}}$ & $345^{\mathrm{a}}$ & $11040(120)$ & 10440(16) & $\ldots$ & $0.804(73)$ & $1.650(96)$ & 3.4 & 0.72 & 41 & Bu6 \\
\hline 7............... & HD 4308 & $\mathrm{~b}$ & $15.560(20)$ & $4.07(20)$ & $0.000(10)$ & $359(47)$ & $13311.7(2.0)$ & & $\ldots$ & $0.0467(70)$ & $0.1179(68)$ & 1.3 & 1.4 & 41 & U6 \\
\hline $8 \ldots \ldots \ldots \ldots \ldots$ & HD 4203 & $\mathrm{~b}$ & $431.88(85)$ & $60.3(2.2)$ & $0.519(27)$ & $329.1(3.1)$ & $11918.9(2.7)$ & $11558.7(7.2)$ & $-4.38(71)$ & $2.07(18)$ & $1.164(67)$ & 4.1 & 0.80 & 23 & Bu6 \\
\hline $9, \ldots \ldots \ldots \ldots$ & HD 6434 & $\mathrm{~b}$ & $21.9980(90)$ & $34.2(1.1)$ & $0.170(30)$ & $156(11)$ & $11490.80(60)$ & & $\ldots$ & $0.397(59)$ & $0.1421(82)$ & 11 & $\ldots$ & 130 & My4 \\
\hline $10 \ldots \ldots \ldots$ & HD 8574 & $\mathrm{~b}$ & $225.0(1.1)$ & $64.1(5.5)$ & $0.370(82)$ & $2(16)$ & $11475.6(5.5)$ & $11504.8(7.3)$ & $\ldots$ & $1.96(22)$ & $0.759(44)$ & 23 & 1.6 & 26 & Bu6 (Pr3) \\
\hline $11 \ldots \ldots \ldots$ & $v$ And & $\mathrm{b}$ & $4.617113(82)$ & $69.8(1.5)$ & $0.023(18)^{\mathrm{a}}$ & $63^{\mathrm{a}}$ & $11802.64(71)$ & $11802.966(33)$ & $\ldots$ & $0.687(58)$ & $0.0595(34)$ & 13 & 1.4 & 268 & Bu6 (Nf4) \\
\hline $12 \ldots \ldots \ldots .$. & $v$ And & $\mathrm{c}$ & $241.23(30)$ & $55.6(1.7)$ & $0.262(21)$ & $245.5(5.3)$ & $10158.1(4.5)$ & $10063.9(3.8)$ & $\ldots$ & $1.98(17)$ & $0.832(48)$ & & & & \\
\hline $13 \ldots \ldots \ldots$. & $v$ And & $\mathrm{d}$ & $1290.1(8.4)$ & $63.4(1.5)$ & $0.258(32)$ & $279(10)$ & $8827(30)$ & $8127(39)$ & $\ldots$ & $3.95(33)$ & $2.54(15)$ & & & & \\
\hline $14 \ldots \ldots \ldots . .$. & HD 10647 & $\mathrm{~b}$ & $1003(56)$ & $17.9(4.6)$ & $0.16(22)^{\mathrm{a}}$ & $336^{\mathrm{a}}$ & $10960(160)$ & 10221(83) & $\ldots$ & $0.93(18)$ & $2.03(15)$ & 9.4 & 1.4 & 28 & Bu6 (My3) \\
\hline $15 \ldots \ldots \ldots . .$. & 109 Psc & $\mathrm{b}$ & $1076.4(2.4)$ & $115.0(1.5)$ & $0.1023(96)$ & $108.9(8.2)$ & $10396(29)$ & $10350.4(5.6)$ & $\ldots$ & $6.38(53)$ & $2.16(12)$ & 6.8 & 1.4 & 59 & Bu6 \\
\hline $16 \ldots \ldots \ldots \ldots$ & HD 11977 & $\mathrm{~b}$ & $711.0(8.0)$ & $105.0(8.0)$ & $0.400(70)$ & $351.5(9.5)$ & 11420.0 & & $\ldots$ & $6.5(1.2)$ & $1.94(11)$ & 29 & & & Sw5 \\
\hline $17 \ldots \ldots \ldots . .$. & HD 11964 & $\mathrm{~b}$ & $2110(270)$ & $9.0(1.5)$ & $0.06(17)^{\mathrm{a}}$ & $168^{\mathrm{a}}$ & $12290(420)$ & $11870(120)$ & $0.67(30)$ & $0.61(10)$ & $3.34(40)$ & 5.4 & 0.87 & 87 & Bu6 \\
\hline $18 \ldots \ldots \ldots \ldots$ & HD 12661 & $\mathrm{~b}$ & $262.53(27)$ & $74.19(85)$ & $0.361(11)$ & $296.3(2.6)$ & $10214.1(2.9)$ & $10046.1(2.5)$ & $\ldots$ & $2.34(19)$ & $0.831(48)$ & 7.8 & 1.1 & 108 & Bu6 \\
\hline $19 \ldots \ldots \ldots . .$. & HD 12661 & $\mathrm{c}$ & $1679(29)$ & $29.27(88)$ & $0.017(29)^{\mathrm{a}}$ & $38^{\mathrm{a}}$ & $12130(330)$ & $12368(22)$ & $\ldots$ & $1.83(16)$ & $2.86(17)$ & & & & \\
\hline $20 \ldots \ldots \ldots . .$. & HD 13445 & $\mathrm{~b}$ & $15.76491(39)$ & $376.7(2.9)$ & $0.0416(72)$ & $269(16)$ & $11903.36(59)$ & $11895.551(76)$ & $-94.9(1.0)$ & $3.91(32)$ & $0.1130(65)$ & 12 & 2.1 & 42 & Bu6 (Q0) \\
\hline $21 \ldots \ldots \ldots \ldots$ & 79 Cet & $\mathrm{b}$ & $75.523(55)$ & $11.99(87)$ & $0.252(52)$ & $42(14)$ & $10338.0(3.0)$ & 10344.1(1.6) & $\ldots$ & $0.260(28)$ & $0.363(21)$ & 3.7 & 0.82 & 71 & Bu6 \\
\hline $22 \ldots \ldots \ldots . .$. & $\iota$ Hor & $\mathrm{b}$ & $302.8(2.3)$ & $57.1(5.2)$ & $0.14(13)^{a}$ & $346^{\mathrm{a}}$ & $11227(46)$ & 10998(19) & $\ldots$ & $2.08(26)$ & $0.930(54)$ & 19 & 1.3 & 25 & Bu6 (Nf 1b) \\
\hline $23 \ldots \ldots \ldots \ldots$ & HIP 14810 & $\mathrm{~b}$ & $6.6740(20)$ & $420.7(3.0)$ & $0.1480(60)$ & $153.0(2.0)$ & $13694.500(40)$ & & $\ldots$ & $3.84(54)$ & $0.0692(40)$ & 8.3 & 1.4 & 15 & Wr6 \\
\hline $24 \ldots \ldots \ldots . .$. & $94 \mathrm{Cet}$ & $\mathrm{b}$ & $535.7(3.1)$ & $36.2(1.9)$ & $0.300(40)$ & $41.0(8.0)$ & 10944(12) & & $\ldots$ & $1.69(26)$ & $1.428(83)$ & 8.1 & $\ldots$ & 48 & My4 \\
\hline $25 \ldots \ldots \ldots \ldots$ & HD 20367 & $\mathrm{~b}$ & $469.5(9.3)$ & $29.0(3.0)$ & $0.320(90)$ & $135(16)$ & $11860(18)$ & $\ldots$ & $\ldots$ & $1.17(23)$ & $1.246(75)$ & 10 & $\ldots$ & 27 & U3 \\
\hline $26 \ldots \ldots \ldots \ldots$ & HD 20782 & $\mathrm{~b}$ & $585.860(30)$ & $115(12)$ & $0.925(30)$ & $147.0(3.0)$ & 11687.1(2.5) & $\ldots$ & $\ldots$ & $1.78(34)$ & $1.364(79)$ & 5.0 & 1.0 & 29 & Jo6 \\
\hline $27 \ldots \ldots \ldots . .$. & $\epsilon$ Eri & $\mathrm{b}$ & $2500(350)$ & $18.6(2.9)$ & $0.25(23)^{\mathrm{a}}$ & $6^{\mathrm{a}}$ & $8940(520)$ & $9330(200)$ & $\ldots$ & $1.06(16)$ & $3.38(43)$ & 12 & 1.0 & 120 & Bu6 (H0) \\
\hline $28 \ldots \ldots \ldots \ldots$ & HD 23079 & $\mathrm{~b}$ & $730.6(5.7)$ & $54.9(1.1)$ & $0.102(31)$ & $55(17)$ & 10492(37) & 10551(14) & $\ldots$ & $2.45(21)$ & $1.596(93)$ & 4.8 & 0.69 & 19 & Bu6 \\
\hline $29 \ldots \ldots \ldots . .$. & HD 23596 & $\mathrm{~b}$ & $1565(21)$ & $124.0(3.0)$ & $0.292(23)$ & 274.1(3.9) & $11604(15)$ & $\ldots$ & $\ldots$ & $7.8(1.1)$ & $2.83(17)$ & 9.2 & 1.1 & 39 & $\operatorname{Pr} 3$ \\
\hline $30 \ldots \ldots \ldots . . . .$. & $\epsilon$ Ret & $\mathrm{b}$ & $428.1(1.1)$ & $32.2(1.4)$ & $0.060(43)^{\mathrm{a}}$ & $216^{\mathrm{a}}$ & $10836(55)$ & $10692.2(8.6)$ & $\ldots$ & $1.56(14)$ & $1.271(73)$ & 6.5 & 1.1 & 55 & Bu6 \\
\hline $31 \ldots \ldots \ldots .$. & HD 27894 & $\mathrm{~b}$ & $17.9910(70)$ & $58.10(50)$ & $0.0490(80)$ & $132.9(9.7)$ & $13275.46(48)$ & $\ldots$ & $\ldots$ & $0.618(88)$ & $0.1221(71)$ & 4.0 & $\ldots$ & 20 & Mo5 \\
\hline $32 \ldots \ldots \ldots . .$. & HD 28185 & $\mathrm{~b}$ & $383.0(2.0)$ & 161(11) & $0.070(40)$ & $351(25)$ & $11863(26)$ & $\ldots$ & $\ldots$ & $5.72(93)$ & $1.031(60)$ & 10 & $\ldots$ & 40 & Sn1 \\
\hline $33 \ldots \ldots \ldots . .$. & HD 30177 & $\mathrm{~b}$ & $2770(100)$ & $146.8(2.8)$ & $0.193(25)$ & $34(15)$ & $11437(72)$ & $11738(16)$ & $\ldots$ & $10.45(88)$ & $3.95(26)$ & 10 & 0.96 & 22 & Bu6 \\
\hline $34 \ldots \ldots \ldots \ldots$ & HD 33283 & $\mathrm{~b}$ & $18.1790(70)$ & $25.2(2.0)$ & $0.480(50)$ & $155.8(8.0)$ & $13017.60(30)$ & +2 & $\ldots$ & 0.330 & 0.145 & 3.6 & 0.77 & 25 & Jh6 \\
\hline $35 \ldots \ldots \ldots \ldots$ & HD 33636 & $\mathrm{~b}$ & $2127.7(8.2)$ & $164.2(2.0)$ & $0.4805(60)$ & $339.5(1.4)$ & $11205.8(6.4)$ & $9396(12)$ & $\ldots$ & $9.28(77)$ & $3.27(19)$ & 8.9 & 0.98 & 38 & Bu6 (Pr3) \\
\hline $36 \ldots \ldots \ldots \ldots$ & HD 33564 & $\mathrm{~b}$ & $388.0(3.0)$ & $232.0(5.0)$ & $0.340(20)$ & $205.0(4.0)$ & $12603.0(8.0)$ & $\ldots$ & $\ldots$ & $9.1(1.3)$ & $1.124(65)$ & 6.7 & $\ldots$ & 15 & $\mathrm{Ga} 5$ \\
\hline $37 \ldots \ldots \ldots . .$. & HD 37124 & $\mathrm{~b}$ & 154.46 & 27.5 & 0.055 & 140.5 & 10000.11 & $\ldots$ & $\ldots$ & $0.64(11)$ & $0.529(31)$ & 18 & 1.9 & 52 & Vo5 (U3) \\
\hline \multirow[t]{2}{*}{$38 \ldots \ldots \ldots . .}$. & HD 37124 & $\mathrm{c}$ & 2295.00 & 12.2 & 0.200 & 266.0 & 9606.00 & $\ldots$ & $\ldots$ & $0.683(88)$ & $3.19(18)$ & & & & \\
\hline & HD 37124 & $\mathrm{c}^{\mathrm{c}}$ & $29.3^{\mathrm{c}}$ & $13.2^{\mathrm{c}}$ & $0.160^{\mathrm{c}}$ & $290.0^{\mathrm{c}}$ & $9981.3^{\mathrm{c}}$ & $\ldots$ & $\ldots$ & $0.170^{\mathrm{c}}$ & $0.170^{\mathrm{c}}$ & $5.1^{\mathrm{c}}$ & $1.1^{\mathrm{c}}$ & & \\
\hline 39........... & HD 37124 & $\mathrm{~d}$ & 843.60 & 15.4 & 0.140 & 314.3 & 9409.40 & & $\ldots$ & $0.624(63)$ & $1.639(95)$ & & & & \\
\hline $40 \ldots \ldots \ldots$. & $\pi$ Men & $\mathrm{b}$ & 2151(85) & $196.4(1.3)$ & $0.6405(72)$ & $330.24(67)$ & $7820(170)$ & $5920(260)$ & $\ldots$ & $10.27(84)$ & $3.38(22)$ & 5.5 & 0.93 & 42 & Bu6 \\
\hline
\end{tabular}


TABLE 3-Continued

\begin{tabular}{|c|c|c|c|c|c|c|c|c|c|c|c|c|c|c|c|}
\hline $\begin{array}{l}\text { Number } \\
\text { (1) }\end{array}$ & $\begin{array}{l}\text { Name } \\
(2)\end{array}$ & $\begin{array}{l}\text { Component } \\
\text { (3) }\end{array}$ & $\begin{array}{l}\text { PERIOD } \\
\text { (days) } \\
\text { (4) }\end{array}$ & $\begin{array}{c}K \\
\left(\mathrm{~m} \mathrm{~s}^{-1}\right) \\
(5)\end{array}$ & $\begin{array}{l}e \\
(6)\end{array}$ & $\begin{array}{l}\omega \\
(\mathrm{deg}) \\
(7)\end{array}$ & $\begin{array}{c}T_{p} \\
(\mathrm{JD}-2,440,000) \\
(8)\end{array}$ & $\begin{array}{c}T_{t} \\
(\mathrm{JD}-2,440,000) \\
(9)\end{array}$ & $\begin{array}{c}\text { TREND } \\
\left(\mathrm{m} \mathrm{s}^{-1} \mathrm{yr}^{-1}\right) \\
(10)\end{array}$ & $\begin{array}{c}M \sin i \\
\left(M_{\mathrm{J}}\right) \\
(11)\end{array}$ & $\begin{array}{c}a \\
(\mathrm{AU}) \\
(12)\end{array}$ & $\begin{array}{c}\mathrm{rms} \\
\left(\mathrm{m} \mathrm{s}^{-1}\right) \\
(13)\end{array}$ & $\begin{array}{l}\sqrt{\chi_{\nu}^{2}} \\
(14)\end{array}$ & $\begin{array}{l}N_{\text {obs }} \\
(15)\end{array}$ & $\begin{array}{c}\text { ReFERENCES } \\
\text { (Alternative) } \\
\text { (16) }\end{array}$ \\
\hline 41............ & HD 37605 & $\mathrm{~b}$ & $54.23(23)$ & $262.9(5.5)$ & $0.737(10)$ & $211.6(1.7)$ & $12994.27(45)$ & $\ldots$ & $\ldots$ & $2.86(41)$ & $0.261(15)$ & 4.7 & 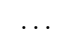 & 27 & $\mathrm{Cc} 4$ \\
\hline $42 \ldots \ldots \ldots \ldots$ & HD 38529 & $\mathrm{~b}$ & 14.3093(13) & $56.8(1.6)$ & $0.248(23)$ & $91.2(6.2)$ & 9991.59(23) & $9991.56(17)$ & $\ldots$ & $0.852(74)$ & $0.1313(76)$ & 13 & 1.6 & 162 & Bu6 \\
\hline $43 \ldots \ldots \ldots \ldots$ & HD 38529 & $\mathrm{c}$ & $2165(14)$ & $170.3(1.7)$ & $0.3506(85)$ & $15.7(1.9)$ & $10085(15)$ & 10319(13) & $\ldots$ & $13.2(1.1)$ & $3.74(22)$ & & & & \\
\hline $44 \ldots \ldots \ldots \ldots$ & HD 41004A & $\mathrm{b}$ & $963(38)$ & $99(60)$ & $0.74(20)$ & $97(31)$ & $12425(37)$ & $\ldots$ & $\ldots$ & $2.6(1.8)$ & $1.70(11)$ & 10 & $\ldots$ & 149 & Z4 \\
\hline $45 \ldots \ldots \ldots \ldots$ & HD 41004B & $\mathrm{b}$ & $1.328300(12)$ & $6114(71)$ & $0.081(12)$ & $178.5(7.8)$ & $12434.880(29)$ & $\ldots$ & $\ldots$ & $18.4(2.6)$ & $0.0177(10)$ & 600 & $\ldots$ & 149 & Z4 \\
\hline $46 \ldots \ldots \ldots \ldots$ & HD 40979 & $\mathrm{~b}$ & $263.84(71)$ & $112.0(5.0)$ & $0.269(34)$ & $318(10)$ & 10748.1(8.6) & 10561.2(6.4) & $\ldots$ & 3.83(36) & $0.855(49)$ & 23 & 1.3 & 65 & Bu6 \\
\hline 47............ & HD 45350 & b & $967.0(6.2)$ & $64.2(2.5)$ & $0.798(53)$ & $342.4(8.6)$ & 11822(13) & 10894(16) & $\ldots$ & $1.96(17)$ & $1.96(11)$ & 4.4 & 0.96 & 40 & Bu6 (Ed6) \\
\hline $48 \ldots \ldots \ldots \ldots$ & HD 46375 & $\mathrm{~b}$ & $3.023573(65)$ & $33.65(74)$ & $0.063(26)$ & $114(24)$ & $11071.53(19)$ & $11071.359(37)$ & $\ldots$ & $0.226(19)$ & $0.0398(23)$ & 4.2 & 0.97 & 50 & Bu6 \\
\hline $49 \ldots \ldots \ldots \ldots$ & HD 47536 & $\mathrm{~b}$ & $712.13(31)$ & 113(11) & $0.200(80)$ & 261(24) & $11599(22)$ & & $\ldots$ & $5.20(99)^{\mathrm{d}}$ & $1.613(93)^{\mathrm{d}}$ & 26 & 0.97 & 39 & Sw3 \\
\hline $50 \ldots \ldots \ldots \ldots$ & HD 49674 & $\mathrm{~b}$ & 4.94737(98) & $12.04(88)$ & $0.087(95)^{\mathrm{a}}$ & $264^{\mathrm{a}}$ & $11882.38(88)$ & $11880.00(18)$ & $\ldots$ & $0.105(11)$ & $0.0580(34)$ & 4.7 & 0.66 & 39 & Bu6 \\
\hline $51 \ldots \ldots \ldots$. & HD 50499 & $\mathrm{~b}$ & $2480(110)$ & $22.9(3.0)$ & $0.14(20)$ & $262(36)$ & 11230(230) & $\ldots$ & -4.8 & $1.75(53)$ & $3.87(26)$ & 4.8 & 1.1 & 35 & Vo5 \\
\hline $52 \ldots \ldots \ldots \ldots$ & HD 50554 & b & $1224(12)$ & $91.5(7.6)$ & $0.444(38)$ & 7.4(4.3) & $10646(16)$ & 10767(18) & $\ldots$ & $4.46(48)$ & $2.28(13)$ & 12 & 1.1 & 51 & Bu6 (Pr3) \\
\hline $53 \ldots \ldots \ldots$ & HD 52265 & $\mathrm{~b}$ & $119.290(86)$ & $42.1(3.1)$ & $0.325(65)$ & $243(15)$ & $10833.7(4.2)$ & $10790.1(6.7)$ & $\ldots$ & $1.09(11)$ & $0.504(29)$ & 10 & 1.6 & 28 & Bu6 (Nf1b) \\
\hline $54 \ldots \ldots \ldots . .$. & HD 63454 & $\mathrm{~b}$ & $2.817822(95)$ & $64.30(70)$ & $0^{\mathrm{b}}$ & $0^{\mathrm{b}}$ & $13111.1290(50)$ & $\ldots$ & $\ldots$ & $0.385(55)$ & $0.0363(21)$ & 7.1 & . & 57 & Mo5 \\
\hline $55 \ldots \ldots \ldots \ldots$ & HD 65216 & $\mathrm{~b}$ & 613(11) & $33.7(1.1)$ & $0.410(60)$ & $198.0(6.0)$ & 10762(25) & $\ldots$ & $\ldots$ & $1.22(19)$ & $1.374(82)$ & 6.8 & $\ldots$ & 70 & My4 \\
\hline $56 \ldots \ldots \ldots .$. & HD 66428 & $\mathrm{~b}$ & $1973(31)^{\mathrm{e}}$ & $48.3(2.7)^{\mathrm{e}}$ & $0.465(30)^{\mathrm{e}}$ & $152.9(3.9)$ & $12139(16)$ & $12012.1(7.1)$ & $\ldots$ & $2.82(27)$ & $3.18(19)$ & 2.9 & 0.46 & 29 & Bu6 \\
\hline $57 \ldots \ldots \ldots \ldots$ & HD 68988 & $\mathrm{~b}$ & $6.27711(21)$ & 184.7(3.7) & $0.1249(87)$ & $31.4(3.5)$ & $11548.84(16)$ & $11549.663(40)$ & $-23.8(1.7)$ & $1.86(16)$ & $0.0704(41)$ & 13 & 2.8 & 28 & Bu6 \\
\hline $58 \ldots \ldots \ldots \ldots$ & HD 70642 & $\mathrm{~b}$ & 2068(39) & $30.4(1.3)$ & $0.034(43)^{\mathrm{a}}$ & $205^{\mathrm{a}}$ & $11350(380)$ & 10707(48) & $\ldots$ & $1.97(18)$ & $3.23(19)$ & 4.3 & 0.90 & 28 & Bu6 \\
\hline $59 \ldots \ldots \ldots \ldots$ & HD 72659 & $\mathrm{~b}$ & $3630(230)$ & $42.5(1.2)$ & $0.269(38)$ & $258(13)$ & 11673(89) & $10060(240)$ & $\ldots$ & $3.30(29)$ & $4.77(37)$ & 4.2 & 0.83 & 32 & Bu6 \\
\hline $60 \ldots \ldots \ldots \ldots$ & HD 73256 & $\mathrm{~b}$ & $2.54858(16)$ & $269.0(8.0)$ & $0.029(20)$ & $337(46)$ & $12500.18(28)$ & $\ldots$ & $\ldots$ & $1.87(27)$ & $0.0371(21)$ & 15 & $\ldots$ & 40 & U3b \\
\hline $61 \ldots \ldots \ldots$ & HD 73526 & $\mathrm{~b}$ & $187.499(30)$ & $76.1(5.1)$ & $0.390(54)$ & $172(29)$ & $10038(15)$ & $\ldots$ & $\ldots$ & $2.04(29)$ & $0.651(38)$ & 9.2 & 0.95 & 30 & T6 \\
\hline $62 \ldots \ldots \ldots \ldots$ & HD 73526 & $\mathrm{c}$ & 376.879(90) & 67.4(3.6) & $0.400(54)$ & 183(13) & $10184.5(8.6)$ & $\ldots$ & $\ldots$ & $2.26(27)$ & $1.037(60)$ & & & & \\
\hline $63 \ldots \ldots \ldots$ & HD 74156 & $\mathrm{~b}$ & 51.643(11) & $112.0(1.9)$ & $0.6360(91)$ & $181.5(1.4)$ & $11981.321(91)$ & $\ldots$ & $\ldots$ & $1.80(26)$ & $0.290(17)$ & 11 & 1.3 & 95 & Nf4 \\
\hline 64............... & HD 74156 & $\mathrm{c}$ & 2025(11) & $104.0(5.5)$ & $0.583(39)$ & $242.4(4.0)$ & 10901(10) & $\ldots$ & $\ldots$ & $6.00(95)$ & $3.35(19)$ & & & & \\
\hline $65 \ldots \ldots \ldots \ldots$ & HD 75289 & $\mathrm{~b}$ & $3.509267(64)$ & $54.9(1.8)$ & $0.034(29)^{\mathrm{a}}$ & $141^{\mathrm{a}}$ & $10830.34(48)$ & $10829.872(38)$ & $\ldots$ & $0.467(41)$ & $0.0482(28)$ & 6.6 & 1.1 & 30 & Bu6 (U0) \\
\hline 66.............. & $55 \mathrm{Cnc}$ & b & $14.652(10)$ & $73.38(82)$ & $0.01(13)$ & $168(33)$ & $10004.354(10)$ & $\ldots$ & $\ldots$ & $0.833(69)$ & $0.1138(66)$ & 7.3 & 1.6 & 300 & MA4 (Nf4) \\
\hline $67 \ldots \ldots \ldots \ldots$ & $55 \mathrm{Cnc}$ & $\mathrm{c}$ & $44.36(25)$ & $9.60(86)$ & $0.071(12)$ & 115(11) & $10036.29(25)$ & $\ldots$ & $\ldots$ & $0.157(20)$ & $0.238(14)$ & & & & \\
\hline $68 \ldots \ldots \ldots \ldots$ & $55 \mathrm{Cnc}$ & $\mathrm{d}$ & $5552(78)$ & $47.5(1.5)$ & $0.091(80)$ & $181.6(6.7)$ & $12685(69)$ & $\ldots$ & $\ldots$ & $3.90(33)$ & $5.97(35)$ & & & & \\
\hline 69................ & $55 \mathrm{Cnc}$ & $\mathrm{e}$ & $2.7955(20)$ & $5.80(81)$ & $0.09(28)$ & 187(41) & $10000.12(32)$ & $\ldots$ & $\ldots$ & $0.0377(59)$ & $0.0377(22)$ & & & & \\
\hline $70 \ldots \ldots \ldots \ldots$ & HD 76700 & b & $3.97097(23)$ & 27.6(1.7) & $0.095(75)^{\mathrm{a}}$ & $30^{\mathrm{a}}$ & $11213.32(67)$ & $11213.89(12)$ & $\ldots$ & $0.233(24)$ & $0.0511(30)$ & 6.9 & 1.0 & 35 & Bu6 \\
\hline $71 \ldots \ldots \ldots$ & HD 80606 & $\mathrm{~b}$ & $111.4487(32)$ & $481.9(2.1)$ & $0.9349(23)^{\mathrm{b}, \mathrm{f}}$ & $301^{\mathrm{b}}$ & $13199.0517(56)$ & $13093.109(90)$ & $\ldots$ & $4.31(35)$ & $0.468(27)$ & 5.4 & 1.0 & 46 & Bu6 (Nf1) \\
\hline $72 \ldots \ldots \ldots \ldots$ & HD 81040 & $\mathrm{~b}$ & $1001.7(7.0)$ & $168.0(9.0)$ & $0.526(42)$ & $81.3(7.2)$ & 12504(12) & $\ldots$ & $\ldots$ & $6.9(1.1)$ & $1.94(11)$ & 26 & 1.8 & 26 & Sz6 \\
\hline $73 \ldots \ldots \ldots$ & HD 82943 & $\mathrm{~b}$ & $219.50(13)^{\mathrm{g}}$ & $59.3(5.2)^{\mathrm{g}}$ & $0.39(26)^{\mathrm{g}}$ & $121.0(3.1)^{\mathrm{g}}$ & $\mathrm{g}$ & $\mathrm{g}$ & $\ldots$ & $1.81(21)$ & $0.752(43)$ & 8.0 & 1.4 & 165 & Le6 (My4) \\
\hline 74............ & HD 82943 & $\mathrm{c}$ & $439.2(1.8)^{\mathrm{g}}$ & $41.70(91)^{\mathrm{g}}$ & $0.020(98)^{\mathrm{g}}$ & $260(10)^{\mathrm{g}}$ & $\mathrm{g}$ & $\mathrm{g}$ & $\ldots$ & $1.74(19)$ & $1.194(69)$ & & & & \\
\hline $75 \ldots \ldots \ldots$ & HD 83443 & $\mathrm{~b}$ & $2.985698(57)$ & $56.2(1.7)$ & $0.012(23)^{\mathrm{a}}$ & $117^{\mathrm{a}}$ & 11211.79(69) & $11211.565(25)$ & $\ldots$ & $0.398(35)$ & $0.0406(23)$ & 9.0 & 0.99 & 51 & Bu6 (My4) \\
\hline 76................... & HD 86081 & b & $2.13750(20)$ & $207.70(80)$ & $0.0080(40)$ & $251(40)$ & 13694.80(30) & $\ldots$ & $\ldots$ & 1.5 & 0.0346 & 3.2 & 0.81 & 26 & Jh6 \\
\hline 77............... & HD 88133 & $\mathrm{~b}$ & $3.41587(59)$ & $36.1(3.0)$ & $0.133(72)^{\mathrm{a}}$ & $349^{\mathrm{a}}$ & 13016.31(32) & $13013.705(95)$ & $\ldots$ & $0.299(33)$ & $0.0472(27)$ & 6.2 & 0.96 & 21 & Bu6 \\
\hline $78 \ldots \ldots \ldots \ldots . . .$. & HD 89307 & $\mathrm{~b}$ & $2900(1100)^{\mathrm{e}}$ & $37.2(3.9)^{\mathrm{e}}$ & $0.01(16)^{\mathrm{a}, \mathrm{e}}$ & $353^{\mathrm{a}}$ & $12520(230)$ & $12800(260)$ & $\ldots$ & $2.61(37)$ & $3.9(1.3)$ & 14 & 1.2 & 12 & Bu6 \\
\hline 79............... & HD 89744 & $\mathrm{~b}$ & $256.80(13)$ & 267.3(5.0) & $0.6770(72)$ & 194.4(1.2) & 11505.33(39) & 11487.03(76) & 7.7(1.4) & $8.58(71)$ & $0.934(54)$ & 16 & 1.3 & 50 & Bu6 (K0) \\
\hline $80 \ldots \ldots \ldots \ldots$ & HD 92788 & $\mathrm{~b}$ & $325.81(26)$ & $106.0(1.7)$ & $0.334(11)$ & $276.4(2.8)$ & $10759.2(2.7)$ & 10585.3(2.4) & $\ldots$ & $3.67(30)$ & $0.965(56)$ & 7.9 & 1.0 & 58 & Bu6 (My4) \\
\hline $81 \ldots \ldots \ldots . .$. & HD 93083 & b & $143.58(60)$ & $18.30(50)$ & $0.140(30)$ & $333.5(7.9)$ & 13181.7(3.0) & $\ldots$ & $\ldots$ & $0.368(54)$ & $0.477(28)$ & 2.0 & $\ldots$ & 16 & Lv5 \\
\hline $82 \ldots \ldots \ldots \ldots$ & BD -10 3166 & $\mathrm{~b}$ & $3.48777(11)$ & $60.9(1.4)$ & $0.019(23)^{\mathrm{a}}$ & $334^{\mathrm{a}}$ & $11171.22(69)$ & $11168.832(31)$ & $1.97(69)$ & $0.458(39)$ & $0.0452(26)$ & 5.7 & 0.84 & 31 & Bu6 \\
\hline
\end{tabular}


TABLE 3-Continued

\begin{tabular}{|c|c|c|c|c|c|c|c|c|c|c|c|c|c|c|c|}
\hline $\begin{array}{c}\text { Number } \\
\text { (1) }\end{array}$ & $\begin{array}{l}\text { Name } \\
(2)\end{array}$ & $\begin{array}{c}\text { Component } \\
\text { (3) }\end{array}$ & $\begin{array}{l}\text { PERIOD } \\
\text { (days) } \\
\text { (4) }\end{array}$ & $\begin{array}{c}K \\
\left(\mathrm{~m} \mathrm{~s}^{-1}\right) \\
(5)\end{array}$ & $\begin{array}{c}e \\
(6)\end{array}$ & $\begin{array}{c}\omega \\
(\operatorname{deg}) \\
(7)\end{array}$ & $\begin{array}{c}T_{p} \\
(\mathrm{JD}-2,440,000) \\
(8)\end{array}$ & $\begin{array}{c}T_{t} \\
(\mathrm{JD}-2,440,000) \\
(9)\end{array}$ & $\begin{array}{c}\text { TREND } \\
\left(\mathrm{m} \mathrm{s}^{-1} \mathrm{yr}^{-1}\right) \\
(10)\end{array}$ & $\begin{array}{c}M \sin i \\
\left(M_{\mathrm{J}}\right) \\
(11)\end{array}$ & $\begin{array}{c}a \\
(\mathrm{AU}) \\
(12)\end{array}$ & $\begin{array}{c}\mathrm{rms} \\
\left(\mathrm{m} \mathrm{s}^{-1}\right) \\
(13)\end{array}$ & $\begin{array}{l}\sqrt{\chi_{\nu}^{2}} \\
(14)\end{array}$ & $\begin{array}{l}N_{\text {obs }} \\
(15)\end{array}$ & $\begin{array}{c}\text { ReFERENCES } \\
\text { (AlteRnATive) } \\
(16)\end{array}$ \\
\hline 83.............. & $47 \mathrm{UMa}$ & $\mathrm{b}$ & 1089.0(2.9) & $49.3(1.2)$ & $0.061(14)$ & $172(15)$ & $10356(34)$ & $\ldots$ & $\ldots$ & $2.63(23)$ & $2.13(12)$ & 7.4 & 1.0 & 90 & Fi2 (Nf4) \\
\hline $84 \ldots \ldots \ldots \ldots$ & $47 \mathrm{UMa}$ & $\mathrm{c}$ & $2594(90)^{\mathrm{e}}$ & $11.1(1.1)^{\mathrm{e}}$ & $0.00(12)^{\mathrm{e}}$ & $127(56)$ & $11360(500)$ & & $\ldots$ & $0.79(13)$ & $3.79(24)$ & & & & \\
\hline $85 \ldots \ldots \ldots . . .$. & HD 99109 & $\mathrm{~b}$ & $439.3(5.6)$ & $14.1(2.2)$ & $0.09(16)^{\mathrm{a}}$ & $256^{\mathrm{a}}$ & $11310(80)$ & $11110(35)$ & $\ldots$ & $0.502(70)$ & $1.105(65)$ & 6.3 & 0.87 & 41 & Bu6 \\
\hline $86 \ldots \ldots \ldots \ldots . . .$. & 83 Leo B & $\mathrm{b}$ & $17.0431(47)$ & $9.8(1.0)$ & $0.254(92)$ & $219(22)$ & $10468.7(1.4)$ & $10463.78(80)$ & $1.29(21)$ & $0.109(13)$ & $0.1232(71)$ & 3.6 & 0.80 & 51 & Bu6 \\
\hline $87 \ldots \ldots \ldots \ldots$. & GJ 436 & $\mathrm{~b}$ & $2.643943(84)$ & $18.3(1.0)$ & $0.207(52)$ & $357(24)$ & $11551.69(11)$ & $11549.557(68)$ & $\ldots$ & $0.0673(65)$ & $0.0278(16)$ & 4.9 & 0.79 & 55 & Bu6 \\
\hline $88 \ldots \ldots \ldots \ldots$ & HD 101930 & $\mathrm{~b}$ & $70.46(18)$ & $18.10(40)$ & $0.110(20)$ & 251(11) & $13145.0(2.0)$ & $\ldots$ & $\ldots$ & $0.299(43)$ & $0.302(17)$ & 1.8 & $\ldots$ & 16 & Lv5 \\
\hline $89 \ldots \ldots \ldots$ & HD 102117 & $\mathrm{~b}$ & $20.8133(64)$ & $11.98(95)$ & $0.121(82)^{\mathrm{a}}$ & $279^{\mathrm{a}}$ & $10942.2(2.6)$ & 10931.1(1.0) & $\ldots$ & $0.172(20)$ & $0.1532(88)$ & 3.8 & 0.75 & 44 & Bu6 (Lv5) \\
\hline $90 \ldots \ldots \ldots . . . .$. & HD 102195 & $\mathrm{~b}$ & $4.1150(10)$ & 64 & $0.060(30)$ & $110(10)$ & $13731.70(50)$ & $\ldots$ & $\ldots$ & 0.48 & 0.049 & $\ldots$ & $\ldots$ & $\ldots$ & Ge6 \\
\hline 91.................. & HD 104985 & $\mathrm{~b}$ & $198.20(30)$ & $161.0(2.0)$ & $0.030(20)$ & $310(30)$ & $11990(20)$ & & $\ldots$ & $6.33(91)$ & $0.779(45)$ & 24 & 3.2 & 26 & St3 \\
\hline $92 \ldots \ldots \ldots \ldots$ & HD 106252 & $\mathrm{~b}$ & $1516(26)$ & $152(21)$ & $0.586(65)$ & $294.9(6.2)$ & $10385(27)$ & $9244(51)$ & $\ldots$ & $7.10(65)$ & $2.60(15)$ & 9.1 & 0.78 & 15 & Bu6 (Pr3) \\
\hline $93 \ldots \ldots \ldots \ldots$ & HD 107148 & $\mathrm{~b}$ & $48.056(57)$ & $10.9(2.0)$ & $0.05(17)^{\mathrm{a}}$ & $75^{\mathrm{a}}$ & $-31(12)$ & $-29(12)$ & $1.03(51)$ & $0.210(36)$ & $0.269(16)$ & 4.4 & 1.4 & 35 & Bu6 \\
\hline $94 \ldots \ldots \ldots \ldots$ & HD 108147 & $\mathrm{~b}$ & $10.8985(45)$ & $25.1(6.1)$ & $0.53(12)$ & $308(24)$ & $10828.86(71)$ & $10820.7(1.5)$ & $\ldots$ & $0.261(40)$ & $0.1020(59)$ & 12 & 1.1 & 54 & Bu6 (Pp2) \\
\hline $95 \ldots \ldots \ldots \ldots$ & HD 108874 & $\mathrm{~b}$ & $395.27(92)$ & $37.91(95)$ & $0.068(24)$ & $250(35)$ & 9739(38) & $\ldots$ & $\ldots$ & $1.37(12)$ & $1.055(61)$ & 3.7 & 0.74 & 49 & Vo5 \\
\hline $96 \ldots \ldots \ldots . .$. & HD 108874 & $\mathrm{c}$ & 1599(46) & $18.35(86)$ & $0.253(42)$ & $20(100)$ & $9590(110)$ & $\ldots$ & $\ldots$ & $1.02(10)$ & $2.68(17)$ & & & & \\
\hline $97 \ldots \ldots \ldots \ldots . . .$. & HD 109749 & $\mathrm{~b}$ & $5.23947(56)$ & $28.58(87)$ & $0^{\mathrm{b}}$ & $0^{\mathrm{b}}$ & $13014.91(85)$ & $\ldots$ & $\ldots$ & $0.277(24)$ & $0.0629(36)$ & 2.7 & 0.59 & 21 & Fi6 \\
\hline 98.................. & HD 111232 & $\mathrm{~b}$ & 1143(14) & $159.3(2.3)$ & $0.200(10)$ & $98.0(6.0)$ & $11230(20)$ & $\ldots$ & $\ldots$ & $6.84(98)$ & $1.97(12)$ & 7.5 & $\ldots$ & 38 & My4 \\
\hline 99............. & HD 114386 & $\mathrm{~b}$ & $938(16)$ & 34.3(1.6) & $0.230(30)$ & 273(14) & 10454(43) & $\ldots$ & $\ldots$ & $1.34(20)$ & 1.71(10) & 10 & $\ldots$ & 58 & My4 \\
\hline $100 \ldots \ldots \ldots$ & HD 114762 & $\mathrm{~b}$ & $83.8881(86)$ & $615.2(6.7)$ & $0.3359(91)$ & $201.7(1.4)$ & $9805.36(34)$ & 9788.23(29) & $\ldots$ & $11.68(96)$ & $0.363(21)$ & 24 & 1.1 & 45 & Bu6 (Lt9) \\
\hline $101 \ldots \ldots \ldots$. & HD 114783 & $\mathrm{~b}$ & $496.9(2.3)$ & $29.36(83)$ & $0.085(33)$ & $93(25)$ & 10840(37) & 10836.0(7.6) & $2.95(40)$ & $1.034(89)$ & $1.169(68)$ & 4.7 & 1.1 & 54 & Bu6 \\
\hline $102 \ldots \ldots \ldots$. & HD 114729 & $\mathrm{~b}$ & 1114(15) & $18.8(1.3)$ & $0.167(55)$ & $93(30)$ & $10520(67)$ & 10515(21) & $\ldots$ & $0.95(10)$ & $2.11(12)$ & 4.9 & 0.95 & 42 & Bu6 \\
\hline $103 \ldots \ldots \ldots . .$. & $70 \mathrm{Vir}$ & $\mathrm{b}$ & $116.6884(44)$ & $316.3(1.7)$ & $0.4007(35)$ & $358.71(54)$ & $7239.82(21)$ & $7138.27(21)$ & $\ldots$ & $7.49(61)$ & $0.484(28)$ & 7.4 & 1.0 & 74 & Bu6 (Nf4) \\
\hline $104 \ldots \ldots \ldots$ & HD 117207 & $\mathrm{~b}$ & 2597(41) & $26.60(93)$ & $0.144(35)$ & 73(16) & $10630(120)$ & $10723(41)$ & $\ldots$ & $1.88(17)$ & $3.79(22)$ & 4.4 & 0.84 & 43 & Bu6 \\
\hline $105 \ldots \ldots \ldots . .$. & HD 117618 & $\mathrm{~b}$ & $25.827(19)$ & $12.8(2.2)$ & $0.42(17)$ & $254(19)$ & $10832.2(1.8)$ & $10821.8(2.4)$ & & $0.178(21)$ & $0.176(10)$ & 5.5 & 0.79 & 57 & Bu6 \\
\hline $106 \ldots \ldots \ldots$. & HD 118203 & $\mathrm{~b}$ & $6.13350(60)$ & $217.0(3.0)$ & $0.309(14)$ & $155.7(2.4)$ & $13394.230(30)$ & $\ldots$ & $49.7(5.7)$ & $2.14(31)$ & $0.0703(41)$ & 18 & $\ldots$ & 43 & Da6 \\
\hline $107 \ldots \ldots \ldots$ & $\tau$ Boo & $\mathrm{b}$ & $3.312463(14)$ & 461.1(7.6) & $0.023(15)^{\mathrm{a}}$ & $188^{\mathrm{a}}$ & $6957.81(54)$ & $6956.916(28)$ & $-18.7(1.1)$ & $4.13(34)$ & $0.0481(28)$ & 62 & 1.7 & 98 & Bu6 \\
\hline $108 \ldots \ldots \ldots . . .$. & HD 121504 & $\mathrm{~b}$ & $63.330(30)$ & $55.80(90)$ & $0.030(10)$ & $265(12)$ & $11450.0(2.0)$ & $\ldots$ & $\ldots$ & $1.22(17)$ & $0.329(19)$ & 12 & $\ldots$ & 100 & My4 \\
\hline $109 \ldots \ldots \ldots$ & HD 128311 & $\mathrm{~b}$ & $458.6(6.8)$ & $66.8(8.7)$ & $0.25(10)$ & $111(36)$ & $10211(76)$ & $\ldots$ & $\ldots$ & $2.19(20)$ & $1.100(65)$ & 18 & 1.9 & $\ldots$ & Vo5 \\
\hline $110 \ldots \ldots \ldots$ & HD 128311 & $\mathrm{c}$ & $928(18)$ & $76.2(4.6)$ & $0.170(90)$ & $200(150)$ & $10010(400)$ & & $\ldots$ & $3.22(49)$ & $1.76(11)$ & & & & \\
\hline $111 \ldots \ldots \ldots$ & HD 130322 & $\mathrm{~b}$ & $10.70875(94)$ & $109.6(4.2)$ & $0.025(32)^{\mathrm{a}}$ & $149^{\mathrm{a}}$ & $212.9(2.1)$ & 211.2(1.1) & $\ldots$ & $1.089(98)$ & $0.0910(53)$ & 11 & 2.4 & 12 & Bu6 (U0) \\
\hline $112 \ldots \ldots \ldots . .$. & $23 \mathrm{Lib}$ & $\mathrm{b}$ & 258.31(16) & $50.03(54)$ & $0.243(11)$ & $358.3(3.7)$ & $10331.7(2.2)$ & 10119.4(1.8) & $2.91(22)$ & 1.62(13) & $0.820(47)$ & 4.0 & 0.89 & 90 & Bu6 \\
\hline $113 \ldots \ldots \ldots$ & HD 136118 & $\mathrm{~b}$ & $1193.1(9.7)$ & $212.8(5.8)$ & $0.351(25)$ & $311.4(3.1)$ & $10598(13)$ & 9734(24) & $\ldots$ & $12.0(1.0)$ & $2.37(14)$ & 22 & 1.2 & 37 & Bu6 \\
\hline $114 \ldots \ldots \ldots$ & GJ 581 & $\mathrm{~b}$ & $5.3660(10)$ & $13.20(40)$ & $0^{\mathrm{b}}$ & $0^{\mathrm{b}}$ & $11004.300(60)$ & & & 0.0521 & $0.0406(23)$ & 2.5 & $\ldots$ & 20 & Bf5 \\
\hline $115 \ldots \ldots \ldots$ & $\iota$ Dra & $\mathrm{b}$ & $511.098(89)$ & $307.6(2.3)$ & $0.7124(39)$ & $91.58(81)$ & $12014.59(30)$ & 12014.32(19) & $-18.1(1.1)$ & $8.82(72)$ & $1.275(74)$ & 14 & 1.9 & 119 & Bu6 \\
\hline $116 \ldots \ldots \ldots$ & HD 137510 & $\mathrm{~b}$ & $804.9(5.0)$ & $418(31)$ & $0.359(28)$ & $31.0(3.8)$ & 11762(27) & $11851.3(9.4)$ & $\ldots$ & $22.7(2.4)$ & $1.91(11)$ & 17 & 1.8 & 10 & Bu6 (Ed4) \\
\hline $117 \ldots \ldots \ldots$ & HD 330075 & $\mathrm{~b}$ & $3.387730(80)$ & $107.00(70)$ & $0^{\mathrm{b}}$ & $0^{\mathrm{b}}$ & $12878.8150(30)$ & $\ldots$ & $\ldots$ & $0.624(88)$ & $0.0392(23)$ & 2.0 & $\ldots$ & 21 & Pp4 \\
\hline $118 \ldots \ldots \ldots$. & HD 141937 & $\mathrm{~b}$ & $653.2(1.2)$ & $234.5(6.4)$ & $0.410(10)$ & $187.72(80)$ & $11847.4(2.0)$ & $\ldots$ & $\ldots$ & $9.7(1.4)$ & $1.517(88)$ & 8.7 & 1.6 & 81 & U2 \\
\hline $119 \ldots \ldots \ldots$ & HD 142415 & $\mathrm{~b}$ & $386.3(1.6)$ & $51.3(2.3)$ & $0.500^{\mathrm{b}}$ & $255.0(4.0)$ & $11519.0(4.0)$ & $\ldots$ & $\ldots$ & $1.69(25)$ & $1.069(62)$ & 11 & $\ldots$ & 137 & My4 \\
\hline $120 \ldots \ldots \ldots$ & $\rho \mathrm{CrB}$ & $\mathrm{b}$ & $39.8449(63)$ & $64.9(2.4)$ & $0.057(28)^{\mathrm{a}}$ & $303^{\mathrm{a}}$ & $10563.2(4.1)$ & $10539.58(35)$ & $\ldots$ & $1.093(98)$ & $0.229(13)$ & 6.9 & 0.97 & 26 & Bu6 (Ny7) \\
\hline 121............ & HD 142022 & $\mathrm{~b}$ & 1928(46) & $92(65)$ & $0.53(20)$ & $170.0(9.0)$ & 10941(75) & & $\ldots$ & $4.5(3.4)$ & $2.93(18)$ & 10 & $\ldots$ & 76 & Eg6 \\
\hline $122 \ldots \ldots \ldots \ldots$ & $14 \mathrm{Her}$ & $\mathrm{b}$ & $1754.0(3.2)$ & $90.7(1.0)$ & $0.3872(94)$ & 19.6(1.7) & $11368.4(5.9)$ & $11530.0(4.9)$ & $\ldots$ & $4.98(41)$ & $2.85(16)$ & 5.6 & 1.4 & 49 & Bu6 (Nf4) \\
\hline $123 \ldots \ldots \ldots . .$. & HD 147513 & $\mathrm{~b}$ & $528.4(6.3)$ & $29.3(1.8)$ & $0.260(50)$ & $282.0(9.0)$ & $11123(20)$ & & $\ldots$ & $1.18(19)$ & $1.310(77)$ & 5.7 & 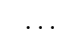 & 30 & My4 \\
\hline $124 \ldots \ldots \ldots$ & HD 149026 & $\mathrm{~b}$ & $2.87598(14)$ & $43.2(2.3)$ & $0^{\mathrm{b}}$ & $0^{\mathrm{b}}$ & $13526.36846(88)$ & $13527.08746(88)^{\mathrm{h}}$ & $\ldots$ & $0.360(35)$ & $0.0432(25)$ & 5.7 & 2.0 & 16 & $\mathrm{Cb6}(\mathrm{St} 5)$ \\
\hline
\end{tabular}


TABLE 3-Continued

\begin{tabular}{|c|c|c|c|c|c|c|c|c|c|c|c|c|c|c|c|}
\hline $\begin{array}{l}\text { Number } \\
\text { (1) }\end{array}$ & $\begin{array}{l}\text { Name } \\
(2)\end{array}$ & $\begin{array}{l}\text { Component } \\
\text { (3) }\end{array}$ & $\begin{array}{l}\text { PERIOD } \\
\text { (days) } \\
\text { (4) }\end{array}$ & $\begin{array}{c}K \\
\left(\mathrm{~m} \mathrm{~s}^{-1}\right) \\
(5)\end{array}$ & $\begin{array}{c}e \\
(6)\end{array}$ & $\begin{array}{c}\omega \\
(\mathrm{deg}) \\
(7)\end{array}$ & $\begin{array}{c}T_{p} \\
(\mathrm{JD}-2,440,000) \\
(8)\end{array}$ & $\begin{array}{c}T_{t} \\
(\mathrm{JD}-2,440,000) \\
(9)\end{array}$ & $\begin{array}{c}\text { TREND } \\
\left(\mathrm{m} \mathrm{s}^{-1} \mathrm{yr}^{-1}\right) \\
(10)\end{array}$ & $\begin{array}{c}M \sin i \\
\left(M_{\mathrm{J}}\right) \\
(11)\end{array}$ & $\begin{array}{c}a \\
(\mathrm{AU}) \\
(12)\end{array}$ & $\begin{array}{c}\mathrm{rms} \\
\left(\mathrm{m} \mathrm{s}^{-1}\right) \\
(13)\end{array}$ & $\begin{array}{l}\sqrt{\chi_{\nu}^{2}} \\
(14)\end{array}$ & $\begin{array}{l}N_{\text {obs }} \\
(15)\end{array}$ & $\begin{array}{c}\text { References } \\
\text { (Alternative) } \\
\text { (16) }\end{array}$ \\
\hline $125 \ldots \ldots \ldots$ & HD 150706 & $\mathrm{~b}$ & $264.9(5.8)$ & $33.0(4.0)$ & $0.38(12)$ & $178(32)$ & $11580(26)$ & & & $0.95(22)$ & $0.802(48)$ & 6.8 & $\ldots$ & 20 & U3 (My3) \\
\hline $126 \ldots \ldots \ldots$. & HD 149143 & $\mathrm{~b}$ & $4.07(70)$ & $149.6(3.0)$ & $0^{\mathrm{b}}$ & $0^{\mathrm{b}}$ & $13483.9(1.2)$ & & $10.0(2.0)$ & $1.33(11)$ & $0.0531(81)$ & 4.7 & 1.1 & 17 & Fi6 (Da6) \\
\hline $127 \ldots \ldots \ldots$ & HD 154857 & $\mathrm{~b}$ & $398.5(9.0)$ & $52.0(5.0)$ & $0.510(60)$ & $50(11)$ & $11963(10)$ & $\ldots$ & $-14.3(3.5)$ & $1.85(16)$ & $1.132(69)$ & 3.2 & 0.87 & 18 & MC4 \\
\hline $128 \ldots \ldots \ldots .$. & $\mu$ Ara & $\mathrm{b}$ & $630.0(6.2)$ & $37.4(1.6)$ & $0.271(40)$ & $259.8(7.4)$ & 10881(28) & $10596(18)$ & & $1.67(17)$ & $1.510(88)$ & 4.7 & 1.1 & 108 & Bu6 (Sn4b) \\
\hline $129 \ldots \ldots \ldots$ & $\mu$ Ara & $\mathrm{c}$ & $2490(100)$ & 18.1(1.1) & $0.463(53)$ & $183.8(7.9)$ & $11030(110)$ & $10750(110)$ & $\ldots$ & $1.18(12)$ & $3.78(25)$ & & & & \\
\hline $130 \ldots \ldots \ldots$ & $\mu$ Ara & d & $9.550(30)$ & $4.10(20)$ & $0.000(20)$ & $4.0(2.0)$ & $13168.940(50)$ & 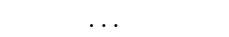 & $\ldots$ & 0.0471 & $0.0924(53)$ & 0.90 & $\ldots$ & 24 & $\mathrm{Sn} 4 \mathrm{~b}$ \\
\hline $131 \ldots \ldots \ldots$ & HD 162020 & $\mathrm{~b}$ & $8.428198(56)$ & $1813.0(4.0)$ & $0.2770(20)$ & $28.40(23)$ & $11990.6770(50)$ & & $\ldots$ & $15.0(2.1)$ & $0.0751(43)$ & 8.1 & 1.2 & 30 & U2 \\
\hline $132 \ldots \ldots \ldots$ & HD 164922 & $\mathrm{~b}$ & $1155(23)$ & 7.3(1.2) & $0.05(14)^{\mathrm{a}}$ & $195^{\mathrm{a}}$ & $11100(280)$ & $10780(68)$ & $\ldots$ & $0.360(46)$ & $2.11(13)$ & 3.7 & 0.60 & 64 & Bu6 \\
\hline $133 \ldots \ldots \ldots$ & HD 168443 & $\mathrm{~b}$ & $58.11055(86)$ & $475.8(1.6)$ & $0.5296(32)$ & $172.68(94)$ & $10047.454(34)$ & $10042.919(43)$ & & $8.01(65)$ & $0.300(17)$ & 5.9 & 1.3 & 106 & Bu6 (U2) \\
\hline $134 \ldots \ldots \ldots$ & HD 168443 & $\mathrm{c}$ & $1764.3(2.4)$ & 297.4(1.2) & $0.2175(15)$ & $64.37(21)$ & $10255.8(4.6)$ & $10335.6(2.7)$ & $\ldots$ & $18.1(1.5)$ & $2.92(17)$ & & & & \\
\hline $135 \ldots \ldots \ldots$. & HD 168746 & $\mathrm{~b}$ & $6.4040(14)$ & $28.6(1.7)$ & $0.107(80)^{\mathrm{a}}$ & $17^{\mathrm{a}}$ & $11757.83(47)$ & 11758.92(19) & & $0.248(23)$ & $0.0659(38)$ & 3.9 & 0.79 & 16 & Bu6 (Pp2) \\
\hline $136 \ldots \ldots \ldots$. & HD 169830 & $\mathrm{~b}$ & $225.62(22)$ & $80.70(90)$ & $0.310(10)$ & $148.0(2.0)$ & $11923.0(1.0)$ & $\ldots$ & $\ldots$ & $2.9(1.3)$ & $0.817(47)$ & 8.9 & $\ldots$ & 112 & My4 \\
\hline $137 \ldots \ldots \ldots$. & HD 169830 & $\mathrm{c}$ & $2100(260)$ & $54.3(3.6)$ & $0.33(02)$ & $252.0(8.0)$ & $12516(25)$ & & & $4.1(1.6)$ & $3.62(43)$ & & & & \\
\hline $138 \ldots \ldots \ldots$ & TrES-1 & & $3.0300650(80)$ & $115.2(6.2)$ & $0^{\mathrm{b}, \mathrm{i}}$ & & & $13186.80600(20)^{\mathrm{h}}$ & & 0.759 & $0.0394(23)$ & 14 & $\cdots$ & 8 & As4 \\
\hline $139 \ldots \ldots \ldots$ & HD 177830 & $\mathrm{~b}$ & $410.1(2.2)$ & $32.64(98)$ & $0.096(48)^{\mathrm{a}}$ & $189^{\mathrm{a}}$ & $10254(42)$ & $10154.4(9.1)$ & $\ldots$ & $1.53(13)$ & $1.227(71)$ & 6.2 & 1.0 & 54 & Bu6 \\
\hline $140 \ldots \ldots \ldots$ & HD 178911B & $\mathrm{b}$ & 71.511(11) & $346.9(4.2)$ & $0.139(14)$ & $172.3(5.0)$ & 11378.23(83) & $11364.97(33)$ & $\cdots$ & $7.35(60)$ & $0.345(20)$ & 7.7 & 1.7 & 14 & Bu6 (Z2) \\
\hline $141 \ldots \ldots \ldots$ & HD 179949 & $\mathrm{~b}$ & $3.092514(32)$ & $112.6(1.8)$ & $0.022(15)^{\mathrm{a}}$ & $192^{\mathrm{a}}$ & $11002.36(44)$ & $11001.510(20)$ & & $0.916(76)$ & $0.0443(26)$ & 12 & 1.1 & 88 & Bu6 \\
\hline $142 \ldots \ldots \ldots$. & HD 183263 & $\mathrm{~b}$ & $635.4(3.9)$ & $87.3(3.2)$ & $0.363(21)$ & $231.5(5.7)$ & $12103.0(7.5)$ & 11910(11) & $-25.5(1.6)$ & $3.82(34)$ & $1.525(88)$ & 8.4 & 1.8 & 34 & Bu6 \\
\hline $143 \ldots \ldots \ldots$ & 16 Cyg B & $\mathrm{b}$ & $798.5(1.0)$ & $50.5(1.6)$ & $0.681(17)$ & $85.8(2.4)$ & 6549.1(6.6) & $6546.3(6.4)$ & & $1.68(15)$ & $1.681(97)$ & 7.3 & 0.99 & 95 & Bu6 \\
\hline $144 \ldots \ldots \ldots$. & HD 187123 & $\mathrm{~b}$ & $3.096598(27)$ & $70.0(1.0)$ & $0.023(15)^{\mathrm{a}}$ & $17^{\mathrm{a}}$ & $10806.75(39)$ & $10807.363(16)$ & $-7.33(29)$ & $0.528(44)$ & $0.0426(25)$ & 5.5 & 1.2 & 65 & Bu6 (Nf4) \\
\hline $145 \ldots \ldots \ldots$ & HD 187085 & $\mathrm{~b}$ & $1147.0(4.0)$ & $26(10)$ & $0.75(10)$ & $93(20)$ & 10910(110) & & $1.30(10)$ & $0.98(43)$ & $2.26(13)$ & 6.0 & 1.2 & 33 & Jo6 \\
\hline $146 \ldots \ldots \ldots$ & HD 188015 & $\mathrm{~b}$ & $461.2(1.7)$ & $37.6(1.2)$ & $0.137(26)$ & $222(10)$ & $11787(17)$ & $11634.4(5.7)$ & $2.64(54)$ & $1.50(13)$ & $1.203(70)$ & 4.3 & 0.93 & 44 & Bu6 \\
\hline $147 \ldots \ldots \ldots$. & HD 189733 & $\mathrm{~b}$ & $2.21900(50)$ & $205.0(6.0)$ & $0^{\mathrm{b}}$ & $\ldots$ & $\ldots$ & $13629.38900(40)$ & $\ldots$ & $1.15(17)$ & $0.0312(18)$ & 15 & $\ldots$ & $\ldots$ & $\mathrm{Bc} 5$ \\
\hline $148 \ldots \ldots \ldots$. & HD 190228 & $\mathrm{~b}$ & $1146(16)$ & $91.0(5.0)$ & $0.499(30)$ & $100.7(3.0)$ & $11236(25)$ & $\ldots$ & $\ldots$ & $4.49(70)$ & $2.25(13)$ & 8.0 & 0.99 & 51 & $\operatorname{Pr} 3$ \\
\hline $149 \ldots \ldots \ldots$ & HD 190360 & $\mathrm{~b}$ & 2891(85) & $23.50(50)$ & $0.360(30)$ & $12.4(9.3)$ & 10630(100) & $\ldots$ & $\ldots$ & $1.55(14)$ & $3.99(25)$ & 3.5 & 0.88 & 87 & Vo5 (Nf3) \\
\hline $150 \ldots \ldots \ldots$ & HD 190360 & c & $17.100(15)$ & $4.6(1.1)$ & $0.01(10)$ & 154(32) & $10000.07(90)$ & $\ldots$ & $\ldots$ & $0.0587(78)$ & $0.1303(75)$ & & & & \\
\hline $151 \ldots \ldots \ldots$ & HD 192263 & $\mathrm{~b}$ & $24.3556(46)$ & $51.9(2.6)$ & $0.055(39)^{\mathrm{a}}$ & $200^{\mathrm{a}}$ & 10994.3(3.9) & 10987.22(39) & $\ldots$ & $0.641(61)$ & $0.1532(88)$ & 7.7 & 0.93 & 31 & Bu6 (Sn3) \\
\hline $152 \ldots \ldots \ldots$ & HD 195019 & $\mathrm{~b}$ & $18.20132(39)$ & $271.5(1.5)$ & $0.0138(44)$ & 231(20) & $11015.5(1.1)$ & $11008.449(40)$ & $\ldots$ & $3.69(30)$ & $0.1388(80)$ & 16 & 1.5 & 154 & Bu6 \\
\hline $153 \ldots \ldots \ldots$. & HD 196050 & $\mathrm{~b}$ & $1378(21)$ & $49.7(2.0)$ & $0.228(38)$ & 187(12) & 10843(56) & $10573(42)$ & $\ldots$ & $2.90(26)$ & $2.54(15)$ & 8.4 & 1.3 & 44 & Bu6 (My4) \\
\hline $154 \ldots \ldots \ldots$ & HD 202206 & $\mathrm{~b}$ & $255.870(60)^{\mathrm{j}}$ & $564.8(1.3)^{\mathrm{j}}$ & $0.4350(10)^{\mathrm{j}}$ & $161.18(30)^{\mathrm{j}}$ & $\mathrm{j}$ & $\mathrm{j}$ & $\ldots$ & $17.3(2.4)$ & $0.823(48)$ & 9.6 & 1.5 & $\ldots$ & $\mathrm{Cr} 5$ \\
\hline $155 \ldots \ldots \ldots$ & HD 202206 & $\mathrm{c}$ & $1383(18)^{\mathrm{j}}$ & $42.0(1.5)^{\mathrm{j}}$ & $0.267(21)^{\mathrm{j}}$ & $79.0(6.7)^{\mathrm{j}}$ & j & $\mathrm{j}$ & $\ldots$ & $2.40(35)$ & $2.52(15)$ & & & & \\
\hline $156 \ldots \ldots \ldots$ & HD 208487 & $\mathrm{~b}$ & $130.08(51)$ & $19.7(3.6)$ & $0.24(16)^{\mathrm{a}}$ & $113^{\mathrm{a}}$ & 10999(15) & 10994(10) & $\cdots$ & $0.520(82)$ & $0.524(30)$ & 8.2 & 1.0 & 35 & Bu6 \\
\hline $157 \ldots \ldots \ldots$ & HD 209458 & $\mathrm{~b}$ & $3.52474554(18)$ & $84.26(98)$ & $0^{\mathrm{b}, \mathrm{k}}$ & $0^{\mathrm{b}}$ & $12853.94426(14)$ & $12854.82545(14)^{\mathrm{h}}$ & $\cdots$ & $0.689(57)$ & $0.0474(27)$ & 5.0 & 1.4 & 64 & W4 (Nf4) \\
\hline $158 \ldots \ldots \ldots .$. & HD 210277 & $\mathrm{~b}$ & $442.19(50)$ & $38.94(75)$ & $0.476(17)$ & $119.1(2.8)$ & $10104.3(2.6)$ & $10092.8(2.1)$ & $\ldots$ & $1.29(11)$ & $1.138(66)$ & 3.8 & 0.90 & 69 & Bu6 (Nf1b) \\
\hline $159 \ldots \ldots \ldots$ & HD 212301 & $\mathrm{~b}$ & $2.24572(28)$ & $59.50(70)$ & $0^{\mathrm{b}}$ & $0^{\mathrm{b}}$ & $13549.1950(40)$ & & $\ldots$ & 0.396 & $0.0341(20)$ & 6.7 & $\ldots$ & 23 & LC6 \\
\hline $160 \ldots \ldots \ldots$ & HD 213240 & $\mathrm{~b}$ & $882.7(7.6)$ & $96.6(2.0)$ & $0.421(15)$ & 201.0(3.2) & 11499(12) & $11347.7(9.4)$ & $\ldots$ & $4.72(40)$ & $1.92(11)$ & 5.0 & 0.75 & 30 & Bu6 (Sn1) \\
\hline $161 \ldots \ldots \ldots$ & GJ 876 & $\mathrm{~b}$ & $60.940(13)^{1}$ & $212.60(76)^{1}$ & $0.0249(26)^{1}$ & $175.7(6.0)^{1}$ & 1 & 1 & $\ldots$ & $1.93(27)$ & $0.208(12)$ & 4.6 & 1.2 & 155 & R5 (De8) \\
\hline $162 \ldots \ldots \ldots$ & GJ 876 & $\mathrm{c}$ & $30.340(13)^{1}$ & $88.36(72)^{1}$ & $0.2243(13)^{1}$ & $198.30(90)^{1}$ & 1 & 1 & $\ldots$ & $0.619(88)$ & $0.1303(75)$ & & & & \\
\hline $163 \ldots \ldots \ldots$ & GJ 876 & d & $1.937760(70)^{1}$ & $6.46(59)^{1}$ & $0^{\mathrm{b}, \mathrm{l}}$ & 1 & 1 & 1 & & $0.0185(31)$ & $0.0208(12)$ & & & & \\
\hline $164 \ldots \ldots \ldots$ & $\tau^{1} \mathrm{Gru}$ & $\mathrm{b}$ & 1311(49) & $19.6(1.5)$ & $0.070(78)^{\mathrm{a}}$ & $100^{\mathrm{a}}$ & $10870(210)$ & $10837(53)$ & $\ldots$ & $1.26(13)$ & $2.56(17)$ & 6.3 & 1.1 & 58 & Bu6 \\
\hline $165 \ldots \ldots \ldots$ & $\rho$ Ind & $\mathrm{b}$ & 1353(25) & $39.0(1.0)$ & $0.319(25)$ & $67.7(8.4)$ & $10605(29)$ & $10647(24)$ & $\ldots$ & $2.26(19)$ & $2.54(15)$ & 5.3 & 1.0 & 39 & Bu6 (My4) \\
\hline $166 \ldots \ldots \ldots$ & HD 216770 & $\mathrm{~b}$ & $118.45(55)$ & $30.9(1.9)$ & $0.370(60)$ & $281(10)$ & $12672.0(3.5)$ & $\ldots$ & $\ldots$ & $0.65(11)$ & $0.456(26)$ & 7.8 & $\ldots$ & 16 & My4 \\
\hline
\end{tabular}


TABLE 3-Continued

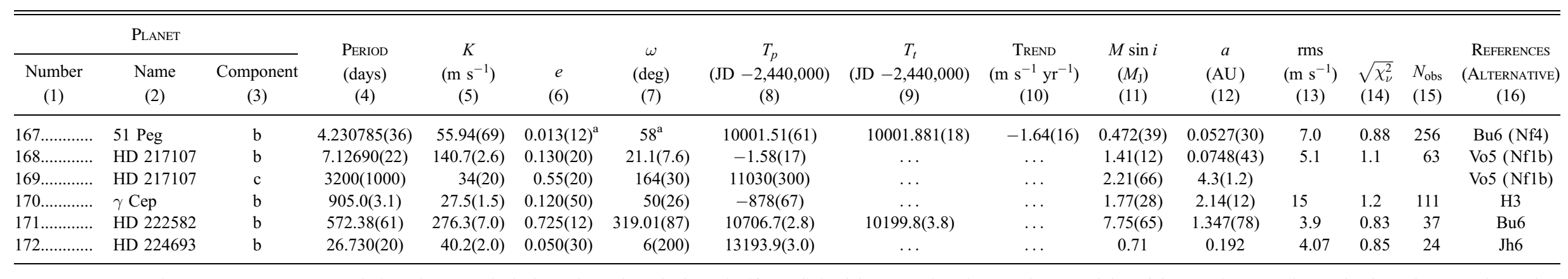

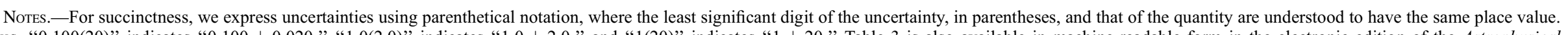

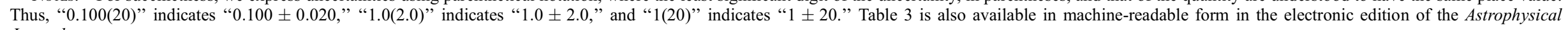
Journal.

${ }^{\text {a }}$ When the uncertainty in $e$ is comparable to $e$, uncertainties in $\omega$ and $e$ become non-Gaussian. See $\S 4$.

${ }^{b}$ Parameter held fixed in fit.

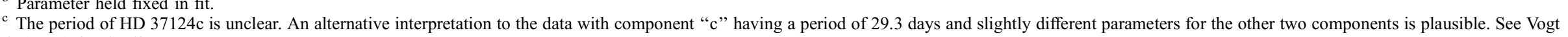

$\underset{\sigma}{a}$ et al. (2005) for details.

d The mass of HD 47536 is ill determined. The solution here is for $M=1.1 M_{\odot}$.
e This parameter is highly uncertain with a non-Gaussian distribution of possible values and high covariance with other parameters.

${ }^{\mathrm{f}}$ Eccentricity held fixed in fit. The quoted error in $e$ represents the change in the $e$ from the best fit required to increase the best-fit $\chi^{2}$ by 1 .

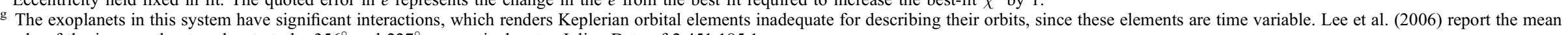
anomaly of the inner and outer planets to be $356^{\circ}$ and $227^{\circ}$, respectively, at a Julian Date of 2,451,185.1.

${ }^{\mathrm{h}}$ This transit ephemeris is expressed as a Heliocentric Julian Date.

Charbonneau et al. (2005) find $e \cos \omega=0.003 \pm 0.0019$.

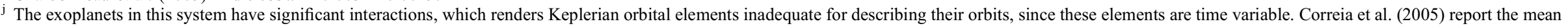
longitude to be $266.23 \pm 0.06$ and $30.59 \pm 2.84$ for the inner and outer planets, respectively, at a Julian Date of 2,452,250.

${ }^{\mathrm{k}}$ Laughlin et al. (2005) find $e$ consistent with 0.

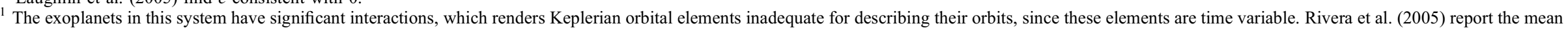
anomaly of the b, c, and d components at JD 2,452,490.0 to be $175.5 \pm 6.0,308.5 \pm 1.4$, and $309.5 \pm 5.1$, respectively.

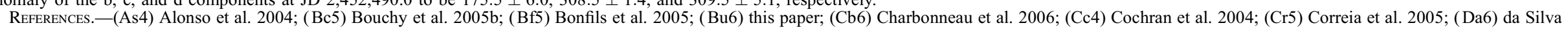

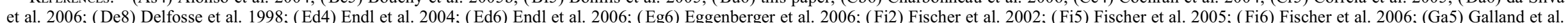

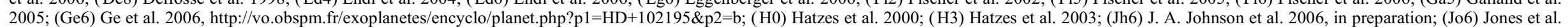

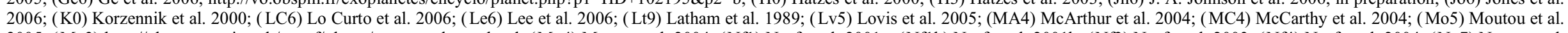

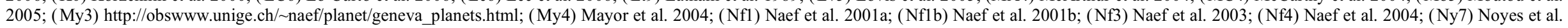

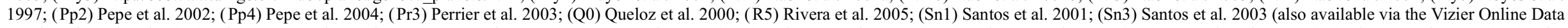

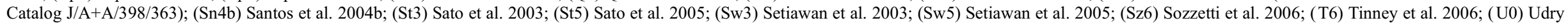

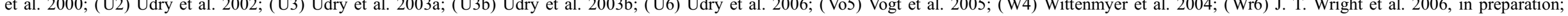
(Z2) Zucker et al. 2002; (Z4) Zucker et al. 2004. 
TABLE 4

Independent Orbital Solutions

\begin{tabular}{|c|c|c|c|c|c|c|c|c|c|c|c|c|c|}
\hline \multicolumn{2}{|l|}{ Planet } & \multirow{2}{*}{$\begin{array}{l}\text { PERIOD } \\
\text { (days) } \\
\text { (3) }\end{array}$} & \multirow{2}{*}{$\begin{array}{c}K \\
\left(\mathrm{~m} \mathrm{~s}^{-1}\right) \\
(4)\end{array}$} & \multirow[b]{2}{*}{$\begin{array}{c}e \\
(5)\end{array}$} & \multirow{2}{*}{$\begin{array}{c}\omega \\
\text { (deg) } \\
(6)\end{array}$} & \multirow{2}{*}{$\begin{array}{c}T_{p} \\
(\mathrm{JD}-2,440,000) \\
(7)\end{array}$} & \multirow{2}{*}{$\begin{array}{c}\text { TREND } \\
\left(\mathrm{m} \mathrm{s}^{-1} \mathrm{yr}^{-1}\right) \\
(8)\end{array}$} & \multirow{2}{*}{$\begin{array}{c}M \sin i \\
\left(M_{\mathrm{J}}\right) \\
(9)\end{array}$} & \multirow{2}{*}{$\begin{array}{c}a \\
(\mathrm{AU}) \\
(10)\end{array}$} & \multirow{2}{*}{$\begin{array}{c}\mathrm{rms} \\
\left(\mathrm{m} \mathrm{s}^{-1}\right) \\
(11)\end{array}$} & \multirow[b]{2}{*}{$\begin{array}{l}\sqrt{\chi_{\nu}^{2}} \\
(12)\end{array}$} & \multirow[b]{2}{*}{$\begin{array}{l}N_{\text {obs }} \\
(13)\end{array}$} & \multirow[b]{2}{*}{$\begin{array}{c}\text { RefERENCES } \\
\text { (14) }\end{array}$} \\
\hline $\begin{array}{l}\text { Name } \\
(1)\end{array}$ & $\begin{array}{l}\text { Component } \\
\text { (2) }\end{array}$ & & & & & & & & & & & & \\
\hline HD 8574 & $\mathrm{~b}$ & $277.55(77)$ & $66(5)$ & $0.288(53)$ & $3.6(10.9)$ & $11467.5(6.6)$ & $\ldots$ & 2.11 & 0.77 & 13 & 1.4 & 41 & $\operatorname{Pr} 3$ \\
\hline \multirow[t]{3}{*}{$v$ And } & $\mathrm{b}$ & $4.61712(9)$ & $77.2(1.3)$ & $0.02(23)$ & $242(37)$ & $10004.28(48)$ & $\ldots$ & $0.75(1)$ & 0.059 & 15 & 2.1 & 71 & $\mathrm{Nf4}$ \\
\hline & $\mathrm{c}$ & $238.10(46)$ & $63.0(1.7)$ & $0.185(28)$ & 214(11) & $10159.4(8.0)$ & $\ldots$ & $2.25(6)$ & 0.821 & $\ldots$ & $\ldots$ & $\ldots$ & \\
\hline & $\mathrm{d}$ & 1319(18) & $63.8(2.3)$ & $0.269(36)$ & $248(11)$ & $9963(53)$ & $\ldots$ & $3.95(13)$ & 2.57 & $\ldots$ & $\ldots$ & $\ldots$ & \\
\hline HD 10647 ......................... & $\mathrm{b}$ & $1040(37)$ & $18(1)$ & $0.18(8)$ & $68(17)$ & $12261(47)$ & & 0.91 & 2.1 & 8.2 & $\ldots$ & 72 & Мy3 \\
\hline HD 13445 ......................... & $\mathrm{b}$ & $15.78(4)$ & $380(1)$ & $0.046(4)$ & $270(4)$ & $11146.7(2)$ & -131 & 4 & 0.11 & 7 & $\ldots$ & 61 & Q0 \\
\hline 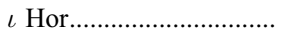 & $\mathrm{b}$ & $311.3(1.3)$ & $68(4)$ & $0.22(6)$ & $79(13)$ & $11309(20)$ & & $2.24(13)$ & 0.91 & 23.2 & 1.5 & 88 & $\mathrm{Nflb}$ \\
\hline$\epsilon$ Eri............... & $\mathrm{b}$ & $2502(20)$ & $19.0(1.7)$ & $0.608(41)$ & $48.9(4.1)$ & $9195(14)$ & $0.42(20)$ & 0.86 & & 14 & $\ldots$ & 225 & $\mathrm{H} 0$ \\
\hline HD 33636 & $\mathrm{~b}$ & $2828(750)$ & $168(15)$ & $0.55(10)$ & $340.2(6.1)$ & $11211(22)$ & $\ldots$ & 10.58 & 4.08 & 9 & 1.0 & 47 & $\operatorname{Pr} 3$ \\
\hline HD 45350 & $\mathrm{~b}$ & $962.1(4.4)$ & $57.4(1.8)$ & $0.764(11)$ & $388.7(4.1)$ & $11827.4(9.4)$ & $\ldots$ & $1.82(14)$ & $1.920(69)$ & 9.05 & 1.16 & 73 & Ed6 \\
\hline HD 50554 & $\mathrm{~b}$ & 1293(37) & 104(5) & $0.501(30)$ & $355.7(4.4)$ & 11832(15) & $\ldots$ & 5.16 & 2.41 & 11.8 & 1.3 & 41 & $\operatorname{Pr} 3$ \\
\hline HD 52265 & $\mathrm{~b}$ & $119.60(42)$ & $42(1)$ & $0.35(3)$ & $211(6)$ & $11422.3(1.7)$ & $\ldots$ & $1.05(3)$ & 0.5 & 7.3 & 0.84 & 71 & $\mathrm{Nflb}$ \\
\hline HD 75289 & $\mathrm{~b}$ & $3.5098(7)$ & $54(1)$ & $0.024(21)$ & $50(49)$ & $11355.91(48)$ & $\ldots$ & 0.42 & 0.046 & 7.5 & $\ldots$ & 88 & U0 \\
\hline \multirow{2}{*}{ 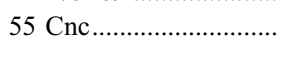 } & $\mathrm{b}$ & 14.647(1) & $78.3(1.8)$ & $0.030(23)$ & $63(12)$ & $10000.80(48)$ & & $0.91(2)$ & 0.115 & 9.0 & 1.4 & 48 & Nf4 \\
\hline & $\mathrm{d}$ & $4545(1421)$ & $37.8(3.9)$ & $0.24(13)$ & $347(23)$ & $10568(200)$ & $\ldots$ & $2.89(47)$ & 5.28 & $\ldots$ & $\ldots$ & $\ldots$ & \\
\hline HD $80606 \ldots \ldots \ldots \ldots \ldots \ldots$ & $\mathrm{b}$ & $111.81(23)$ & 411(31) & $0.927(12)$ & $291.0(6.7)$ & $11973.72(29)$ & $\ldots$ & $3.90(9)$ & 0.47 & 17.7 & $\ldots$ & 61 & Nf1 \\
\hline \multirow{2}{*}{ HD 82943} & $\mathrm{~b}$ & 435.1(1.4) & $45.8(1.0)$ & $0.18(4)$ & 237(13) & $11758(13)$ & $\ldots$ & 1.84 & 1.18 & 6.8 & $\ldots$ & 142 & My4 \\
\hline & $\mathrm{c}$ & $219.4(2)$ & $61.5(1.7)$ & $0.38(1)$ & $124(3)$ & $12284(1)$ & $\ldots$ & 1.85 & 0.75 & $\ldots$ & & $\ldots$ & \\
\hline HD 83443 ........................ & $\mathrm{b}$ & $2.98565(3)$ & $58.1(4)$ & $0.013(13)$ & $11(11)$ & $11497.5(3)$ & $\ldots$ & 3.58 & 0.96 & 9.0 & $\ldots$ & 257 & My4 \\
\hline HD 89744 & $\mathrm{~b}$ & $256.0(7)$ & 257(14) & $0.70(2)$ & 195(3) & 10994(2) & $\ldots$ & 7.2 & 0.88 & 20.5 & 1.6 & 88 & K0 \\
\hline HD 92788 & $\mathrm{~b}$ & $325.0(5)$ & $106.2(1.8)$ & $0.35(1)$ & $279(3)$ & $11090.3(3.5)$ & $\ldots$ & 3.58 & 0.96 & $\ldots$ & 8.0 & 55 & My4 \\
\hline $47 \mathrm{UMa}$ & $\mathrm{b}$ & $1100.8(7.2)$ & $53.6(1.9)$ & $0.097(39)$ & $300(20)$ & $12915(64)$ & $\ldots$ & $2.76(10)$ & 2.11 & 7.4 & 1.1 & 44 & $\mathrm{Nf4}$ \\
\hline HD 102117........................ & $\mathrm{b}$ & 20.67(4) & $10.2(4)$ & $0.00(7)$ & $162.8(3.0)$ & $13100.1(1)$ & $\ldots$ & 0.14 & 0.149 & 0.9 & $\ldots$ & 13 & Lv5 \\
\hline 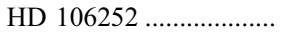 & $\mathrm{b}$ & $1600(18)$ & $147(4)$ & $0.471(28)$ & 292.2(3.2) & 11871(17) & $\ldots$ & 7.56 & 2.7 & 10.5 & 1.1 & 40 & $\operatorname{Pr} 3$ \\
\hline HD 108147 ...................... & $\mathrm{b}$ & 10.901(1) & $36(1)$ & $0.498(25)$ & $319.0(3.0)$ & 11591.6(1) & $\ldots$ & 0.4 & 0.104 & 9.2 & $\ldots$ & 118 & Pp2 \\
\hline 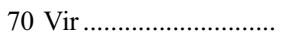 & $\mathrm{b}$ & $116.689(11)$ & $314.1(2.0)$ & $0.397(5)$ & $359.40(92)$ & $8990.39(33)$ & $\ldots$ & $6.56(4)$ & 0.456 & 6.1 & 0.93 & 35 & Nf4 \\
\hline HD $130322 \ldots \ldots \ldots \ldots \ldots \ldots$ & $\mathrm{b}$ & $10.720(7)$ & $115(2)$ & $0.044(18)$ & 204(23) & $11287.38(68)$ & $\ldots$ & 1.02 & 0.088 & 15.4 & $\ldots$ & 118 & U0 \\
\hline 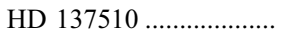 & $\mathrm{b}$ & $798.2(1.4)$ & $531.6(5.3)$ & $0.402(8)$ & $30.8(1.2)$ & $12582.0(2.6)$ & $\ldots$ & $26.0(1.4)$ & $1.85(5)$ & 15 & $\ldots$ & 76 & Ed4 \\
\hline 14 Her ............................. & $\mathrm{b}$ & $1796.4(8.3)$ & $90.3(1.0)$ & $0.338(11)$ & $22.6(2.0)$ & $9582(12)$ & $\ldots$ & $4.74(6)$ & 2.8 & 11.3 & 1.6 & 119 & Nf4 \\
\hline HD $149143 \ldots \ldots \ldots \ldots \ldots \ldots$ & $\mathrm{b}$ & $4.088(6)$ & $163(8)$ & $0.08(4)$ & $42(35)$ & $13588.00(40)$ & $\ldots$ & 1.36 & 0.052 & 13.3 & $\ldots$ & 8 & Da5 \\
\hline HD 168746 & $\mathrm{~b}$ & $6.403(1)$ & $27(1)$ & $0.081(29)$ & $16(21)$ & $11994.7(4)$ & $\ldots$ & 0.23 & 0.065 & 9.8 & $\ldots$ & 154 & $\mathrm{Pp} 2$ \\
\hline HD 178911...................... & $\mathrm{b}$ & $71.487(18)$ & $339.3(3.1)$ & $0.1243(75)$ & $169.8(3.6)$ & $10305.70(62)$ & $\ldots$ & $6.292(59)$ & & 11 & $\ldots$ & 51 & $\mathrm{Z} 2$ \\
\hline 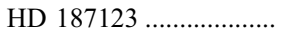 & $\mathrm{b}$ & $3.0966(1)$ & $70.7(1.7)$ & $0^{\mathrm{a}}$ & $0^{\mathrm{a}}$ & $11010.972(27)$ & $-8.9(9)$ & $0.52(1)$ & 0.042 & 10.5 & 1.2 & 57 & Nf4 \\
\hline HD 190360 & $\mathrm{~b}$ & $3902(1758)$ & $20(3)$ & $0.48(20)$ & 1(13) & 10557(89) & $\ldots$ & $1.33(19)$ & 4.8 & 9.3 & 1.3 & 69 & Nf3 \\
\hline HD 192263 & $\mathrm{~b}$ & $24.348(5)$ & $61(1)$ & $0^{\mathrm{a}}$ & $0^{\mathrm{a}}$ & $11979.28(8)$ & $\ldots$ & 0.72 & 0.15 & 12.5 & $\ldots$ & 182 & Sn3 \\
\hline HD $196050 \ldots \ldots \ldots \ldots \ldots \ldots$ & $\mathrm{b}$ & $1321(54)$ & $55.0(6.2)$ & $0.3^{\mathrm{a}}$ & $147(12)$ & $12045(66)$ & $\ldots$ & 3.02 & 2.43 & 7.2 & $\ldots$ & 31 & My4 \\
\hline HD 209458 & $\mathrm{~b}$ & $3.5246(1)$ & $85.1(1.0)$ & $0^{\mathrm{a}}$ & $0^{\mathrm{a}}$ & $12765.790(21)$ & $\ldots$ & $0.699(7)$ & 0.048 & 14.9 & 1.5 & 187 & $\mathrm{Nf4}$ \\
\hline 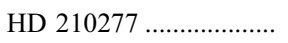 & $\mathrm{b}$ & $436.6^{\mathrm{a}}$ & $52(9)$ & $0.342(55)$ & $104(13)$ & $11410(13)$ & $\ldots$ & $1.73(29)$ & 1.09 & 7.5 & 0.82 & 42 & $\mathrm{Nf} 1 \mathrm{~b}$ \\
\hline HD $213240 \ldots \ldots \ldots \ldots \ldots \ldots$ & $\mathrm{b}$ & 951(42) & 91(3) & $0.45(4)$ & 214(7) & $11520(11)$ & $\ldots$ & 4.5 & 2.03 & 11 & $\ldots$ & 72 & Sn1 \\
\hline$\rho$ Ind & $\mathrm{b}$ & $1256(35)$ & $34.6(5.7)$ & $0.29(12)$ & $63(22)$ & 10693(13) & $\ldots$ & 1.82 & 2.32 & 7.2 & $\ldots$ & 21 & My4 \\
\hline 51 Peg ............................ & $\mathrm{b}$ & $4.23077(4)$ & $57.3(8)$ & $0^{\mathrm{a}}$ & $0^{\mathrm{a}}$ & $12497.000(22)$ & $\ldots$ & $0.468(7)$ & 0.052 & 11.8 & 1.64 & 153 & $\mathrm{Nf} 4$ \\
\hline HD 217107 ....................... & $\mathrm{b}$ & $7.1260(5)$ & $140(1)$ & $0.126(9)$ & 24.4 & $11452.388(79)$ & 43.3 & $1.275(13)$ & & 7.0 & $\ldots$ & 63 & $\mathrm{Nflb}$ \\
\hline
\end{tabular}

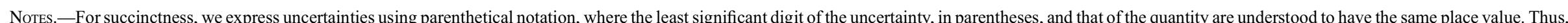

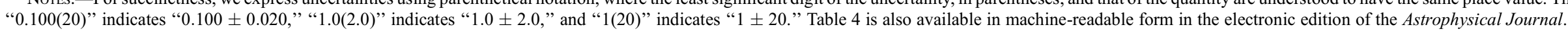
a Parameter held fixed in fit.

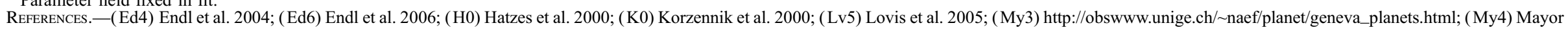
et al. 2004; (Nf1) Naef et al. 2001a; (Nf1b) Naef et al. 2001b; (Nf4) Naef et al. 2004; (Pp2) Pepe et al. 2002; (Pr3) Perrier et al. 2003; (Q0) Queloz et al. 2000; (Sn1) Santos et al. 2001; (U0) Udry et al. 2000. 


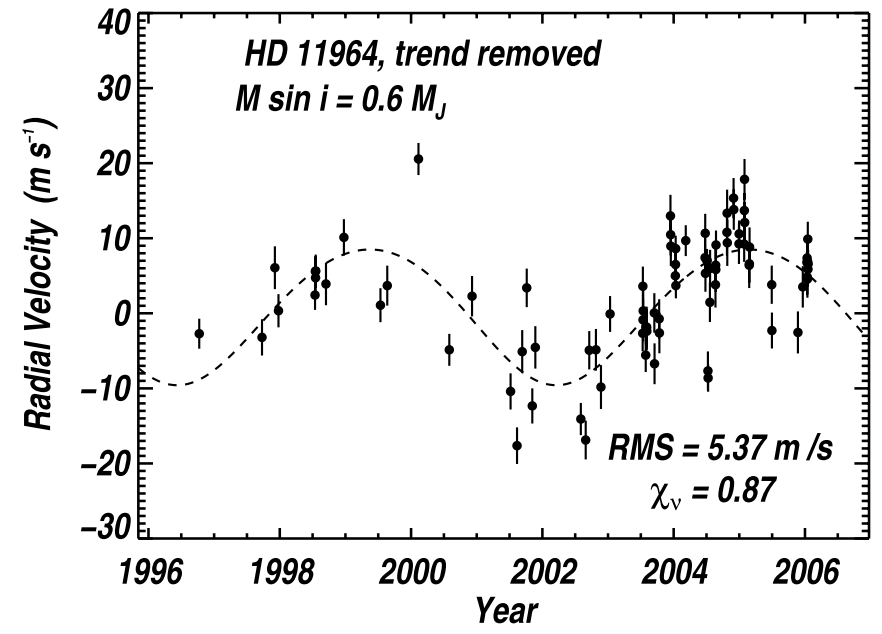

FIG. 1.-Best-fit orbit to the radial velocities measured at Keck Observatory for HD 11964, with $P=5.8 \mathrm{yr}, e \sim 0$, and $M \sin i=0.6 M_{\mathrm{J}}$.

solution is of comparable quality to that in Table 3 , we reproduce it in Table 4.

\section{NEW EXOPLANETS}

We announce here five new exoplanets, HD 11964b, HD 66428b, HD 99109b, HD 107148b, and HD 164922b (see Figs. 15 , respectively). Their orbital parameters and the properties of their host stars are listed among the other entries in the tables below. The data for these detections were obtained at Keck Observatory. All of these exoplanets orbit inactive stars $\left(\log R_{H K}^{\prime}<-5\right)$ that are metal$\operatorname{rich}([\mathrm{Fe} / \mathrm{H}]>0.1)$.

HD 11964 is somewhat evolved, sitting 2 mag above the main sequence. The fit for HD $11964 \mathrm{~b}$ is good, but the $5.3 \mathrm{~m} \mathrm{~s}^{-1}$ residuals are comparable to the $9 \mathrm{~m} \mathrm{~s}^{-1}$ amplitude, placing the exoplanetary interpretation of the velocity variations somewhat in doubt.

\section{DISCUSSION}

For many exoplanets we find an improved orbital solution when we superimpose a linear trend and the velocity curve. Such systems likely contain additional companions of indeterminate mass and orbital periods substantially longer than the span of the observations. When such systems are observed long enough that the radial velocity signature of these more distant companions begins to deviate from a linear trend, these fits naturally

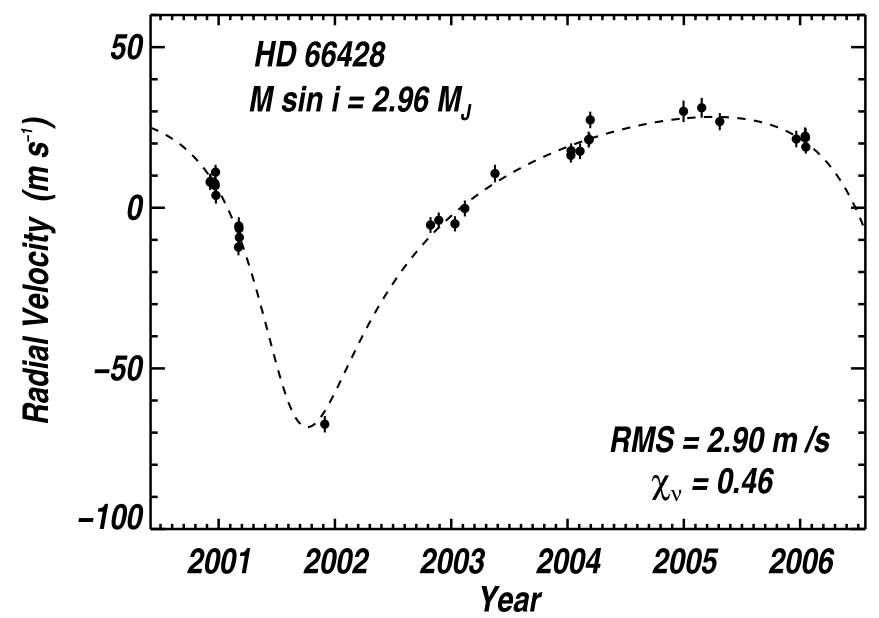

FIG. 2.-Best-fit orbit to the radial velocities measured at Keck Observatory for HD 66428, with $P=5.4 \mathrm{yr}, e=0.5$, and $M \sin i=3 M_{\mathrm{J}}$.

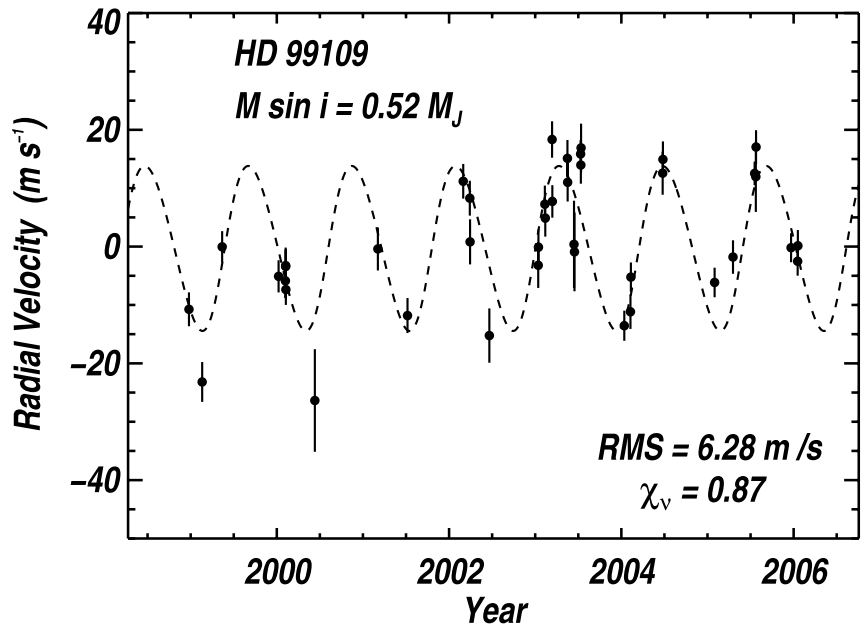

FIG. 3.-Best-fit orbit to the radial velocities measured at Keck Observatory for HD 99109, with $P=1.2 \mathrm{yr}, e \sim 0$, and $M \sin i=0.5 M_{\mathrm{J}}$.

become poor, even though double-Keplerian fits remain poorly constrained.

An excellent example is HD 13445b, which shows a strong trend of roughly $-95 \mathrm{~m} \mathrm{~s}^{-1}$, consistent with the presence of a massive companion beyond $4 \mathrm{AU}$. The poor quality of the fit $\left[\left(\chi_{\nu}^{2}\right)^{1 / 2}=2.1\right]$ may indicate curvature in the signal of the massive companion: indeed a double-Keplerian fit with an outer planet with $P>10 \mathrm{yr}$ produces a fit with an $\mathrm{rms}$ of $4 \mathrm{~m} \mathrm{~s}^{-1}$. This may be consistent with reports of a massive companion at $20 \mathrm{AU}$ (Eggenberger et al. 2003; Els et al. 2001). A second example is HD 68988, where the rms of the residuals of a double-Keplerian is $3.3 \mathrm{~m} \mathrm{~s}^{-1}$, down from $6.4 \mathrm{~m} \mathrm{~s}^{-1}$ for a single-Keplerian plus trend model. In both of these cases the mass and period of the more distant companion are underconstrained, so the planetary nature of the companion is uncertain.

A forthcoming work (J. T. Wright et al. 2006, in preparation) will comb the archive of velocities in Table 1 for companions, such as HD 13345c and HD 68988c, of uncertain mass and orbital period.

$v$ And.-The precision of the Lick data prior to 1995 is not as high as today (pre-1995 data scatter about the fit with an rms of $\sim 100 \mathrm{~m} \mathrm{~s}^{-1}$ ), and data before 1992 are particularly suspicious. The orbital elements in Table 3 represent a fit with data taken before 1992 excluded; Table 1 includes these pre-1992 data.

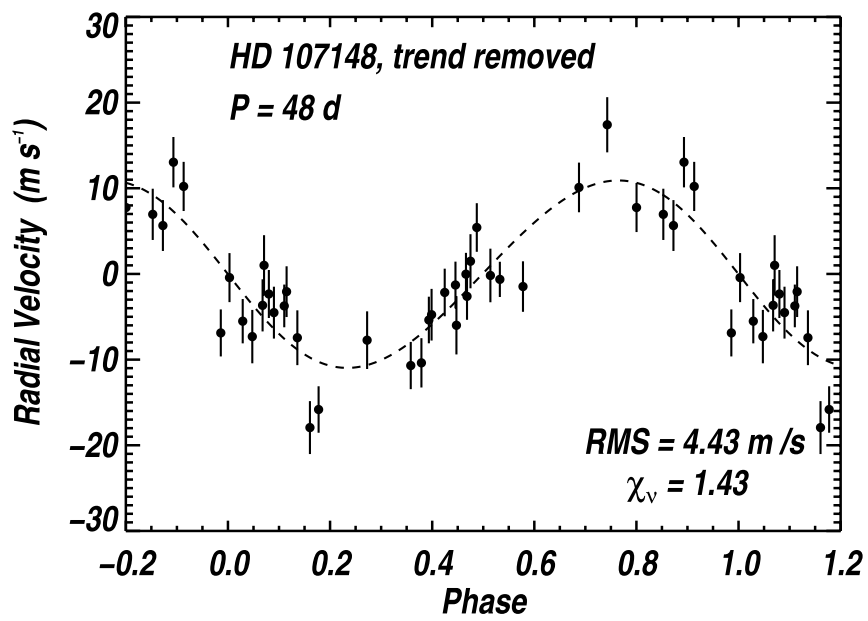

FIG. 4.-Best-fit orbit to the radial velocities measured at Keck Observatory for $\mathrm{HD} 107148$, with $P=48$ days, $e \sim 0$, and $M \sin i=0.2 M_{\mathrm{J}}$. 


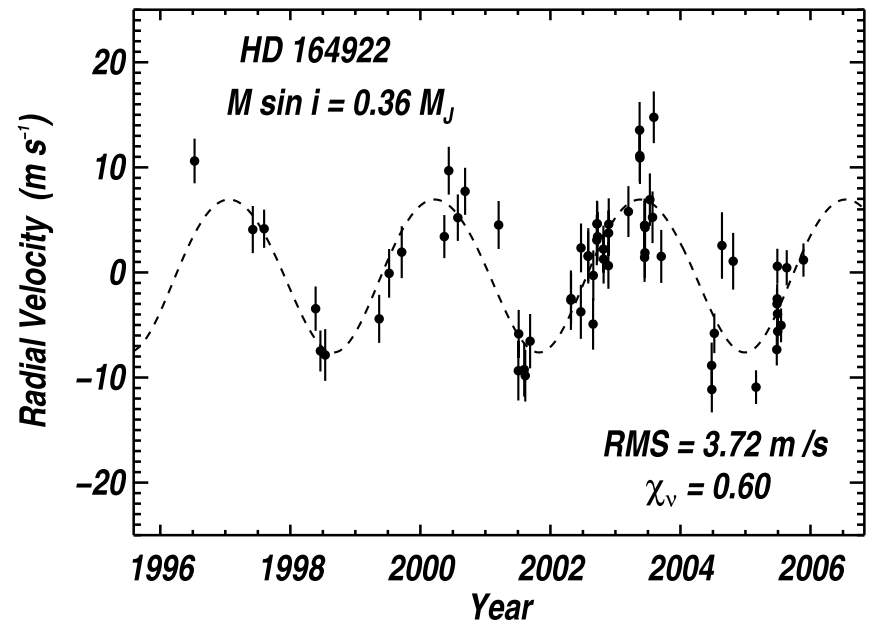

FIG. 5.-Best-fit orbit to the radial velocities measured at Keck Observatory for HD 164922, with $P=3.2 \mathrm{yr}, e \sim 0$, and $M \sin i=0.4 M_{\mathrm{J}}$.

HD 73526b, HD 73526c.-These planets are in a $2: 1$ orbital resonance. The dynamics of the system is discussed in Tinney et al. (2006).

$\tau$ Boo $b$.- The residuals to the fit of the 3.31 day planet orbiting $\tau$ Boo show a trend of $15 \mathrm{~m} \mathrm{~s}^{-1} \mathrm{yr}^{-1}$ and may also show some curvature. The precision of the Lick data prior to 1995 is not as high as it is today (the fit for these times shows scatter of $\sim 100 \mathrm{~m} \mathrm{~s}^{-1}$ ) and may not be reliable for constraining the properties of the second companion.

$H D$ 149026b. - This planet transits its parent star. Sato et al. (2005) find $R=0.726 R_{\mathrm{J}} \pm 0.064 R_{\mathrm{J}}$ and $i=85^{\circ} .8_{-1.3}^{+1.6}$. The semiamplitude, $K$, and goodness-of-fit parameters in Table 3 represent the fit from data presented here, with $P$ and $T_{t}$ held fixed at the values from Charbonneau et al. (2006).

TrES-1.-This planet transits its parent star, 2MASS 19040985+3637574 (GSC 02652-01324). Alonso et al. (2004) find $R=1.08_{-0.04}^{+0.18} R_{\mathrm{J}}$ and $i=88^{\circ} .5_{-2.2}^{+1^{\circ} .5}$. The semiamplitude, $K$, and goodness-of-fit parameters in Table 3 represent the fit from data presented here, with $P$ and $T_{t}$ held fixed at the values from Alonso et al. (2004).

$H D$ 189733b.-This planet transits its parent star. Bouchy et al. (2005b) find $i=85^{\circ} .3 \pm 0.1$ and $R=1.26 R_{\mathrm{J}} \pm 0.03 R_{\mathrm{J}}$.

$H D$ 209458b. - This planet transits its parent star. Brown et al. (2001) find $i=86^{\circ} .1 \pm 00^{\circ} .1$ and $R=1.347 R_{\mathrm{J}} \pm 0.06 R_{\mathrm{J}}$, and Laughlin et al. (2005) find an eccentricity consistent with 0 . The semiamplitude, $K$, and goodness-of-fit parameters in Table 3 represent the fit from data presented here, with $P$ and $T_{t}$ held fixed at the values from Wittenmyer et al. (2004).

\section{DISTRIBUTION OF EXOPLANETS}

Figures 6-11 show the distribution of the exoplanets in this catalog. One must take care when interpreting these figures for at least two reasons: (1) selection effects make some aspects of these distributions inconsistent with the parent population of exoplanets, and (2) the selection effects of the various planet search programs are different. Marcy et al. (2005a) analyze the properties and distribution of planets detected around 1330 FGKM dwarfs monitored at Lick, Keck, and the AAT and discuss the biases in and uniformity of that sample. The figures presented here are best interpreted as describing the distribution of properties of the known exoplanets as drawn from multiple, nonuniform samples, as opposed to that of the parent population of exoplanets.
The target list for the California \& Carnegie and AngloAustralian planet searches has been published in Wright et al. (2004), Nidever et al. (2002), and Jones et al. (2002). A complete target list for the Geneva group is not public and not recoverable, although a list of HARPS target stars is currently available on the ESO Web site. ${ }^{13}$ Both searches may be considered roughly magnitude limited within a set of $B-V$ bins excluding giant stars, but both groups have also added additional stars using other criteria (such as metallicity).

Figure 6 shows the minimum mass distribution of the 167 known nearby exoplanets with $M \sin i<15$ AU. The mass distribution shows a dramatic decrease in the number of planets at high masses, a decrease that is roughly characterized by a power law, $d N / d M \propto M^{-1.1}$, affected very little by the unknown $\sin i$ (Jorissen et al. 2001). We have calculated the exponent in this power law with a linear least-squares fit to the logarithm of the mass distribution assuming Poisson errors. We neglected uncertainties in the masses of the planets due to uncertainties in stellar masses and the $\sin i$ ambiguity. For this reason, and because the surveys that detected these planets have heterogeneous selection effects, we regard this power law simply as a rough description of the distribution of known planets. A. Cumming et al. (2006, in preparation) find, for the more uniform sample of the California $\&$ Carnegie planet search, that the distribution of planets with $P>100$ days is well fitted with a broken power law:

$$
d N / d M \propto \begin{cases}M^{-1.2}, & M<0.6 M_{\mathrm{J}}, \\ M^{-1.9}, & M>0.6 M_{\mathrm{J}} .\end{cases}
$$

The low end of this distribution suffers from a selection effect common to all Doppler surveys: low-mass planets induce small velocity variations and so are difficult to detect and underrepresented in Figure 6. Massive planets are easier to detect, making the apparent paucity of planets with $M>3 M_{\mathrm{J}}$ and that of objects with $M>12 M_{\text {J }}$ (the "brown dwarf desert") real.

Figure 7 shows the orbital distance distribution of the 167 known nearby exoplanets with $0.03 \mathrm{AU}<a<10$ AU. Since orbital distance is a function of orbital period, the existing Doppler

${ }^{13}$ See http://www.eso.org/observing/proposals/gto/harps.

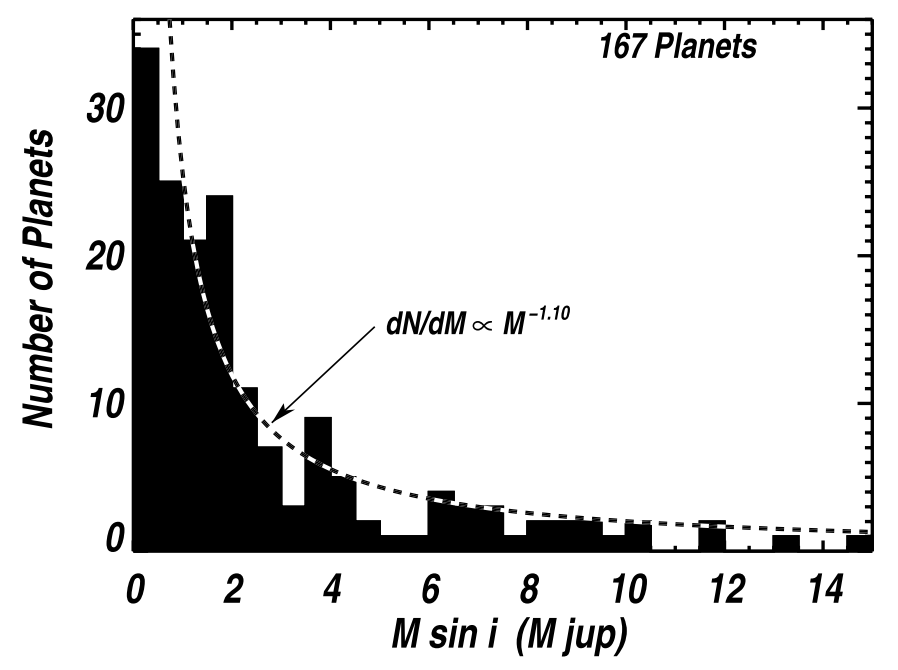

FIG. 6.-Minimum mass distribution of the 167 known nearby exoplanets with $M \sin i<15 M_{\mathrm{J}}$. The mass distribution shows a dramatic decrease in the number of planets at high masses, a decrease that is roughly characterized by a power law, $d N / d M \propto M^{-1.16}$. Lower mass planets have smaller Doppler amplitudes and are thus more difficult to detect. This distribution represents results from many surveys and so is drawn from an inhomogeneous sample. 


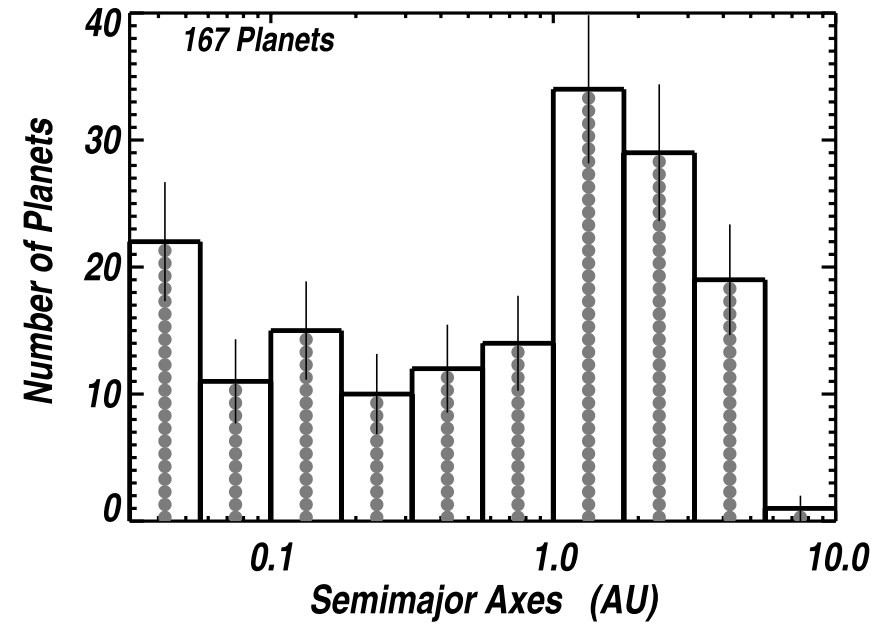

FIG. 7.-Orbital distance distribution of the 167 known nearby exoplanets with $0.03 \mathrm{AU}<a<10 \mathrm{AU}$ in logarithmic distance bins. Planets with $a>3 \mathrm{AU}$ have periods comparable to or longer than the length of most Doppler surveys, so the distribution is incomplete beyond that distance. This distribution represents results from many surveys and so is drawn from an inhomogeneous sample.

surveys are increasingly incomplete for $a \gtrsim 3 \mathrm{AU}$, corresponding to $P \gtrsim 5$ yr. Note that the abscissa is logarithmic. Among the 1330 FGKM dwarfs studied by Marcy et al. (2005a), the occurrence rate of planets within $0.1 \mathrm{AU}$ is $1.2 \%$. A modest (flat) extrapolation beyond $3 \mathrm{AU}$ (in logarithmic bins) suggests that there exist roughly as many planets at distances between 3 and $30 \mathrm{AU}$ as below $3 \mathrm{AU}$, making the occurrence of giant planets roughly $12 \%$ within $30 \mathrm{AU}$. The rapid rise of planet frequency with semimajor axis beyond $0.5 \mathrm{AU}$ portends a large population of Jupiter-like planets beyond 3 AU.

Figure 8 shows the distribution of periods among the known nearby "hot jupiters." There is a clear "pileup" of planets with orbital periods near 3 days, suggesting that whatever orbital migration mechanism brings these giant planets close to their parent stars ceases when they reach this period. Alternatively, some breaking mechanism may stop them there, or may weaken inward of the distance, sending the planets into the star. Note that the Doppler surveys generally have uniform sensitivity to hot jupiters at all

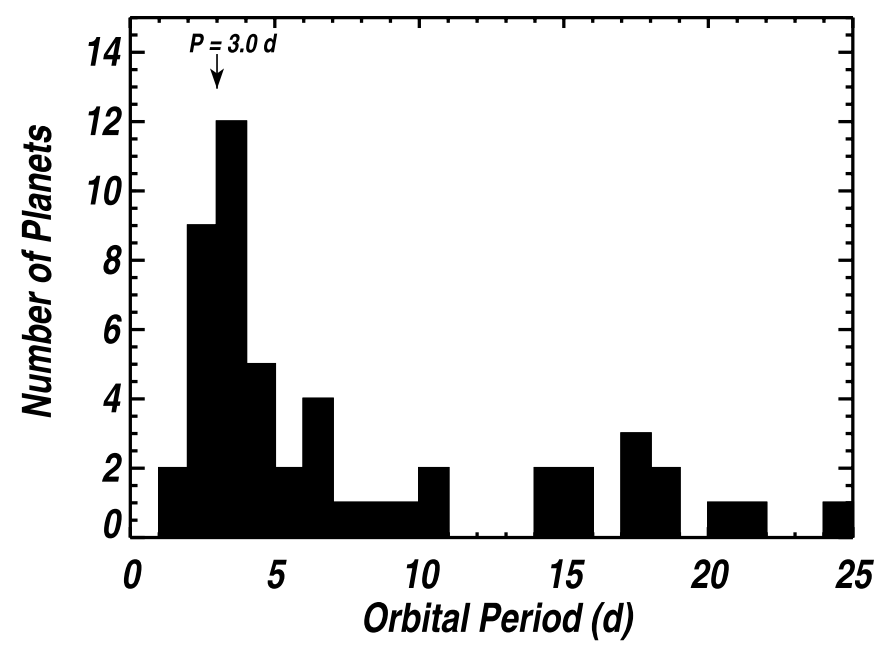

FIG. 8.-Distribution of periods among the known nearby hot jupiters. There is a clear pileup of planets with orbital periods near 3 days. Doppler surveys generally have uniform sensitivity to hot jupiters, so for massive planets there is no important selection effect contributing to the 3 day pileup. This distribution represents results from many surveys and so is drawn from an inhomogeneous sample.

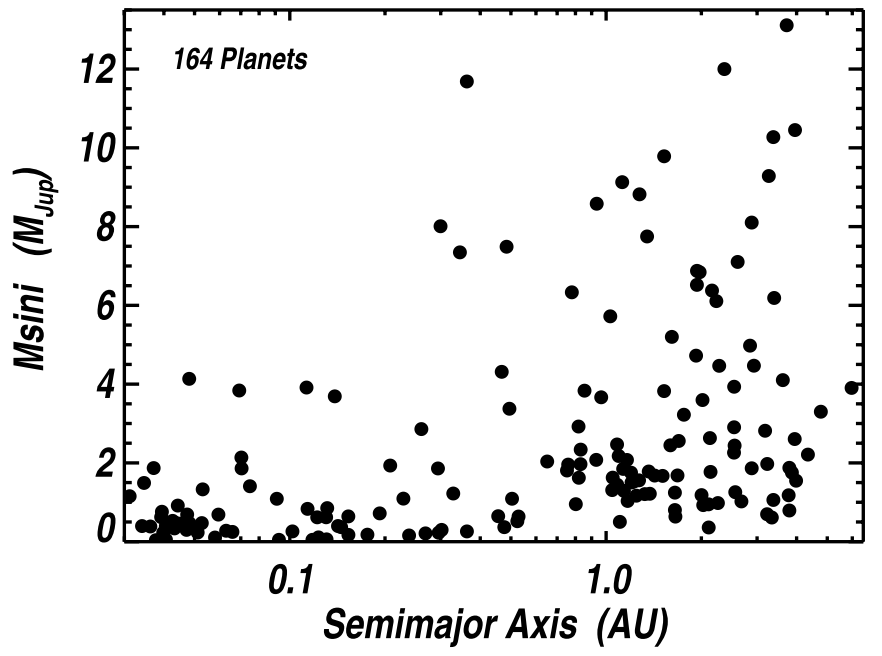

FIG. 9.-Minimum mass as a function of semimajor axis for the 164 known nearby exoplanets with $0.03 \mathrm{AU}<a<6.5 \mathrm{AU}$. Doppler surveys are generally incomplete for exoplanets with $a>3 \mathrm{AU}$, low-mass planets $\left(M \sin i<1 M_{\mathrm{J}}\right)$ beyond $1 \mathrm{AU}$, and very low mass planets $\left(M \sin i<0.1 M_{\mathrm{J}}\right)$ everywhere. This plot represents results from many surveys and so is drawn from an inhomogeneous sample.

of the orbital periods in Figure 8, so for massive planets there is no important selection effect contributing to the 3 day pileup.

Figure 9 shows minimum mass as a function of semimajor axis for the 164 known nearby exoplanets with $0.03 \mathrm{AU}<$ $a<6.5 \mathrm{AU}$. There is a dearth of close-in exoplanets with high mass that cannot be due to a selection effect since high-mass planets have large Doppler signatures; indeed Doppler surveys are generally complete with respect to high-mass, close-in exoplanets. Selection effects make detection of low-mass planets beyond $1 \mathrm{AU}$ difficult, however, so it is not clear that the mass distribution for planets beyond $1 \mathrm{AU}$ is different from that of hot jupiters.

Figure 10 shows orbital eccentricity as a function of semimajor axis for 168 known nearby exoplanets. Planets within $0.1 \mathrm{AU}$ are nearly always on circular or nearly circular orbits, presumably due to tidal circularization. Beyond $0.3 \mathrm{AU}$, the

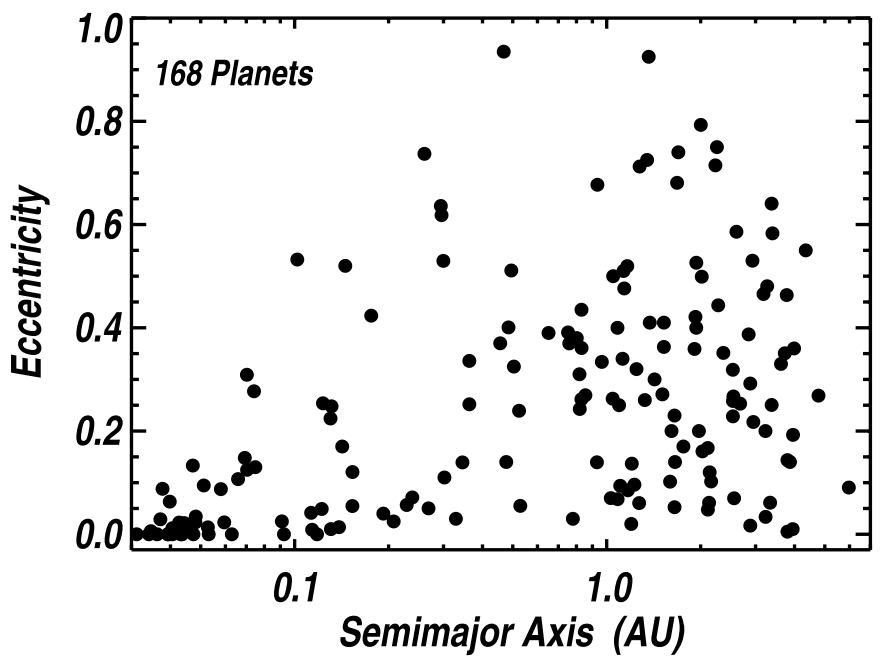

FIG. 10.-Orbital eccentricity as a function of semimajor axis for the 168 known nearby exoplanets. Planets within $0.1 \mathrm{AU}$ are presumably tidally circularized. Beyond 0.1 AU, the distribution of eccentricities appears essentially uniform between 0 and 0.8 . For most Doppler surveys, sensitivity is not a strong function of eccentricity for $0<e<0.8$ and $a<3 \mathrm{AU}$. This plot represents results from many surveys and so is drawn from an inhomogeneous sample. 


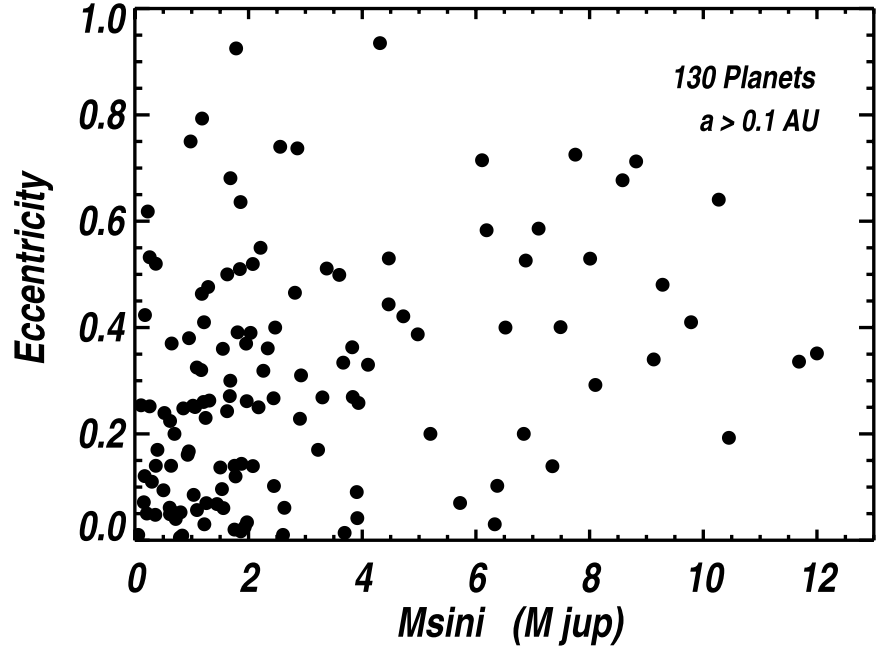

FIG. 11.-Distribution of orbital eccentricities as a function of minimum mass for the 130 known nearby exoplanets with $M \sin i<13 M_{\mathrm{J}}$, excluding those for which $a<0.1$ AU, i.e., those planets that may have been tidally circularized. High-mass exoplanets ( $\left.M \sin i>5 M_{\mathrm{J}}\right)$ have a slightly higher median eccentricity than lower mass exoplanets. The completeness of Doppler surveys increases with $M \sin i$ and is generally insensitive to eccentricity. This distribution represents results from many surveys and so is drawn from an inhomogeneous sample.

distribution of eccentricities appears essentially uniform between 0 and 0.8 . For most Doppler surveys, sensitivity is not a strong function of eccentricity for $0<e<0.7$ and $a<3$ AU.

Figure 11 shows orbital eccentricity as a function of minimum mass for nearby exoplanets with $M \sin i<13 M_{\mathrm{J}}$. We have excluded those planets that may have been tidally circularized, i.e., those for which $a<0.1$ AU. This figure shows no strong correlation between eccentricity and mass, but close inspection shows that high-mass exoplanets $\left(M \sin i>5 M_{\mathrm{J}}\right)$ have a higher median eccentricity than lower mass exoplanets.

\section{CONCLUSIONS}

We have remeasured precise orbital elements for planets orbiting stars for which we have precision radial velocity data from Keck, Lick, and AAO using the latest data and improved data reduction techniques. In addition, we have compiled the pub- lished orbital parameters of all other exoplanets within $200 \mathrm{pc}$, as well as spectroscopically derived stellar parameters of their host stars. Finally, we present four new extrasolar planets, bringing to 172 the total of known exoplanets in this catalog with a minimum mass $M \sin i<24 M_{\mathrm{J}}$.

The 172 known exoplanets span a range of eccentricities, which weakly correlate with minimum planetary mass. Planets within $0.1 \mathrm{AU}$ are nearly always in circular orbits, presumably due to tidal circularization. The 3 day pileup and the brown dwarf desert are both strongly apparent and unaffected by the important observational biases. Finally, the mass distribution increases sharply toward lower masses (roughly as the inverse of the minimum planetary mass) and toward larger orbital distance. Since these regions are where current surveys are most incomplete, this implies that many more low-mass and long-period planets await discovery as Doppler surveys cover a longer time baseline and become more precise. A forthcoming work will discuss some more speculative exoplanet candidates of this nature just emerging from our planet searches.

The authors wish to thank the many observers over many years who helped gather the data herein at telescopes around the world, as well as the many collaborators who helped reduce, analyze, and interpret this inestimable data set, including Jeff Valenti, Bernie Walp, Andrew Cumming, Eugenio Rivera, Greg Laughlin, Sabine Frink, Tony Misch, Grant Hill, David Nidever, Eric Nielsen, Amy Reines, Joe Barranco, Bob Noyes, Eric Williams, Preet Dosanjh, Mike Eiklenborg, Mario Savio, Heather Hauser, and Barbara Schaefer. The authors are also grateful for the careful attention Kevin Apps has given this paper and our planet searches.

The authors wish to recognize and acknowledge the very significant cultural role and reverence that the summit of Mauna Kea has always had within the indigenous Hawaiian community. We are most fortunate to have the opportunity to conduct observations from this mountain.

This research has made use of the SIMBAD database, operated at CDS, Strasbourg, France, and of NASA's Astrophysics Data System Bibliographic Services and is made possible by the generous support of Sun Microsystems, NASA, and the NSF.
Allende Prieto, C., \& Lambert, D. L. 1999, A\&A, 352, 555

Alonso, R., et al. 2004, ApJ, 613, L153

Benedict, G. F., et al. 2001, AJ, 121, 1607

Bonfils, X., et al. 2005, A\&A, 443, L15

Bouchy, F., Pont, F., Melo, C., Santos, N. C., Mayor, M., Queloz, D., \& Udry, S. 2005a, A\&A, 431, 1105

Bouchy, F., et al. 2005b, A\&A, 444, L15

Brown, T. M., Charbonneau, D., Gilliland, R. L., Noyes, R. W., \& Burrows, A. 2001, ApJ, 552, 699

Butler, R. P., \& Marcy, G. W. 1996, ApJ, 464, L153

Butler, R. P., Marcy, G. W., Vogt, S. S., \& Apps, K. 1998, PASP, 110, 1389

Butler, R. P., Marcy, G. W., Vogt, S. S., Fischer, D. A., Henry, G. W., Laughlin, G., \& Wright, J. T. 2003, ApJ, 582, 455

Butler, R. P., Marcy, G. W., Williams, E., McCarthy, C., Dosanjh, P., \& Vogt, S. S. 1996, PASP, 108, 500

Butler, R. P., Vogt, S. S., Marcy, G. W., Fischer, D. A., Wright, J. T., Henry, G. W., Laughlin, G., \& Lissauer, J. J. 2004, ApJ, 617, 580

Butler, R. P., et al. 2002, ApJ, 578, 565

Charbonneau, D., Brown, T. M., Latham, D. W., \& Mayor, M. 2000, ApJ, 529, L45

Charbonneau, D., et al. 2005, ApJ, 626, 523 2006, ApJ, 636, 445

Chauvin, G., Lagrange, A.-M., Dumas, C., Zuckerman, B., Mouillet, D., Song, I., Beuzit, J.-L., \& Lowrance, P. 2004, A\&A, 425, L29

Cochran, W. D., Hatzes, A. P., Butler, R. P., \& Marcy, G. W. 1997, ApJ, 483, 457

\section{REFERENCES}

Cochran, W. D., et al. 2004, ApJ, 611, L133

Correia, A. C. M., Udry, S., Mayor, M., Laskar, J., Naef, D., Pepe, F., Queloz, D., \& Santos, N. C. 2005, A\&A, 440, 751

da Silva, R., et al. 2006, A\&A, 446, 717

Delfosse, X., Forveille, T., Mayor, M., Perrier, C., Naef, D., \& Queloz, D. 1998, A\&A, 338, L67

Diego, F., Charalambous, A., Fish, A. C., \& Walker, D. D. 1990, Proc. Soc. Photo-Opt. Instr. Eng., 1235, 562

Eaton, J. A., Henry, G. W., \& Fekel, F. C. 2003, in The Future of Small Telescopes in the New Millennium, Volume II-The Telescopes We Use, ed. T. D. Oswalt (Dordrecht: Kluwer), 189

Eggenberger, A., Mayor, M., Naef, D., Pepe, F., Santos, N. C., Udry, S., \& Lovis, C. 2006, A\&A, 447, 1159

Eggenberger, A., Udry, S., \& Mayor, M. 2003, in ASP Conf. Ser. 294, Scientific Frontiers in Research on Extrasolar Planets, ed. D. Deming \& S. Seager (San Francisco: ASP), 43

Els, S. G., Sterzik, M. F., Marchis, F., Pantin, E., Endl, M., \& Kürster, M. 2001, A\&A, 370, L1

Endl, M., Cochran, W. D., Tull, R. G., \& MacQueen, P. J. 2003, AJ, 126, 3099

Endl, M., Cochran, W. D., Wittenmyer, R. A., \& Hatzes, A. P. 2006, preprint (astro-ph/0603007)

Endl, M., Hatzes, A. P., Cochran, W. D., McArthur, B., Allende Prieto, C., Paulson, D. B., Guenther, E., \& Bedalov, A. 2004, ApJ, 611, 1121

Fischer, D. A., Marcy, G. W., Butler, R. P., Laughlin, G., \& Vogt, S. S. 2002, ApJ, 564, 1028 
Fischer, D. A., Marcy, G. W., Butler, R. P., Vogt, S. S., \& Apps, K. 1999, PASP, 111,50

Fischer, D. A., et al. 2005, ApJ, 620, 481 2006, ApJ, 637, 1094

Flower, P. J. 1996, ApJ, 469, 355

Fuhrmann, K. 2004, Astron. Nachr., 325, 3

Galland, F., Lagrange, A.-M., Udry, S., Chelli, A., Pepe, F., Beuzit, J.-L., \& Mayor, M. 2005, A\&A, 444, L21

Ge, J., et al. 2006, ApJ, in press (astro-ph/0605247)

Gonzalez, G., Wallerstein, G., \& Saar, S. H. 1999, ApJ, 511, L111

Halbwachs, J. L., Arenou, F., Mayor, M., Udry, S., \& Queloz, D. 2000, A\&A, 355,581

Hatzes, A. P., Cochran, W. D., Endl, M., McArthur, B., Paulson, D. B., Walker, G. A. H., Campbell, B., \& Yang, S. 2003, ApJ, 599, 1383

Hatzes, A. P., et al. 2000, ApJ, 544, L145

Henry, G. W. 1999, PASP, 111, 845

Henry, G. W., Baliunas, S. L., Donahue, R. A., Fekel, F. C., \& Soon, W. 2000, ApJ, 531, 415

Jenkins, J. S., Jones, H. R. A., Tinney, C. G., Butler, R. P., McCarthy, C., Marcy, G. W., Pinfield, D. J., Carter, B. D., \& Penny, A. J. 2005, MNRAS, submitted

Jones, H. R. A., Butler, R. P., Tinney, C. G., Marcy, G. W., Carter, C. G., Penny, A. J., McCarthy, C., \& Bailey, J. 2006, MNRAS, 369, 249

Jones, H. R. A., Paul Butler, R., Marcy, G. W., Tinney, C. G., Penny, A. J., McCarthy, C., \& Carter, B. D. 2002, MNRAS, 337, 1170

Jorissen, A., Mayor, M., \& Udry, S. 2001, A\&A, 379, 992

Konacki, M., Torres, G., Sasselov, D. D., \& Jha, S. 2003, ApJ, 597, 1076

Korzennik, S. G., Brown, T. M., Fischer, D. A., Nisenson, P., \& Noyes, R. W. 2000, ApJ, 533, L147

Kürster, M., et al. 2003, A\&A, 403, 1077

Latham, D. W., Stefanik, R. P., Mazeh, T., Mayor, M., \& Burki, G. 1989, Nature, 339, 38

Laughlin, G., Marcy, G. W., Vogt, S. S., Fischer, D. A., \& Butler, R. P. 2005, ApJ, 629, L121

Lee, M. H., Butler, R. P., Fischer, D. A., Marcy, G. W., \& Vogt, S. S. 2006, ApJ, 641, 1178

Lo Curto, G., et al. 2006, A\&A, 451, 345

Lovis, C., et al. 2005, A\&A, 437, 1121

Marcy, G., Butler, R. P., Fischer, D., Vogt, S., Wright, J. T., Tinney, C. G., \& Jones, H. R. A. 2005a, Prog. Theor. Phys. Suppl., 158, 24

Marcy, G. W., \& Benitz, K. J. 1989, ApJ, 344, 441

Marcy, G. W., \& Butler, R. P. 1996, ApJ, 464, L147

2000, PASP, 112, 137

Marcy, G. W., Butler, R. P., Vogt, S. S., Fischer, D. A., Henry, G. W., Laughlin, G., Wright, J. T., \& Johnson, J. A. 2005b, ApJ, 619, 570

Marcy, G. W., Butler, R. P., Williams, E., Bildsten, L., Graham, J. R., Ghez, A. M., \& Jernigan, J. G. 1997, ApJ, 481, 926

Mayor, M., \& Queloz, D. 1995, Nature, 378, 355

Mayor, M., \& Santos, N. C. 2003, in Astronomy, Cosmology and Fundamental Physics, ed. P. A. Shaver, L. DiLella, \& A. Giménez (Berlin: Springer), 359

Mayor, M., Udry, S., Naef, D., Pepe, F., Queloz, D., Santos, N. C., \& Burnet, M. 2004, A\&A, 415, 391

McArthur, B. E., et al. 2004, ApJ, 614, L81

McCarthy, C., Butler, R. P., Tinney, C. G., Jones, H. R. A., Marcy, G. W., Carter, B., Penny, A. J., \& Fischer, D. A. 2004, ApJ, 617, 575

Moutou, C., et al. 2005, A\&A, 439, 367

Naef, D., Mayor, M., Beuzit, J. L., Perrier, C., Queloz, D., Sivan, J. P., \& Udry, S. 2004, A\&A, 414, 351

Naef, D., Mayor, M., Pepe, F., Queloz, D., Santos, N. C., Udry, S., \& Burnet, M. 2001a, A\&A, 375, 205

Naef, D., et al. 2001b, A\&A, 375, L27 2003, A\&A, 410, 1051

Neuhäuser, R., Guenther, E. W., Wuchterl, G., Mugrauer, M., Bedalov, A., \& Hauschildt, P. H. 2005, A\&A, 435, L13
Nidever, D. L., Marcy, G. W., Butler, R. P., Fischer, D. A., \& Vogt, S. S. 2002, ApJS, 141, 503

Nordström, B., et al. 2004, A\&A, 418, 989

Noyes, R. W., Contos, A. R., Korzennik, S. G., Nisenson, P., Brown, T. M., \& Horner, S. D. 1999, in IAU Colloq. 170, Precise Stellar Radial Velocities, ed. J. B. Hearnshaw \& C. D. Scarfe (ASP Conf. Ser. 185; San Francisco: ASP), 162

Noyes, R. W., Jha, S., Korzennik, S. G., Krockenberger, M., Nisenson, P., Brown, T. M., Kennelly, E. J., \& Horner, S. D. 1997, ApJ, 483, L111

Pepe, F., Mayor, M., Galland, F., Naef, D., Queloz, D., Santos, N. C., Udry, S., \& Burnet, M. 2002, A\&A, 388, 632

Pepe, F., et al. 2004, A\&A, 423, 385

Perrier, C., Sivan, J.-P., Naef, D., Beuzit, J. L., Mayor, M., Queloz, D., \& Udry, S. 2003, A\&A, 410, 1039

Perryman, M. A. C., et al. 1997, The Hipparcos and Tycho Catalogues (ESA SP-1200; Noordwijk: ESA)

Queloz, D., et al. 2000, A\&A, 354, 99 2001, A\&A, 379, 279

Rivera, E. J., et al. 2005, ApJ, 634, 625

Santos, N. C., Israelian, G., \& Mayor, M. 2004a, A\&A, 415, 1153

Santos, N. C., Israelian, G., Mayor, M., Bento, J. P., Almeida, P. C., Sousa, S. G., \& Ecuvillon, A. 2005, A\&A, 437, 1127

Santos, N. C., Israelian, G., Mayor, M., Rebolo, R., \& Udry, S. 2003, A\&A, 398,363

Santos, N. C., Mayor, M., Naef, D., Pepe, F., Queloz, D., Udry, S., \& Burnet, M. 2001, A\&A, 379, 999

Santos, N. C., et al. 2004b, A\&A, 426, L19

Sato, B., et al. 2003, ApJ, 597, L157

$$
\text { 2005, ApJ, 633, } 465
$$

Setiawan, J., et al. 2003, A\&A, 398, L19

. 2005, A\&A, 437, L31

Sozzetti, A., et al. 2004, ApJ, 616, L167 2006, A\&A, 449, 417

Tinney, C. G., Butler, R. P., Marcy, G. W., Jones, H. R. A., Laughlin, G., Carter, B., Bailey, J., O’Toole, S. 2006, ApJ, submitted (astro-ph/0602557)

Tinney, C. G., Butler, R. P., Marcy, G. W., Jones, H. R. A., Penny, A. J., Vogt, S. S., Apps, K., \& Henry, G. W. 2001, ApJ, 551, 507

Tinney, C. G., McCarthy, C., Jones, H. R. A., Butler, R. P., Carter, B. D., Marcy, G. W., \& Penny, A. J. 2002, MNRAS, 332, 759

Torres, G., Konacki, M., Sasselov, D. D., \& Jha, S. 2003, BAAS, 203, 17.09

Udry, S., Mayor, M., Naef, D., Pepe, F., Queloz, D., Santos, N. C., \& Burnet, M. 2002, A\&A, 390, 267

Udry, S., Mayor, M., \& Queloz, D. 2003a, in ASP Conf. Ser. 294, Scientific Frontiers in Research on Extrasolar Planets, ed. D. Deming \& S. Seager (San Francisco: ASP), 17

Udry, S., et al. 2000, A\&A, 356, 590

. 2003b, A\&A, 407, 679

2006, A\&A, 447, 361

Valenti, J. A., \& Fischer, D. A. 2005, ApJS, 159, 141

Vogt, S. S. 1987, PASP, 99,1214

Vogt, S. S., Butler, R. P., Marcy, G. W., Fischer, D. A., Henry, G. W., Laughlin, G., Wright, J. T., \& Johnson, J. A. 2005, ApJ, 632, 638

Vogt, S. S., et al. 1994, Proc. SPIE, 2198, 362

Wittenmyer, R. A., et al. 2004, in ASP Conf. Ser. 321, Extrasolar Planets: Today and Tomorrow, ed. J.-P. Beaulieu, A. Lecavelier des Etangs, \& C. Terquem (San Francisco: ASP), 215

Wolszczan, A., \& Frail, D. A. 1992, Nature, 355, 145

Wright, J. T. 2004, AJ, 128, 1273 2005, PASP, 117, 657

Wright, J. T., Marcy, G. W., Butler, R. P., \& Vogt, S. S. 2004, ApJS, 152, 261

Zucker, S., Mazeh, T., Santos, N. C., Udry, S., \& Mayor, M. 2003, A\&A, 404, 775

2004, A\&A, 426, 695

Zucker, S., et al. 2002, ApJ, 568, 363 